\title{
Solid-state NMR characterization of Alzheimer-like tau amyloid fibrils
}

\author{
Dissertation \\ zur Erlangung des mathematisch-naturwissenschaftlichen Doktorgrades \\ "Doctor rerum naturalium" \\ der Georg-August-Universität Göttingen \\ vorgelegt von \\ Venita Daebel \\ aus Brandenburg an der Havel
}

Göttingen, 2012 
Referent: $\quad$ Prof. Dr. Christian Griesinger

NMR-basierte Strukturbiologie

Max-Planck-Institut für Biophysikalische Chemie, Göttingen

Koreferent: $\quad$ Prof. Dr. Ulf Diederichsen

Organische und Biomolekulare Chemie

Georg-August-Universität Göttingen, Göttingen

Tag der mündlichen Prüfung: $\quad$ 27.08.2012 
"Progress does not happen on a time schedule" ["The Eavesdropper"] 


\section{Affidavit}

I hereby declare that this thesis has been written independently and with no other sources and aids than quoted.

Furthermore I confirm that this thesis has not been submitted as part of another examination process neither in identical nor in similar form.

Venita Daebel

Date, Place 


\section{Acknowledgements}

My very special gratitude I express to Adam Lange for being always constructive and helpful, not only as my supervisor, but as a person. He not only supported me in the best way, but believed in me and my skills, even if I - as a neuroscientist in a biophysical field - sometimes did not. Without his faith, I would have never even thought about applying for my future position.

I am sincerely grateful to Dr. Vinesh Vijayan - from whom I have inherited the project - for giving me helpful support, especially in the early stages.

Special thanks I also owe to Prof. Griesinger for being my first supervisor, for always being uncomplicated and dependable in doing so. Of course, I am thankful for the great NMR equipment I was fortunate to use, but moreover I enjoyed the (rare) lunch times we shared talking about diving and the latest news about the canteen food.

I owe my gratitude to my second supervisor and kind collaborator, Prof. Diederichsen, whom I especially thank for my one week stay in his group learning more about solid-phase synthesis and for being a referee for this thesis. Nothing less I owe Karsten Meyenberg for his supervision during my project week.

I deeply thank Prof. E. Mandelkow, Prof. E.-M. Mandelkow and their coworkers Jacek Biernat, Subashchandrabose Chinnathambi, and Katharina Tepper for the excellent sample preparation as well as great meetings to discuss about recent progress. I am especially thankful for their open ears and cooperativeness.

I would like to thank Prof. de Groot, Prof. Frahm and Dr. Kuhn for being part of my thesis committee. Furthermore, I am sincerely grateful to Prof. de Groot and his coworker Dirk Matthes for a very pleasant atmosphere during discussions of shared projects. I would like to thank Dietmar Riedel and Gudrun Heim for fruitful discussions related to electron microscopy. 
I am grateful to Prof. Zweckstetter, Dr. Schwalbe and Elias Akoury for providing the H/D exchange data and for effective cooperation.

I would like to thank the GRK 782 and the MPG for organizational and financial support.

For carefully proof-reading this thesis at any time and most of all always IN time, I more than thank my great colleagues Birgit Habenstein, Saskia Villinger, Benjamin Schomburg as well as Dirk Matthes and Katharina Tepper. Your support is the best I could wish for!

For introducing me to solid-state NMR and for keeping their nerves I am deeply thankful to Adam Lange and Ovidiu Andronesi as well as to Robert Schneider, Manuel Etzkorn, Karsten Seidel, and Vinesh Vijayan. For methodological discussions later on, I am grateful to Antoine Loquet, Jean-Philippe Demers, Birgit Habenstein, Hannes Fasshuber and Benjamin Schomburg. Brigitta Angerstein I owe many thanks for all her technical support. Working together with people who are more than only colleagues is a gift - Solids, you rock!

My very special thanks goes to everybody I was and I still am working together with. "Meine Herde", Fabian Peters and Mampfred Schmatz, we had the greatest times together. Saskia, Korvin, Edward, Manuel, Stefan, Fabian, Han, Birgit and Benjamin, we shared legendary moments in Bruges, Australia, Prague, Iceland, Langeoog and last but not least in the NMRii. I hope we will continue doing short trips!! The world has so much more to offer!!

There are so many more people I owe many thanks for making my everyday-life so much brighter. Feel addressed, please!

Meiner Familie danke ich aus tiefstem Herzen. Ohne euch wäre ich nie da, wo ich heute bin. Henna, danke für all deine Kraft und dein Vertrauen, die du all die Jahre in mich investiert hast. 


\section{Summary}

One of the hallmarks of Alzheimer's disease (AD) is the self-assembly of the microtubule-associated protein tau into fibers termed "paired helical filaments" (PHF). However, the structural basis of PHF assembly at atomic detail is largely unknown. Here, we applied solid-state nuclear magnetic resonance (solid-state NMR) spectroscopy to investigate in vitro assembled PHF from a truncated three-repeat tau isoform (K19) that represents the core of PHF. We found that the rigid core of the fibrils is formed by amino acids V306 to S324, only 18 of 99 residues, and comprises three $\beta$ strands connected by two short kinks. The first $\beta$-strand is formed by the well-studied hexapeptide motif ${ }^{306} \mathrm{VQIVYK}^{311}$ that is known to self-aggregate in a steric zipper arrangement. Results on mixed $\left[{ }^{15} \mathrm{~N}:{ }^{13} \mathrm{C}\right]$-labeled K19 fibrils show that $\beta$-strands are stacked in a parallel, in-register manner. Disulfide bridges (DSB) formed between C322 residues of different molecules lead to a disturbance of the $\beta$-sheet structure and polymorphism in solid-state NMR spectra is observed. In particular residues K321-S324 exhibit two sets of resonances. Experiments on K19 C322A PHF further confirm the influence of DSB formation on the core structure. The structural data are supported by H/D exchange NMR measurements on K19 as well as a truncated four-repeat isoform of tau (K18). Site-directed mutagenesis studies show that single point mutations within the three different $\beta$-strands result in a significant loss of PHF aggregation efficiency highlighting the importance of the $\beta$-structure rich region for tau aggregation. 


\section{Zusammenfassung}

Eines der bedeutendsten Kennzeichen des Morbus Alzheimer ist die Zusammenlagerung des Mikrotubuli-assoziierten Proteins Tau in Fibrillen, die als „gepaarte helikale Filamente“ (PHF) bezeichnet werden. Allerdings sind die strukturellen Grundlagen der PHF Aggregation auf atomarer Ebene weitestgehend unbekannt.

In dieser Studie wurden mittels Festkörper-Kernspinresonanz-Spektroskopie (FKNMR) in vitro hergestellte PHF einer Tau Isoform untersucht, die aus drei Wiederholungseinheiten besteht und den Kern der PHF repräsentiert (K19).

Wir haben herausgefunden, dass der rigide Kern der Fibrillen von den Aminosäuren V306 bis S324 - lediglich 18 von 99 Residuen - gebildet wird und aus $3 \beta$-FaltblattSträngen besteht, die durch zwei kurze Knickstellen miteinander verbunden sind. Der erste $\beta$-Strang wird von dem gut untersuchten Hexapeptid ${ }^{306}$ VQIVYK $^{311}$ gebildet. Von diesem ist bekannt, dass es sich ebenfalls zusammenlagern kann und dabei so genannte hydrophobe „steric zipper“ Kontakte ausbildet.

Ergebnisse an einer gemischt $\left[{ }^{15} \mathrm{~N}:{ }^{13} \mathrm{C}\right]$-markierten K19 PHF Probe zeigen, dass sich die $\beta$-Stränge parallel und nicht zu einander verschoben übereinander lagern. Zwischen C322-Resten verschiedener Moleküle bilden sich Disulfid-Brücken (DSB) aus, die zu einer lokalen Beeinträchtigung der $\beta$-Faltblatt-Struktur führen, wodurch in den FKNMR Spektren Polymorphismus beobachtbar ist. Insbesondere die Aminosäurereste K321-S324 weisen zwei Resonanz-Sätze auf. Des Weiteren bestätigen Experimente, die an K19 C322A PHF durchgeführt wurden, den Einfluss der DSB auf die Struktur des Fibrillenkerns. Die Strukturdaten werden durch H/D-Austausch NMR Messungen an K19 sowie K18, einer Isoform bestehend aus vier Wiederholungseinheiten, gestützt.

Zielgerichtete Mutagenese-Studien an K19 zeigen, dass Mutationen innerhalb der drei verschiedenen $\beta$-Stränge $\mathrm{zu}$ einem signifikanten Verlust der PHF 
Aggregationseffizienz führen, was die Bedeutung der $\beta$-Strang-reichen Region für die Zusammenlagerung von Tau Proteinen unterstreicht. 


\section{Contents}

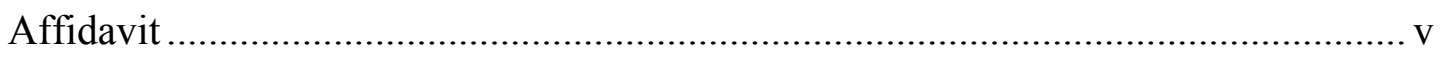

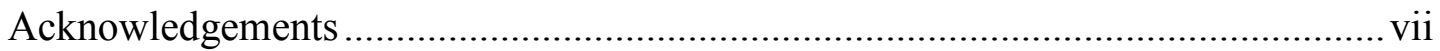

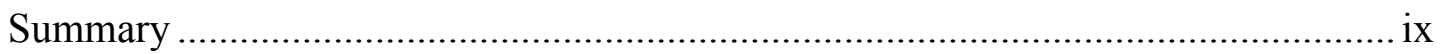

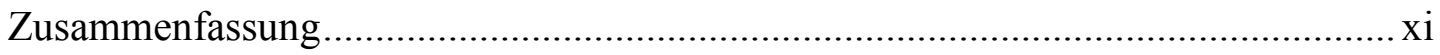

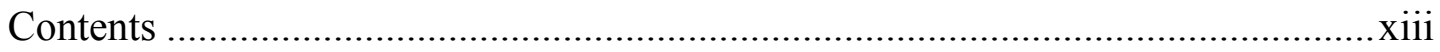

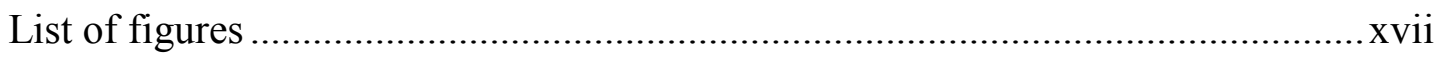

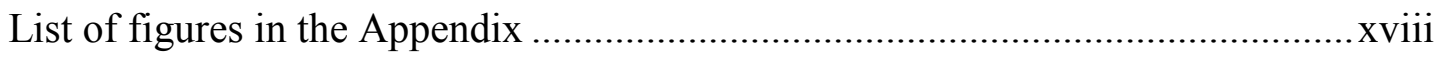

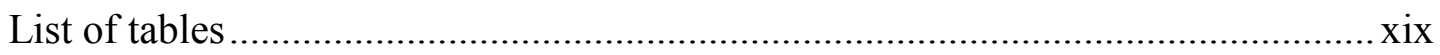

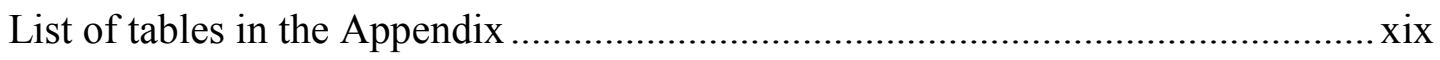

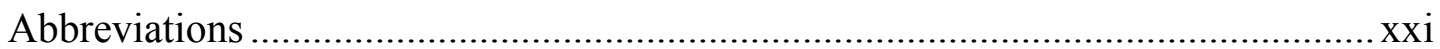

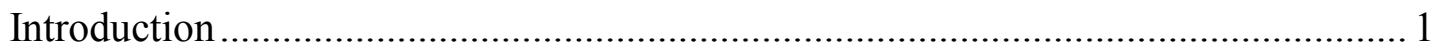

2.1 Theoretical aspects of biological solid-state NMR ..................................... 1

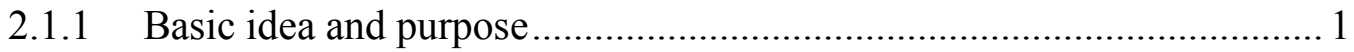

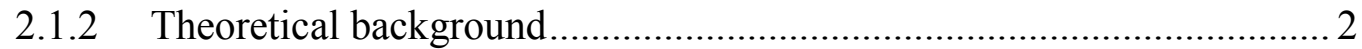

2.1.3 From sample preparation to structure determination ........................... 5

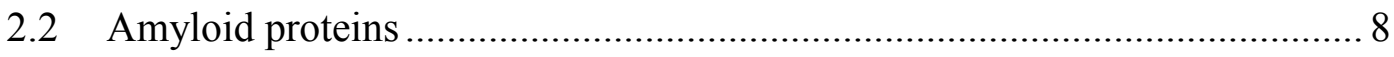

2.2.1 Definition ................................................................................. 8

2.2.2 Folding and aggregation of amyloid proteins .................................. 9

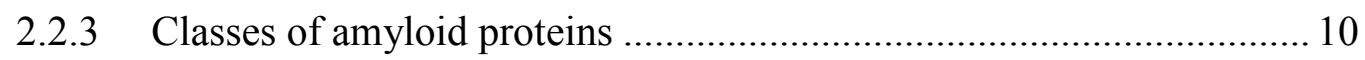

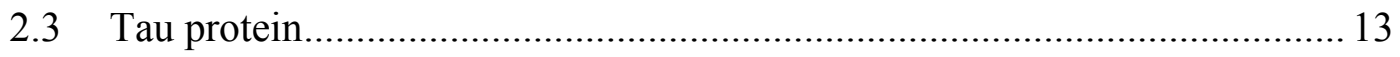




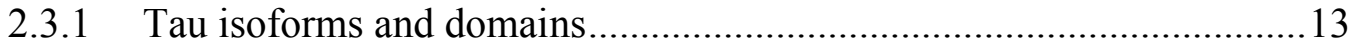

2.3.2 Tau as a key player in neurodegenerative diseases ............................. 15

2.3.3 Recent findings of the rigid core of AD-like tau PHF .........................17

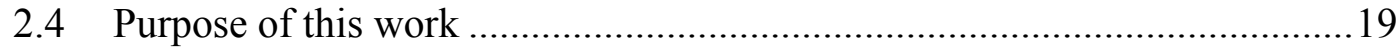

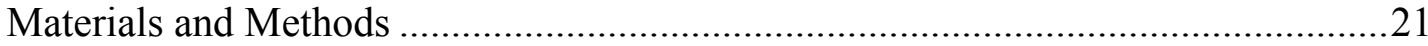

4.1 Sample preparation and characterization ..................................................21

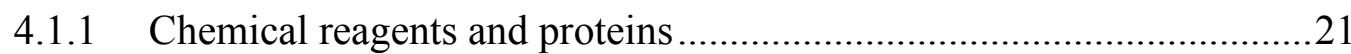

4.1.2 Labeling schemes for solid-state NMR samples ..............................21

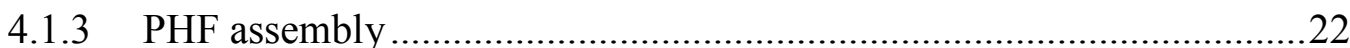

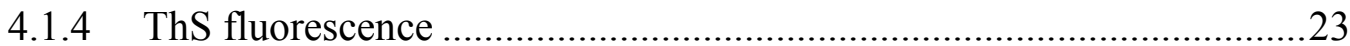

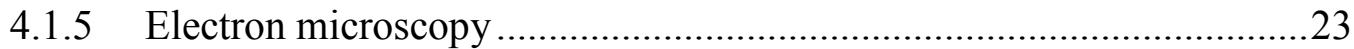

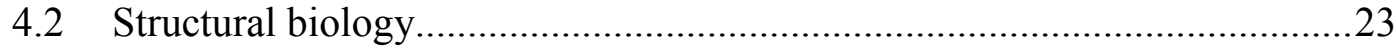

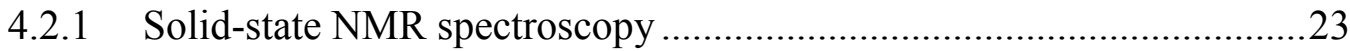

4.2.2 NMR-detected solvent protection of K18 and K19 filaments ..............24

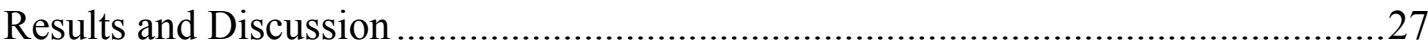

6.1 High resolution spectra obtained with solid-state NMR ............................27

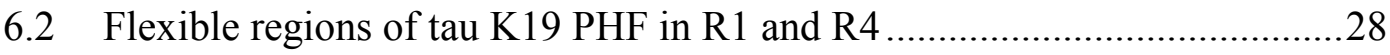

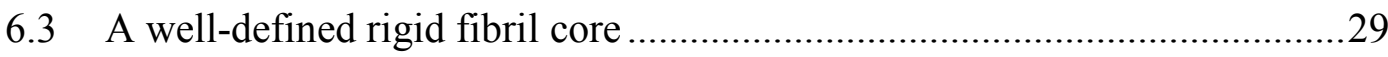

6.4 Spectra of K19 PHF reveal two conformations for residues K321-S324 .....33

6.5 Secondary structure analysis of the K19 PHF core residues ........................35

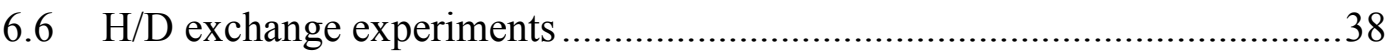

6.7 Aggregation behavior of K19 single mutants ........................................40

6.8 Supramolecular arrangement of K19 molecules within the fibril core .........44

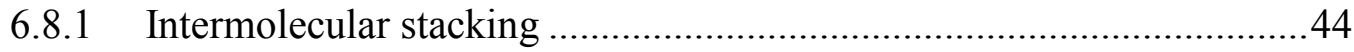

6.8.2 Intermolecular disulfide bonds ................................................... 45

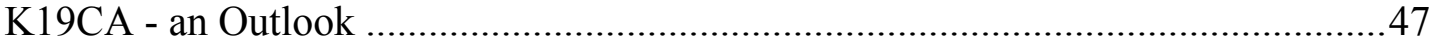


8.1 Partial Assignment of the K19CA PHF core ........................................... 47

8.2 Possible arrangements of $\beta$-strands $\beta 1$ to $\beta 3$ in the K19 PHF core ............. 49

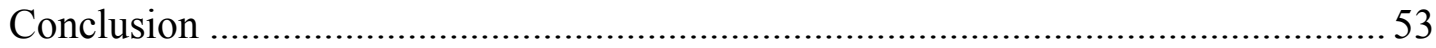

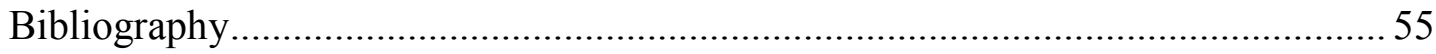

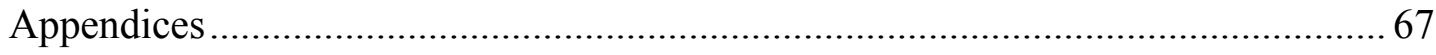

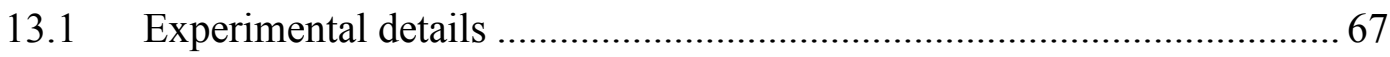

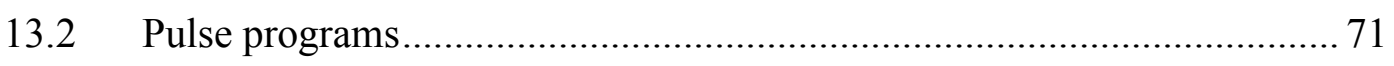

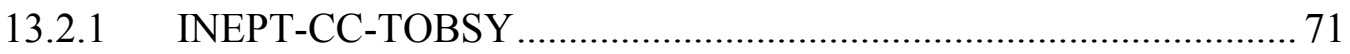

13.2.2 DREAM

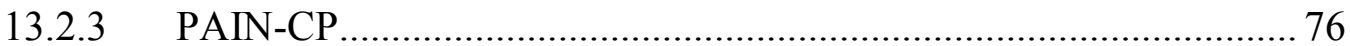

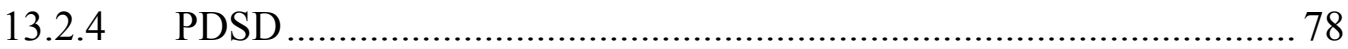

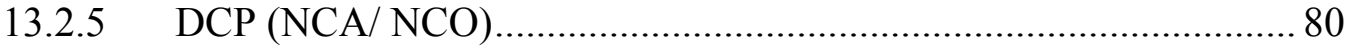

13.2.6 NCC experiments (NCACX/ NCOCX) ........................................ 82

13.2.7

13.3 Spectra that were used for the assignment process ............................... 86

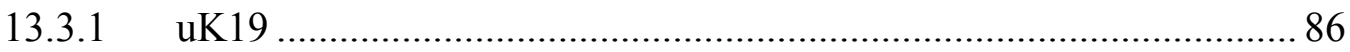

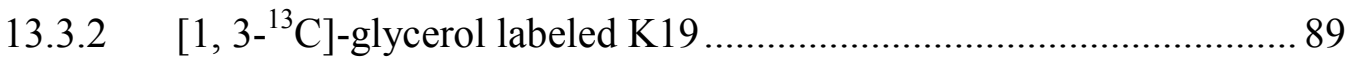

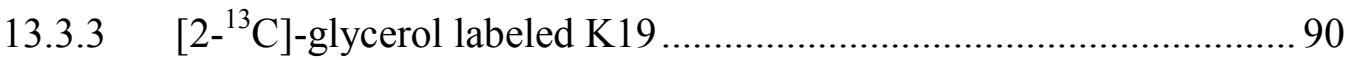

13.3.4 K19

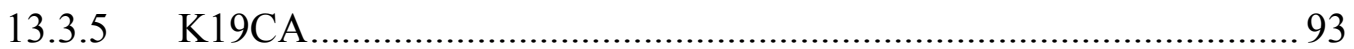

13.3.6 $\left[1,3-{ }^{13} \mathrm{C}\right]-$ and $\left[2-{ }^{13} \mathrm{C}\right]$-glycerol labeled K19CA ............................ 95

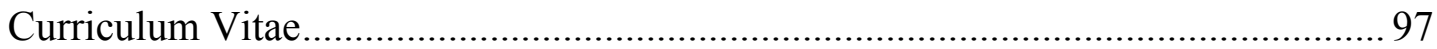




\section{List of figures}

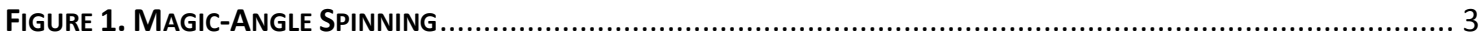

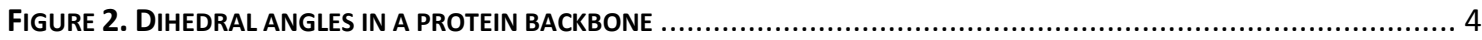

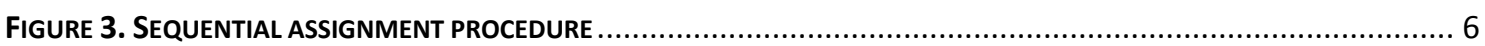

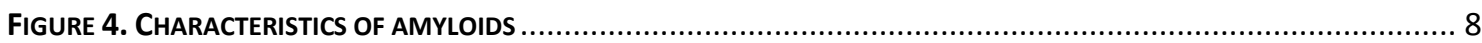

FIGURE 5. ENERGY LANDSCAPE REPRESENTING FOLDING AND AGGREGATION OF AMYLOID PROTEINS........................ 10

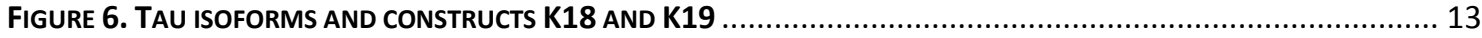

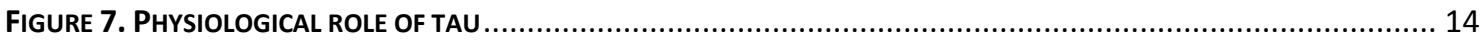

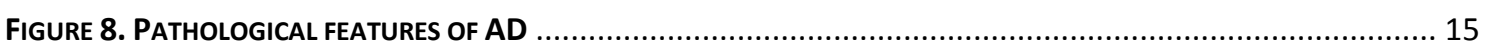

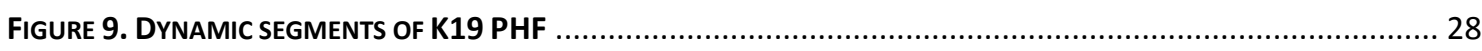

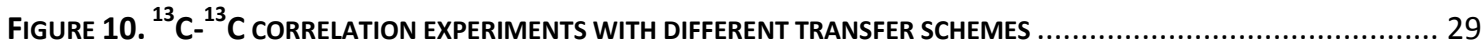

FIGURE 11. SEQUENTIAL RESONANCE ASSIGNMENT OF THE RIGID CORE OF K19 PHF ...................................... 30

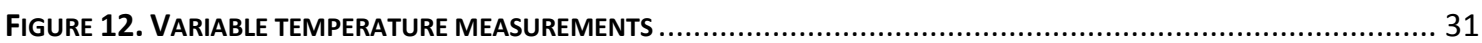

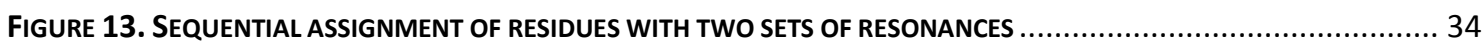

FIGURE 14. EFFECT OF DISULFIDE BOND FORMATION ON SOLID-STATE NMR SPECTRA..................................... 35

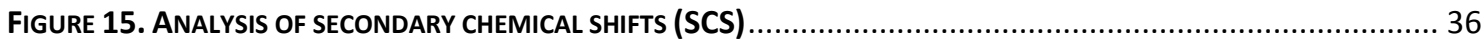

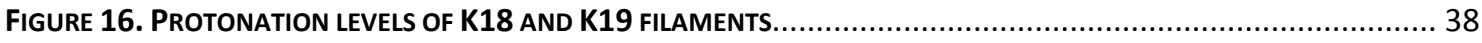

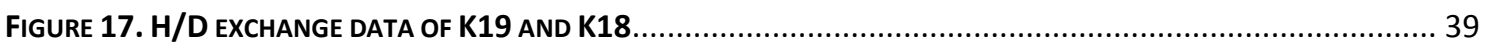

FIGURE 18. OVERVIEW OF THE K19 SINGLE POINT MUTATIONS WITHIN THE ASSIGNED PHF CORE REGION................... 40

FIGURE 19. PHF ASSEMBLY OF DIFFERENT K19 SINGLE MUTANTS MONITORED BY THS FLUORESCENCE ...................... 41

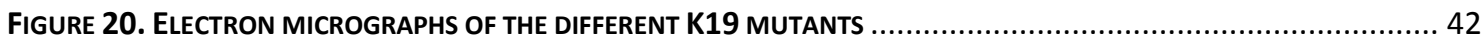

FIGURE 21. COMPARISON OF MAGNETIZATION TRANSFERS IN NCA AND PAIN-CP EXPERIMENTS............................. 44

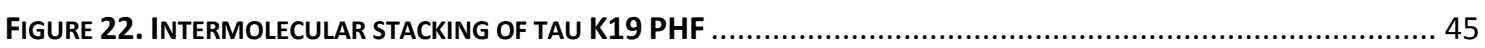

FIGURE 23. MODELS FOR CYSTEINE DISULFIDE BOND (DSB) FORMATION WITHIN K19 PHF ................................. 46

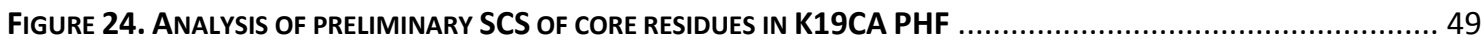

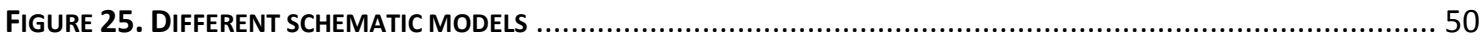




\section{List of figures in the Appendix}

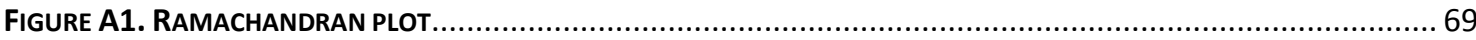

FigURE A2. PREDICTIONS FOR THE INTERMOLECULAR DSB FoRMATION COMPARED WITH EXPERIMENTAL DATA.............. 70

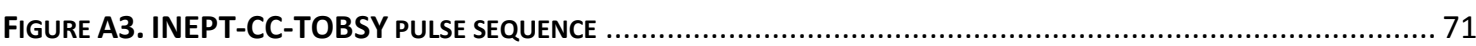

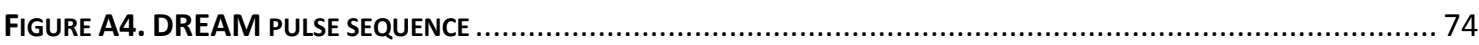

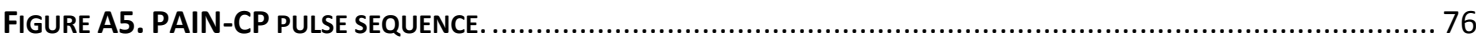

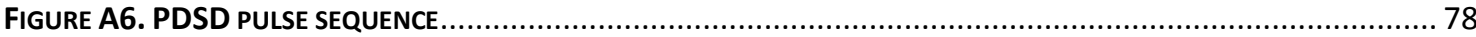

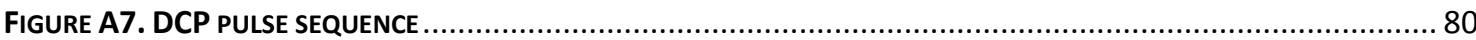

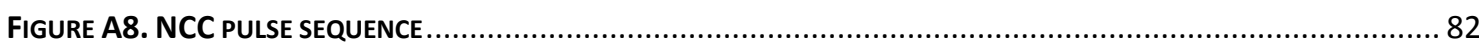

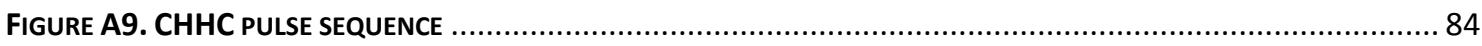

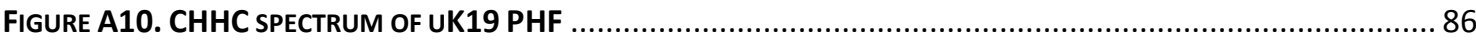

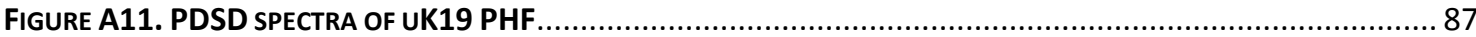

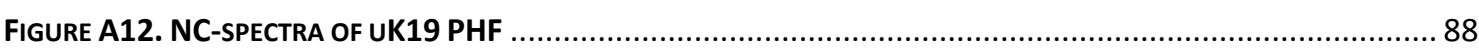

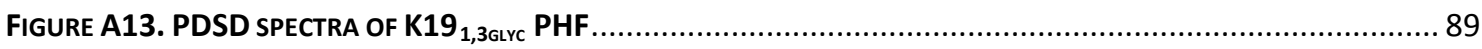

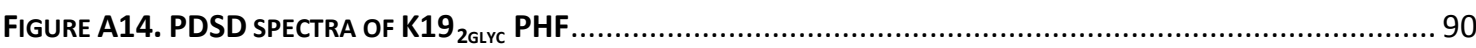

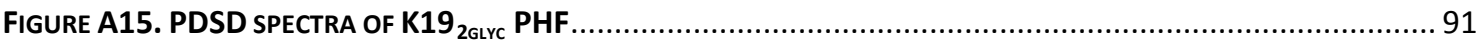

FIGURE A16. PDSD SPECTRA OF K19

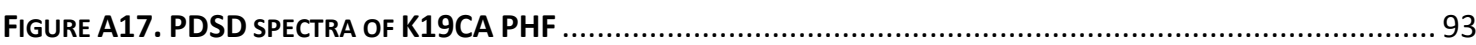

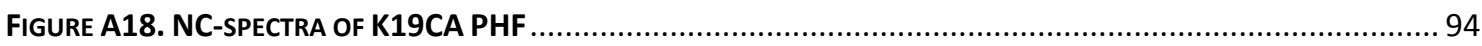

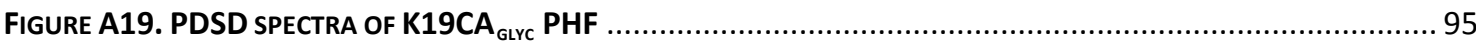




\section{List of tables}

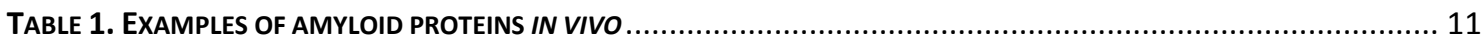

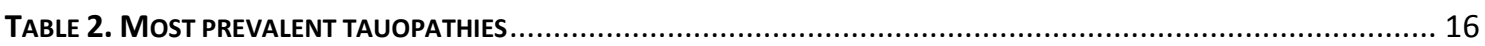

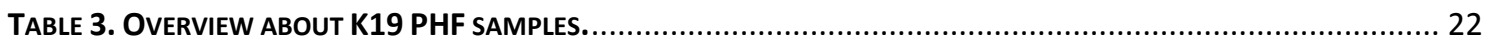

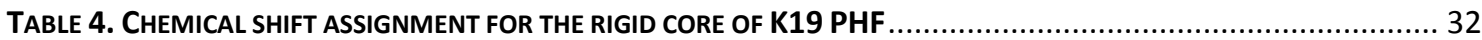

TABLE 5. PARTIAL CHEMICAL SHIfT ASSIgNMENT FOR THE RIGID CORE OF K19CA PHF ................................. 47

\section{List of tables in the Appendix}

TABLE A1. DetaILS OF EXPERIMENTS MEASURED ON K19 PHF SAMPLES 


\section{Abbreviations}

Aa

AD

APP

BMRB

$\mathrm{C}$

CBD

$\mathrm{CCW}$

CD

CNS

CP

CSA

CW

d

DARR

DREAM

DSB

DSS

DTT

EM

EPR

FK

FPLC

FTIR

$\gamma$

GARP

HSQC

INEPT

K18

K19

MAPT
Amino acid/s

Alzheimer's disease

Amyloid precursor protein

Biological magnetic resonance bank

Carboxy-

Corticobasal degeneration

Counter-clockwise

Circular dichroism

Central nervous system

Cross-polarization

Chemical shift anisotropy

Clockwise

Distance

Dipolar-assisted rotational resonance

Dipolar recoupling enhancement through amplitude modulation

Disulfide bond

4,4-dimethyl-4-silapentane-1-sulfonic acid

Dithiothreitol

Electron microscopy

Electron paramagnetic resonance

Festkörper

Fast performance liquid chromatography

Fourier transform infrared spectroscopy

Gyromagnetic ratio

Globally optimized alternating-phase rectangular pulses

Heteronuclear single quantum coherence

Insensitive nuclei enhanced by polarization transfer

Tau construct comprising four repeat regions

Tau construct comprising three repeat regions

Microtubule-associated protein tau 


$\begin{array}{ll}\text { MAS } & \text { Magic-angle spinning } \\ \text { MT } & \text { Microtubule } \\ \text { N } & \text { Amino- } \\ \text { NFT } & \text { Neurofibrillary tangle/s } \\ \text { NMR } & \text { Nuclear magnetic resonance } \\ \text { NOESY } & \text { Nuclear Overhauser effect spectroscopy } \\ \text { PAIN } & \text { Proton-assisted insensitive nuclei } \\ \text { PAR } & \text { Proton-assisted recoupling } \\ \text { PDB } & \text { Protein data bank } \\ \text { PDSD } & \text { Proton-driven spin diffusion } \\ \text { PHF } & \text { Paired helical filament/s } \\ \text { PrP } & \text { Prion protein } \\ \text { R } & \text { Repeat } \\ \text { SCS } & \text { Secondary chemical shift } \\ \text { SPINAL } & \text { Small phase incremental alteration } \\ \text { SPPE } & \text { Subacute sclerosing panencephalitis } \\ \text { ThS } & \text { Thioflavin S } \\ \text { ThT } & \text { Thioflavin T } \\ \text { TOBSY } & \text { Total through-bond-correlation spectroscopy } \\ \text { TOCSY } & \text { Total through-space-correlation spectroscopy } \\ \text { U } & \text { U-shape } \\ \text { WT } & \text { Wild type } \\ \text { Z } & \text { Z-shape } \\ & \end{array}$




\section{Introduction}

\subsection{Theoretical aspects of biological solid-state NMR}

\subsubsection{Basic idea and purpose}

Since the 1980's, not only X-ray crystallography, but also solution NMR (nuclear magnetic resonance) spectroscopy became a powerful technique for the investigation of protein structures at atomic resolution (1). Through ongoing developments regarding higher magnetic fields, advanced probes, selected pulse sequences, efficient sample preparation, and specific labeling schemes solution NMR has emerged as a wellestablished standard method to study the high-resolution structure as well as dynamics of proteins with a molecular weight of up to $1 \mathrm{MDa}(2,3)$.

However, neither X-ray crystallography, nor solution NMR can be used as the method of choice for insoluble proteins that do not or only poorly crystallize, due to their intrinsic nature. In the last two decades, solid-state NMR has achieved to become an excellent method to study the structure and dynamics of those insoluble proteins (4, $5)$.

Solid-state NMR does not depend on tumbling rates or long-range order, and therefore can be used for a diversity of insoluble molecules, e.g. powders, microcrystalline proteins (6-14), membrane proteins (15-17), and assemblies of molecules, such as amyloid fibrils (18-33), large protein complexes $(34,35)$ and protein-ligand complexes $(36,37)$, respectively.

As in solution NMR, ongoing developments of tailored labeling schemes (6, 38-40), deuterium dilution (41-45), multidimensional spectroscopy (46) and state-of-the-art hardware support a permanent improvement of resolution and sensitivity in solid-state NMR spectroscopy (5). 


\subsubsection{Theoretical background}

It is necessary to have a basic understanding about NMR spectroscopy, particularly the functionality of solid-state NMR, to comprehend the information encoded in spectra. This Chapter provides a short overview only. For further reading, academic books and reviews are available $(1,47-50)$.

NMR spectroscopy is based on first-principle interactions that arise between magnetic moments of nuclei with the local magnetic field, between two magnetic moments through direct (dipolar) or indirect $(\mathrm{J}-)$ coupling, or between the electric quadrupolar moment of the nucleus and electric field gradients. Source of the local magnetic field can be the external static field $\left(\mathrm{B}_{0}\right)$ and an applied external field $\left(\mathrm{B}_{1}\right)$ generated by radio frequency pulses. Each nucleus with a non-zero spin has a resulting magnetic moment and is thus detectable by NMR spectroscopy. In biological solid-state NMR, especially nuclei with a spin- $-1 / 2$, such as ${ }^{1} \mathrm{H},{ }^{13} \mathrm{C}$ and ${ }^{15} \mathrm{~N}$ are investigated, because they are either ubiquitously abundant as a natural isotope $\left({ }^{1} \mathrm{H}\right)$ or they form the backbone of polypeptide chains $\left({ }^{13} \mathrm{C},{ }^{15} \mathrm{~N}\right)$, comprising diverse information about the structure and dynamics of proteins. Because the natural abundance of the latter isotopes is very low, samples have to be isotopically labeled using molecular biological methods such as recombinant expression of proteins (see 1.1.3).

In solid-state NMR, there are two undesired interactions causing line broadening that need to be eliminated:

(i) Chemical shift anisotropy: Each nucleus is surrounded by electrons. When exposed to external magnetic fields, currents are generated in the electron clouds, which in turn produce an induced field. This local induced field influences the effective magnetic field $\left(\mathrm{B}_{\text {eff }}\right)$ of the nucleus by shielding it from the external field, altering the nuclear resonance frequency. This chemical shift $(\delta)$ consists of two parts, an isotropic one, and an orientation-dependent one, called CSA (chemical shift anisotropy). The CSA derives from a non-spherical distribution of electrons, which results in a loss of spectral resolution. Nevertheless, with respect to $\mathrm{B}_{0}$, the shielding effects depend on the orientation of the surrounding electrons and with that on the orientation of the molecule itself, which can be used for orientation-dependent measurements (51).

(ii) Dipolar coupling: When two magnetic moments are in spatial proximity to each other, dipolar coupling occurs by mutual influence of the two spins, dependent on the 
orientation of the internuclear vector relative to $\mathrm{B}_{0}$, their gyromagnetic ratios $(\gamma)$ and the internuclear distance. The dipolar couplings are called heteronuclear between different isotopes (e.g. ${ }^{1} \mathrm{H},{ }^{13} \mathrm{C}$ ) and homonuclear between identical isotopes (e.g. $\left.{ }^{1} \mathrm{H},{ }^{1} \mathrm{H}\right)$.

In solution NMR, the tumbling rate of the studied molecules is sufficient to average out the orientation-dependent terms of chemical shift anisotropy and dipolar couplings over time. In contrast, insoluble proteins or molecules in an environment that does not allow for tumbling can be studied by MAS (magic-angle spinning) solid-state NMR (52). Here, isotropic tumbling is imitated by spinning the sample around an axis inclined to $\mathrm{B}_{0}$ with an angle of $54.74^{\circ}$ to average out the anisotropic parts of the CSA and dipolar couplings (Figure 1). Combined with heteronuclear decoupling (53), MAS effectively increases spectral resolution. Homonuclear dipolar couplings can be neglected, because couplings for the usually acquired ${ }^{13} \mathrm{C}$ are sufficiently small enough $(\sim 5 \mathrm{kHz})$ to be eliminated by MAS $(47,48)$.

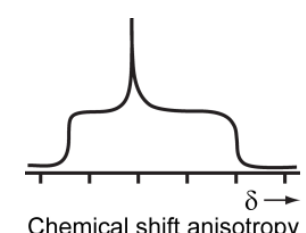

Chemical shift anisotropy

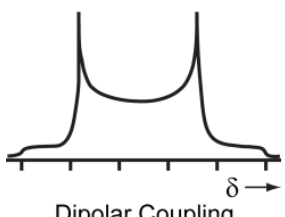

Dipolar Coupling
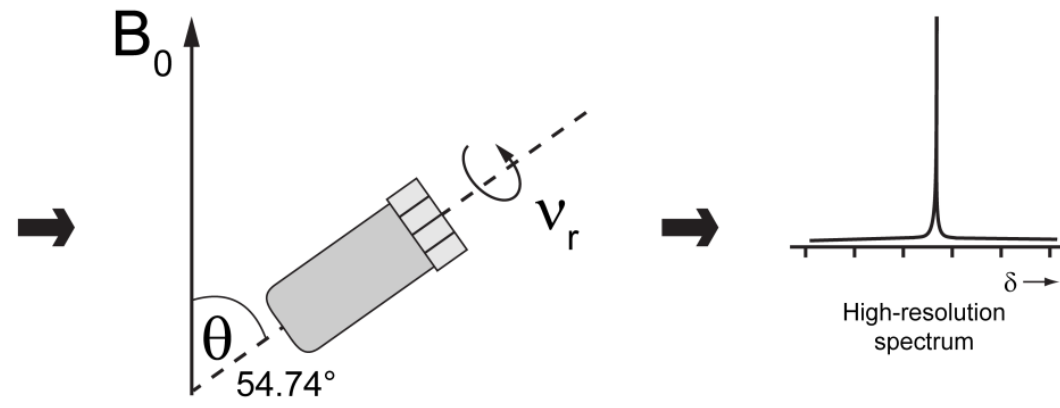

Figure 1. Magic-Angle Spinning. The spinning axis is inclined at an angle of $54.74^{\circ}$ relative to the external magnetic field $\mathrm{B}_{0}$. Spinning rates $\left(v_{\mathrm{r}}\right)$ of more than $60 \mathrm{kHz}$ are used to average out anisotropic parts of the chemical shift and dipolar couplings which leads to a narrow linewidth.

As already mentioned, a diversity of information on the structure and dynamics of a protein can be studied using solid-state NMR. Encoded in the spectra of nuclei belonging to a polypeptide is the information about flexibility, dihedral angles $(\psi, \varphi)$ and spatial proximities.

The isotropic part of the chemical shift $(\delta)$ can be directly obtained from the position of a signal in a spectrum. $\delta$ reflects the chemical environment of a nucleus. By comparing $\mathrm{C} \alpha$ and $\mathrm{C} \beta$ values with reference values of carbons that are in a random coil 
conformation, secondary structural elements in the peptide backbone, such as $\alpha$-helical, $\beta$-sheet or random coil conformations, can be deduced (54-56). In the BMRB (57) and PDB (58) databases, chemical shifts of protein structures are deposited. Programs, such as TALOS+ (59) or DANGLE (60), predict backbone torsion angles ( $\psi, \varphi$, Figure 2) of the investigated protein by comparing its chemical shifts with those deposited in the databases.

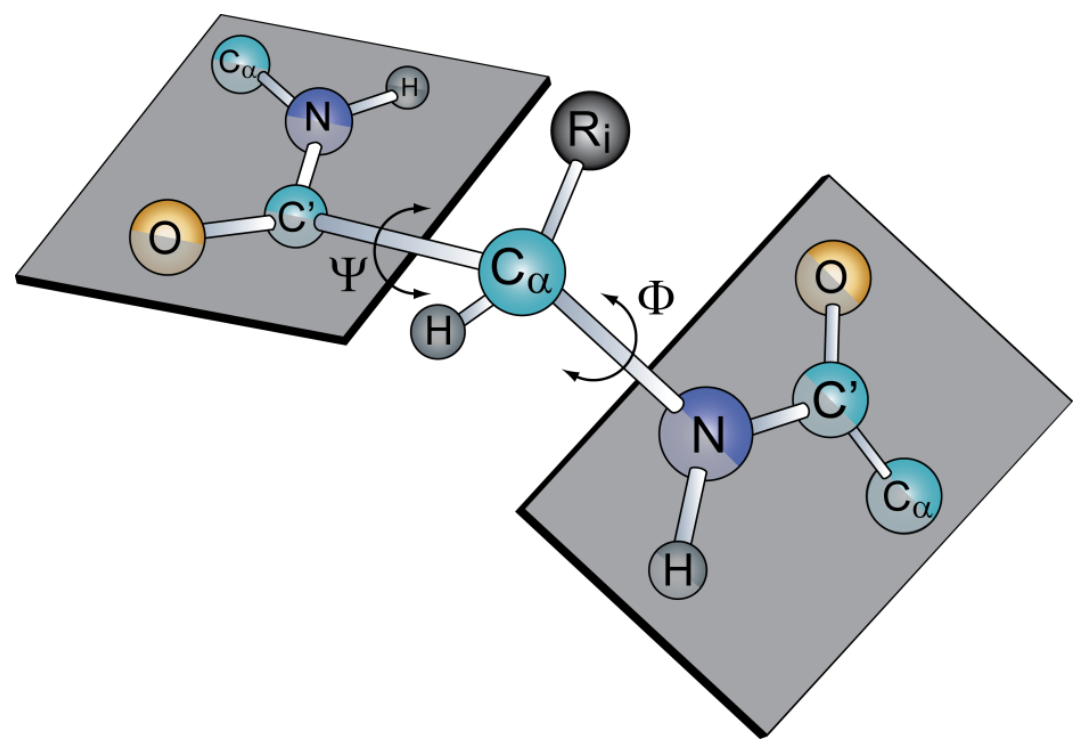

Figure 2. Dihedral angles in a protein backbone. Different secondary structures of protein backbone atoms result from different dihedral angle conformations that can be predicted by programs like TALOS+ (59).

Generally, pulse sequences used for solid-state NMR assignments are based on dipolar-coupling polarization transfer and reveal information about distances (d), e.g. $\mathrm{d}_{\mathrm{CC}}, \mathrm{d}_{\mathrm{HH}}$ and $\mathrm{d}_{\mathrm{NC}}$ that are indispensable for the assignment process and can provide additional structural constraints for structure calculations (61). In addition, those distances can be used to learn more about protein-protein interactions, such as proteinligand-binding (37).

Adequate experiments use specific heteronuclear (e.g. NCACX, NCOCX) (62) magnetization transfers or homonuclear dipolar recoupling sequences (e.g. PDSD (proton driven spin diffusion) $(63,64)$, DARR (dipolar assisted rotational resonance) (65)). As the name implies, in PDSD protons are used to accelerate moderate magnetization transfer among low abundant and low $\gamma$ nuclei (a process called spin diffusion). The same principle holds for DARR, including ${ }^{13} \mathrm{C}-{ }^{1} \mathrm{H}$ dipolar recoupling. 
To gain higher polarization transfer efficiencies, a special adiabatic dipolar filtering scheme is introduced in the DREAM (dipolar recoupling enhancement through amplitude modulation) sequence $(66,67)$. In addition, INEPT (insensitive nuclei enhanced by polarization transfer)-based experiments give information about local molecular flexibility, combining polarization transfers based on through-bond Jcoupling (68-70). Further information can be provided by a diversity of methods, e.g. studies of water-accessibility and water-protein interactions (71-75) or application of paramagnetic spin labeling to determine paramagnetic spin-residue distances (76-78).

\subsubsection{From sample preparation to structure determination}

The fundament of each biological solid-state NMR study is the sample preparation. Because mainly nuclei with a spin- $-1 / 2\left({ }^{1} \mathrm{H},{ }^{13} \mathrm{C},{ }^{15} \mathrm{~N}\right)$ are detected, the protein has to be recombinantly expressed in e.g. Escherichia coli using growth medium that contains $\left[{ }^{13} \mathrm{C}\right]-$ or $\left[{ }^{15} \mathrm{~N}\right]$-isotopically labeled D-glucose or $\mathrm{NH}_{4} \mathrm{Cl}$, respectively. Dependent on the labeling scheme, the protein is either uniformly labeled or enriched with specific isotope labeled molecules like $\left[1,3-{ }^{13} \mathrm{C}\right] /\left[2-{ }^{13} \mathrm{C}\right]$-glycerol or $\left[1-{ }^{13} \mathrm{C}\right] /\left[2-{ }^{13} \mathrm{C}\right]$-glucose as the only carbon source, leading to a reduction of dipolar truncation effects and thus allowing to obtain long-range information $(6,38-40,79)$. Furthermore, there is the so called reverse labeling or forward labeling with only selected amino acids being not or fully labeled, respectively $(22,80)$, decreasing spectral overlap.

The time-consuming assignment procedure mainly consists of three steps: (i) Identifying spin-systems and the type of amino acids (aa) they belong to (intraresidue assignment), (ii) retracing the primary sequence by correlating vicinal aa with each other (sequential assignment), and (iii) finding long-range correlations to gain spatial information about the tertiary structure (interresidue assignment).

For the intraresidue assignment, not only homonuclear ${ }^{13} \mathrm{C}-{ }^{13} \mathrm{C}$ experiments such as DREAM, DARR or PDSD, but also heteronuclear techniques, such as NCA and NCACX are commonly recorded. Experiments that involve correlations to preceding residues, such as NCO and NCOCX, or vicinal aa (e.g. PDSD) are required for a sequential assignment (Figure 3). 

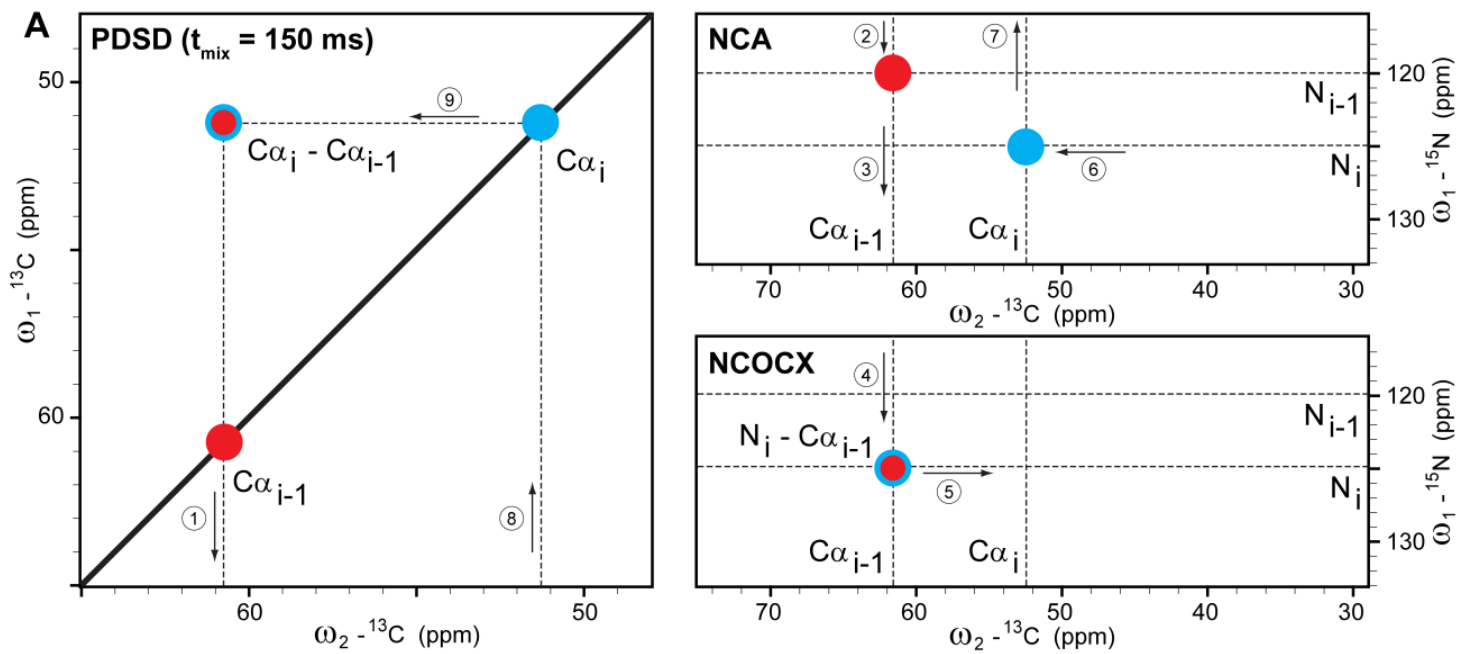

B

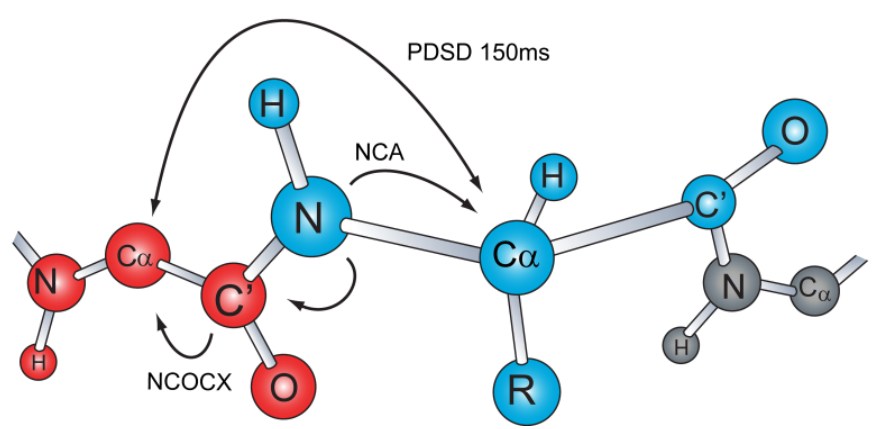

Residue i

Residue i-1

Residue $\mathrm{i}+1$

Figure 3. Sequential assignment procedure. (A) On the left, a ${ }^{13} \mathrm{C}-{ }^{13} \mathrm{C}$ PDSD $\left(\mathrm{t}_{\mathrm{mix}}=150 \mathrm{~ms}\right)$ spectrum, on the upper right, an NCA spectrum and on the lower right, an NCOCX spectrum are shown. Blue circles symbolize residue i, red ones residue i-1. Circles showing both colors stand for a sequential correlation. By following the numbered arrows, a sequential walk is shown. (B) Depicted is a section of a protein backbone with red atoms standing for residue $\mathrm{i}-1$, blue for residue $\mathrm{i}$ and gray for residue $\mathrm{i}+1$. By arrows the polarization transfers of PDSD, NCA and NCOCX are indicated.

PDSD and DARR sequences include a spin diffusion step, which allows the magnetization to spread in a time-dependent manner. The longer the mixing time (ms scale), the farther the polarization can be transferred, introducing further spatial information. Hence, spectra recorded on uniformly labeled samples with a ${ }^{13} \mathrm{C}-{ }^{13} \mathrm{C}$ mixing of $20 \mathrm{~ms}$ are analyzed for intraresidue correlations, while a longer mixing time of $150 \mathrm{~ms}$ leads to sequential or even medium-range (residue i to $\mathrm{i} \pm 2$ to 4 ) correlations. Longer mixing times provide long-range (residue $\mathrm{i}$ to $\mathrm{i} \pm \geq 5$ ) information, e.g. PDSD experiments recorded on sparsely labeled samples with mixing times of $500 \mathrm{~ms}$.

To obtain as many long-range restraints as possible, different experimental approaches have been developed recently. $\mathrm{CHHC} / \mathrm{NHHC}$ experiments are based on fast 
polarization transfer between highly abundant ${ }^{1} \mathrm{H}$-spins encoded in highly resolved evolution and detection periods of rare spins $\left({ }^{13} \mathrm{C},{ }^{15} \mathrm{~N}\right)(81)$. The indirect detection of ${ }^{1} \mathrm{H}-{ }^{1} \mathrm{H}$ contacts using such $\mathrm{CHHC} / \mathrm{NHHC}$ experiments became a standard method to complete structure determination $(23,82-86)$. Next to that, pulse sequences, such as PAR (proton-assisted recoupling) (87) and PAIN-CP (proton-assisted insensitive nuclei cross polarization) (88) have been developed to determine structures and structural properties, e.g. the stacking of molecules within protein complexes $(27,34,89)$. 


\subsection{Amyloid proteins}

\subsubsection{Definition}

In 1854, Virchow introduced the term "amyloid" (from Latin 'amylum' for 'starch '), when he observed aggregates behaving starch-like in positive iodine staining experiments (90). According to the classical definition, amyloid proteins are extracellular deposits with distinctive $\beta$-sheet structure that can be stained with Congo red dye and show an enhanced apple-green birefringence in polarizing light (91-94). Similarly, thioflavine $\mathrm{T}$ or $\mathrm{S}(\mathrm{ThT} / \mathrm{S})$ can be used for identification. In the presence of amyloid aggregates a shift in fluorescence emission is observed $(95,96)$.
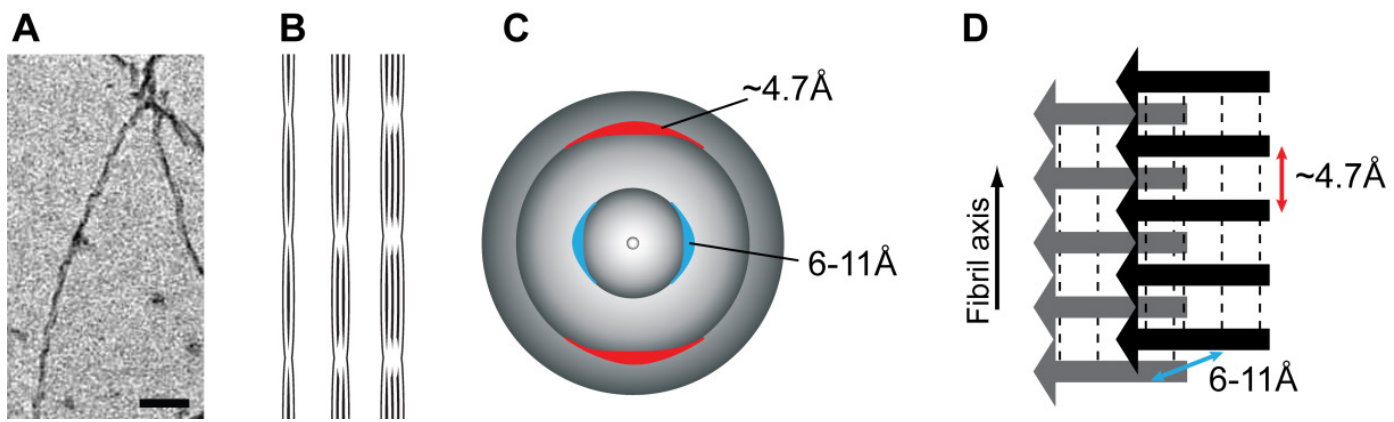

Figure 4. Characteristics of amyloids. (A) Electron micrograph of tau K19 amyloid fibrils (scale bar $=100 \mathrm{~nm}$ ). Schematic representations of amyloid fibrils comprising two, three and four protofilaments, respectively, (B) and of typical X-ray fiber diffraction pattern with a meridional reflection at $\sim 4.7 \AA$ (red) and an equatorial reflection at 6-11 $\AA$ (blue) (C). (D) The characteristic pattern corresponds to repetitive spacing of the cross- $\beta$ structure in amyloid fibrils (inter-sheet distance: blue; inter-strand distance within one $\beta$-sheet: red; backbone hydrogen bonds are indicated by dashed lines).

Because in recent studies amyloid deposits were also found intracellular (97-99), the classical definition has been expanded to include more biophysical aspects. Hence, amyloid proteins are first of all characterized as in vivo or in vitro elongated, unbranched self-assembled polypeptides, mainly in a fibrillar form $(100,101)$. In 1967, electron microscopy (EM) data of Shirahama and Cohen revealed that amyloid fibrils are composed of smaller subunits, called protofilaments (Figure 4A and B) (102-105). 
Further insight into the quaternary structure was provided by X-ray diffraction studies (Figure 4C and D). Due to a repeating cross- $\beta$ sheet motif within the amyloid fibers that runs perpendicular to the fibril axis, a characteristic X-ray diffraction pattern can be observed. A meridional reflection at $\sim 4.7 \AA$ and an equatorial reflection at $\sim 6$ $11 \AA$ occur, corresponding to the distance between $\beta$-strands stacked within one sheet (inter-strand distance within one sheet) and the $\beta$-strand spacing between two vicinal sheets perpendicular to the fibril axis (inter-sheet distance), respectively (106-112). The cross- $\beta$ motif is especially promoted by extensive hydrogen bonding between the $\beta$ strands. Up to now, several amyloid fibrils have been characterized by solid-state NMR, e.g. fungal prion protein HET-s (23) and yeast Ure2 prion protein $(14,113,114)$, human prion protein (115) and Amyloid $\beta$ (116-118). Notably, to the current knowledge, most of these amyloids feature an in-register parallel supramolecular $\beta$-strand orientation that probably increases stabilizing interactions by aligning hydrophobic and polar side chains, respectively, with themselves.

\subsubsection{Folding and aggregation of amyloid proteins}

By analyzing protein denaturation processes as well as disulfide bond formation, fundamental insights into protein folding and thermodynamics were provided already several decades ago (119). Later findings about transcriptional regulation, posttranslational modification, and assistance by chaperones or membranes are only some examples that proved that protein folding is a complex procedure (120-122).

Under physiological conditions, a functional protein is folded into its so-called "native state", typically forming a compact 3D structure. Nevertheless, cellular processes are accompanied by partially and natively unfolded proteins as well (123). However, under destabilizing conditions, native folds can be reorganized resulting in a different 3D structure and a change of functionality of the protein. Dependent on the gain or loss of function, rearranged protein structures are called to be in an alternative or misfolded state, respectively (120).

In case of amyloid proteins, rearrangement of folding causes self-association mostly driven by hydrophobic interactions - into stable supramolecular organized structures. Recent studies of aggregation kinetics suggest different pathways and rate- 
limiting steps (124-128). Though detailed information is still missing, in general the self-assembly of amyloids is initiated from high energy states, with the state of maximum energy termed aggregation nucleus. After the critical step of nucleation, the aggregation process yields conformations with lower energy, either by incorporation of further subunits or by another conformational rearrangement leading to the mature amyloid fibril, as represented in Figure 5.

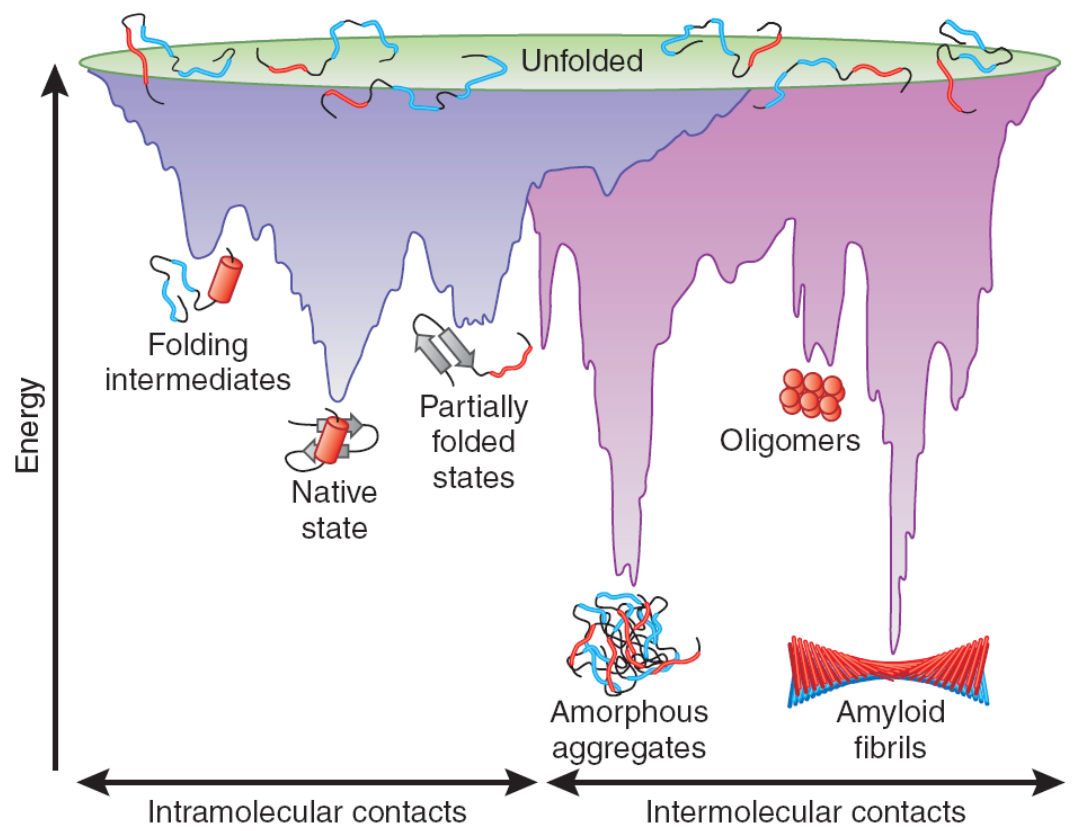

Figure 5. Energy landscape representing folding and aggregation of amyloid proteins. The purple area shows a diversity of conformations that are available for a single molecule "funneling" to the native state. In contrast, the pink area describes conformations made of intermolecular contacts moving either toward amorphous aggregates or amyloid fibrils. Protein aggregation can derive from intermediates assembled during de novo folding or by destabilization of the native state into partially folded states. Intermediates of amyloid fibril formation can result in oligomeric aggregates. [Reprinted by permission from Macmillan Publishers Ltd: Nat. Struct. Mol. Biol. (120), copyright (2009).]

\subsubsection{Classes of amyloid proteins}

As amyloid aggregates can be beneficial or pathogenic, amyloid proteins can be classified as follows: (i) Functional amyloids, (ii) non-neuropathic amyloids, and (iii) neuropathic amyloids. A diversity of more than 20 human diseases is linked to amyloid depositions (exemplified in Table 1), either in single types of organic tissue, systemic, 
or exclusively in the brain $(91,129)$. The pathology of these disorders may result from proteins that did not reach their native fold or that required refolding due to altering conditions in the (extra-) cellular environment that causes a change in protein functionality as well. Especially in neurodegenerative diseases, such as Alzheimer's, Parkinson's, or Huntington's (AD, PD, HD), amyloid aggregates play a central role (123).

Table 1. Examples of amyloid proteins in vivo.

\begin{tabular}{|c|c|c|c|c|c|}
\hline Class & $\begin{array}{l}\text { Amyloid protein } \\
\text { or peptide }\end{array}$ & $\begin{array}{l}\text { Native state } \\
\text { structure }\end{array}$ & Amyloid structure & $\begin{array}{l}\text { Amyloid function or } \\
\text { pathological phenotype }\end{array}$ & Ref. \\
\hline \multirow[t]{4}{*}{$\begin{array}{l}\text { Functional } \\
\text { amyloids }\end{array}$} & Peptide hormones & Diverse & Amyloid-like & Storage & (130) \\
\hline & Pmel17 & Globular & In-register amyloid & $\begin{array}{l}\text { Accelerates covalent } \\
\text { polymerization of reactive } \\
\text { small molecules into melanin } \\
\text { in mammalian skin }\end{array}$ & $\begin{array}{l}(131- \\
134)\end{array}$ \\
\hline & HET-s & $\begin{array}{l}\text { Partially } \\
\text { unfolded }\end{array}$ & Triangular $\beta$-solenoid & $\begin{array}{l}\text { Prevents parasitism in fungus } \\
\text { Podospora anserina }\end{array}$ & $\begin{array}{c}(23,135- \\
137)\end{array}$ \\
\hline & Ure $2 p$ & $\begin{array}{l}\text { Partially } \\
\text { unfolded }\end{array}$ & $\begin{array}{l}\text { Parallel in-register } \\
\text { amyloid or native- } \\
\text { like }\end{array}$ & $\begin{array}{l}\text { Regulates the utilization of } \\
\text { poor nitrogen sources in yeast }\end{array}$ & $\begin{array}{c}(113 \\
138-140)\end{array}$ \\
\hline \multirow[t]{3}{*}{$\begin{array}{l}\text { Non- } \\
\text { neuropathic } \\
\text { amyloids }\end{array}$} & $\begin{array}{l}\text { Fragment of serum } \\
\text { amyloid A protein }\end{array}$ & $\begin{array}{l}\alpha \text {-helical } \\
\text { unknown } \\
\text { fold }\end{array}$ & Amyloid & AA amyloidosis (systemic) & $\begin{array}{l}(141, \\
142)\end{array}$ \\
\hline & $\begin{array}{c}\text { Immunglobulin }(\mathrm{Ig}) \\
\text { light chain or } \\
\text { fragment }\end{array}$ & $\begin{array}{l}\beta \text {-strand Ig- } \\
\text { like fold }\end{array}$ & Amyloid & AL amyloidosis (systemic) & $\begin{array}{l}(141, \\
143)\end{array}$ \\
\hline & $\begin{array}{c}\text { Islet amyloid } \\
\text { polypeptide (IAPP) }\end{array}$ & Unfolded & $\begin{array}{c}\text { Out-of-plane } \beta \text {-strand } \\
\text { hairpin model }\end{array}$ & Type II diabetes & (144) \\
\hline \multirow[t]{5}{*}{$\begin{array}{l}\text { Neuropathic } \\
\text { amyloids }\end{array}$} & Amyloid $\beta$ & Unfolded & Parallel $\beta$-sheets & Alzheimer's disease & $\begin{array}{c}(118 \\
145-148)\end{array}$ \\
\hline & Tau & Unfolded & $\begin{array}{l}\text { Parallel in-register } \\
\text { amyloid }\end{array}$ & Alzheimer's disease & $\begin{array}{l}(149- \\
152)\end{array}$ \\
\hline & Prion & $\begin{array}{l}\text { Partially } \\
\text { unfolded }\end{array}$ & $\begin{array}{l}\text { Triangular } \beta \text {-helical } \\
\text { trimers or globular }\end{array}$ & $\begin{array}{l}\text { Transmissible spongiform } \\
\text { encephalopathies }\end{array}$ & $\begin{array}{l}(153- \\
155)\end{array}$ \\
\hline & $\alpha$-Synuclein & Unfolded & $\begin{array}{l}\text { Parallel in-register } \\
\text { amyloid }\end{array}$ & Parkinson's disease & $\begin{array}{l}(22,26, \\
39)\end{array}$ \\
\hline & $\begin{array}{l}\text { Huntingtin (with } \\
\text { poly-Q tail) }\end{array}$ & $\begin{array}{l}\text { Partially } \\
\text { unfolded }\end{array}$ & $\begin{array}{l}\text { In-register amyloid } \\
\text { core with } \alpha \text {-helical } \\
\quad \text { extensions }\end{array}$ & Huntington's disease & $\begin{array}{l}(156, \\
157)\end{array}$ \\
\hline
\end{tabular}

Moreover, it was demonstrated that many proteins and peptide sequences are able to aggregate into amyloid fibrils in vitro under carefully selected conditions. This paved the way for extensive investigations of nucleation steps, intermolecular interactions, 
fibrillar structures, transgenic animal models (e.g. in M. musculus, C. elegans, D. melanogaster, D. rerio), as well as toxicity of certain species such as oligomeric aggregates, with the objective of developing potential therapeutics (158-165). 


\subsection{Tau protein}

\subsubsection{Tau isoforms and domains}

In 1975, the intrinsically unfolded tau protein has been discovered as an essential factor for microtubule assembly $(166,167)$. Human tau is encoded on chromosome $17 \mathrm{q} 21$ by the MAPT (microtubule-associated protein tau) gene $(168,169)$, and tau protein emerges mainly in the CNS (central nervous system) in neuronal axons.

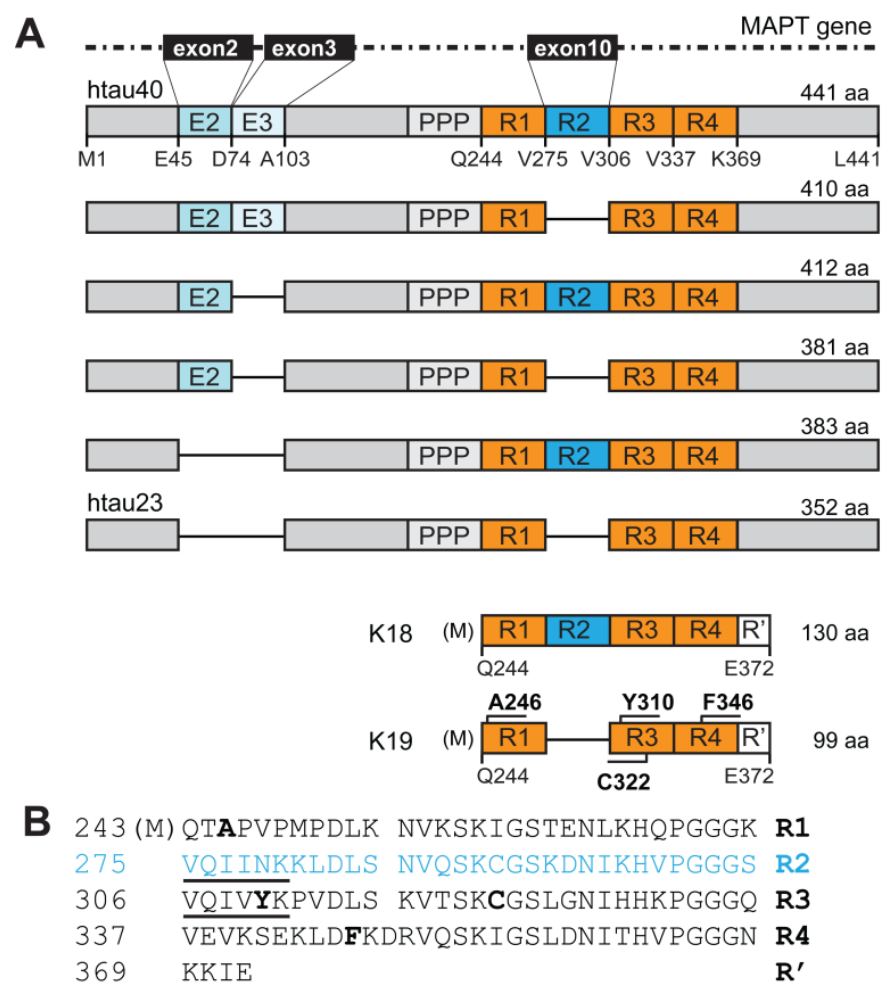

Figure 6. Tau isoforms and constructs K18 and K19. (A) Tau is encoded by the MAPT gene and expressed in the adult human brain in six isoforms with htau40 as the longest and htau23 as the shortest one. While K18 is a truncated form of htau40, K19 originates from htau23. Repeat domains common to all constructs are shown in orange, whereas the alternatively spliced R2 is depicted in blue - as well as N-terminally exons E2 and E3 (light blue). In K19, amino acids (aa) are labeled in bold that are unique within the construct sequence and valuable for solid-state NMR studies. The proline-rich region is labeled with "PPP”. (B) Aa sequence of the constructs K19 and K18. Aa from R2 (K18) are shown in blue. Underlined residues belong to hexapeptide motifs that are known to promote fibril formation. Aa in bold letters are exclusively present in one of the repeats and have unique chemical shifts that make them easily identifiable in NMR spectra. 
Due to alternative splicing, the adult brain comprises largely six different isoforms (Figure 6): Two amino (N) -terminal exons and the second out of four repeats (R2) in the carboxy (C) -terminal microtubule (MT) -binding domain can be present or absent $(170,171)$. Additionally, another tau isoform of high molecular weight occurs in the peripheral nervous system (e.g. in dorsal root ganglia), consisting of both N-terminal exons and R2, as well as of another exon, 4a $(172,173)$. In the CNS, htau40 is the longest tau isoform that comprises 441 aa. In contrast, htau23 lacks all three exons and consists of only 352 residues. The ratio of three repeat (3R) and four-repeat (4R) tau is dependent on developmental stages and approximately 1:1 in adult human brain tissue (174).

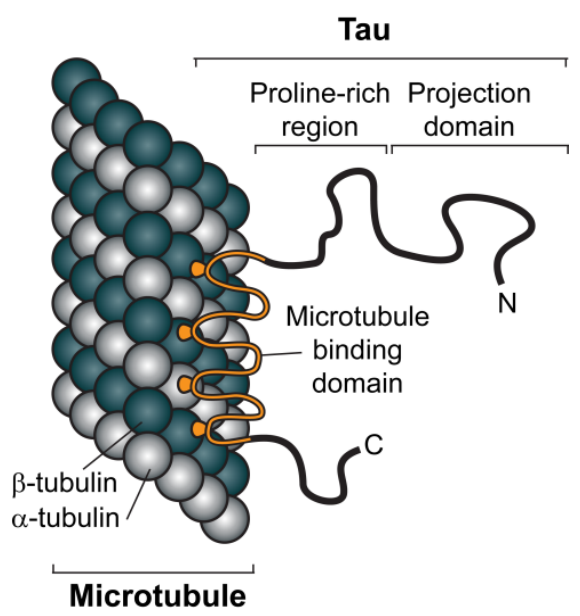

Figure 7. Physiological role of tau. Tau is an important microtubule (MT) -associated protein that stabilizes $\alpha \beta$ tubulin dimers to form the cylindrical MT in neuronal axons. Important for MT-binding is the MT-binding domain (orange) in the $\mathrm{C}$-terminal half of tau protein. N-terminally located are the projection domain and a proline-rich-region. [Adapted from (175)]

Independent of the isoform, tau has an overall similar domain structure. The Cterminal part of the protein is mainly defined by the MT-binding domain, which consists of either $3 \mathrm{R}$ or $4 \mathrm{R}$ with each repeat comprising $\sim 31$ residues. As implicated in Figure 7, this domain interacts with MT to promote their assembly and stabilization (176). Especially residues 200 to 400 show a distinct interaction with MT, covering the MT-binding domain and some flanking aa $(177,178)$. Additional weak interactions with MT were demonstrated for further C-terminal parts as well (150). Because the Nterminal half of tau is not binding to but projecting away from the MT, it is called the 
projection domain $(178,179)$. N-terminally, the MT-binding domain is flanked by a proline rich domain (approximately residues 150 to 240). This region contains many Ser-Pro and Thr-Pro motifs that are known targets for kinases and play an important role in tau-related disorders termed tauopathies $(175,178,180)$.

\subsubsection{Tau as a key player in neurodegenerative diseases}

The major physiological role of tau is to bind to MT (a major component of the eukaryotic cytoskeleton) and regulate their dynamics ensuring axonal transport (181). However upon abnormal phosphorylation, tau detaches from microtubules and selfassembles into amyloid fibrils (182-184).

A

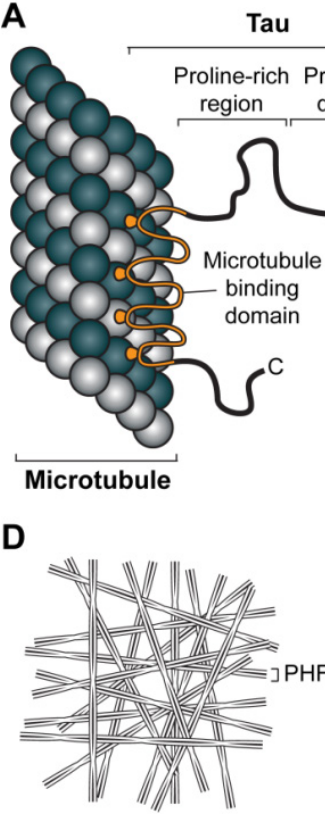

Neurofibrillary tangles
B

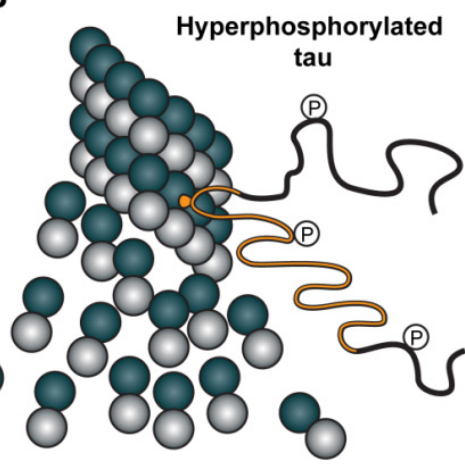

C

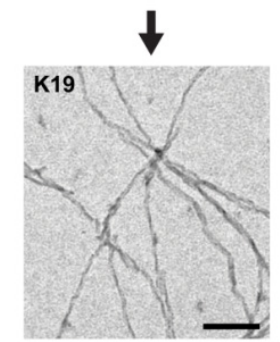

Paired helical filaments (PHF)

Figure 8. Pathological features of AD. (A) Physiological binding of tau to MT. (B) Abnormally phosphorylated tau detaches from MT that causes a collapse of MT into its $\alpha \beta$-dimers. (C) Electron micrograph of self-assembled tau K19 molecules into amyloid PHF (scale bar $=100 \mathrm{~nm}$ ). (D) Schematic representation of PHF that further aggregate into neurofibrillary tangles.

In $\mathrm{AD}$ and other tauopathies abnormally phosphorylated tau aggregates into PHF (paired helical filaments) (185), which represent the major constituents of NFT 
(neurofibrillary tangles; Figure 8) (97). A progressive intraneuronal accumulation of these tangles is one of the neuropathological hallmarks of AD (186).

Table 2. Most prevalent tauopathies. [Reprinted and adapted with permission from Wiley: Intern Med J (187), copyright (2006).]

\begin{tabular}{|c|c|c|c|}
\hline & Pattern of dementia & Movement disorder & 3R:4R \\
\hline \multicolumn{4}{|l|}{$\begin{array}{c}\text { Predominantly tau } \\
\text { pathology }\end{array}$} \\
\hline PSP & $\begin{array}{c}\text { Frontal dysexecutive, } \\
\text { PNFA }\end{array}$ & $\begin{array}{l}\text { Axial rigidity with postural instability and } \\
\text { ophthalmoplegia or asymmetric parkinsonism }\end{array}$ & $1: 2-4$ \\
\hline CBD & $\begin{array}{c}\text { Parietal, frontal } \\
\text { dysexecutive, PNFA }\end{array}$ & $\begin{array}{c}\text { Asymmetric parkinsonism, dystonia, myoclonus } \\
\text { or tremor, alien limb }\end{array}$ & $1: 2$ \\
\hline $\begin{array}{l}\text { Argyrophilic gain } \\
\text { disease }\end{array}$ & Limbic dementia & No & $1: 2$ \\
\hline Pick disease & $\begin{array}{l}\text { Frontal dysexecutive, } \\
\text { PNFA, SD }\end{array}$ & Rare & $3: 1$ \\
\hline FTDP-17 & $\begin{array}{l}\text { Frontal behavioral or } \\
\text { amnestic }\end{array}$ & $\begin{array}{l}\text { Variable parkinsonism, can be PSP-like or CBD- } \\
\text { like }\end{array}$ & $\begin{array}{l}1: 2,1: 1 \\
\text { or } 2: 1\end{array}$ \\
\hline $\begin{array}{l}\text { Post encephalitic } \\
\text { parkinsonism }\end{array}$ & Rare & $\begin{array}{c}\text { Symmetric rigidity with bradykinesia, } \\
\text { ophthalmoplegia }\end{array}$ & $1: 1$ \\
\hline $\begin{array}{c}\text { Parkinsonism- } \\
\text { dementia complex of } \\
\text { Guam }\end{array}$ & $\begin{array}{l}\text { Frontal dysexecutive, } \\
\text { cortical }\end{array}$ & $\begin{array}{c}\text { Symmetric rigidity with bradykinesia, } \\
\text { ophthalmoplegia }\end{array}$ & $1: 1$ \\
\hline $\begin{array}{l}\text { Guadeloupean } \\
\text { parkinsonism }\end{array}$ & Frontal dysexecutive & $\begin{array}{c}\text { Symmetric rigidity with bradykinesia, } \\
\text { ophthalmoplegia }\end{array}$ & $1: 2$ \\
\hline \multicolumn{4}{|l|}{$\begin{array}{l}\text { Associated with } \\
\text { amyloid deposition }\end{array}$} \\
\hline $\mathrm{AD}$ & Amnestic, cortical & Rare & $1: 1$ \\
\hline Down syndrome & Amnestic, cortical & No & $1: 1$ \\
\hline Dementia pugilistica & Amnestic, cortical & Parkinsonism & $1: 1$ \\
\hline $\begin{array}{l}\text { Familial British } \\
\text { dementia }\end{array}$ & Amnestic, cortical & No & - \\
\hline $\begin{array}{l}\text { Familial Danish } \\
\text { dementia }\end{array}$ & Amnestic, cortical & No & - \\
\hline \multicolumn{4}{|l|}{$\begin{array}{l}\text { In association with } \\
\text { other pathology }\end{array}$} \\
\hline Myotonic dystrophy & Frontal behavioral & No & $2: 1$ \\
\hline $\begin{array}{l}\text { Hallervorden-Spatz } \\
\text { disease }\end{array}$ & Mental retardation & Gait disturbance, extrapyramidal syndrome & - \\
\hline Niemann Pick type C & Mental retardation & Dystonia, ataxia, ophthalmoplegia & - \\
\hline SSPE & Mental retardation & Myoclonus, ataxia, late rigidity & - \\
\hline
\end{tabular}

PSP: progressive supranuclear palsy; PNFA: progressive non fluent aphasia; CBD: corticobasal degeneration; SD: semantic dementia; FTDP-17: frontotemporal dementia with parkinsonism linked to chromosome 17; SPPE: subacute sclerosing panencephalitis. 
Intracellular deposits of tau in the human brain occur in more than 20 neurodegenerative disorders with the most prevalent tauopathies listed in Table 2 (187, 188).

Tau-linked disorders occur sporadic or are hereditary, and can be divided into different classes (187): (i) Prototypical tauopathies exhibit amyloid deposits in the CNS primarily derived from tau, e.g. PSP (progressive supranuclear palsy) (189), CBD (corticobasal degeneration) (190), or Pick disease (191). (ii) Next to tau deposits, additional amyloid aggregates emerge intra- or extracellular. The best-known tauopathy of this class is $\mathrm{AD}$, with an intracellular accumulation of tau into NFT and an extracellular formation of Amyloid $\beta$ plaques caused by wrong cleavage of the amyloid precursor protein (APP) (for review see e.g. (192-194)). Recently, a direct link between tau missorting from axons to dendrites and Amyloid $\beta$ toxicity could be demonstrated by Ittner and coworkers (192). (iii) Some tauopathies are associated with further pathological characteristics, such as Myotonic dystrophy and SPPE (subacute sclerosing panencephalitis) (187).

Common to all tauopathies is the deposition of tau-based amyloid fibrils. A detailed understanding about the assembly mechanism as well as the structure of tau aggregates, such as PHF, is essential to develop target-specific drugs that prevent or dissolve tau deposits and promotes degradation of pathological tau molecules $(193,195)$. Despite tremendous research in the field of tauopathies, fundamental problems remain unsolved and therapeutics that modify or prevent an onset of tau-linked disorders are still missing (193).

\subsubsection{Recent findings of the rigid core of AD-like tau PHF}

The sporadic form of AD is the most common dementia that mostly affects people of the age of $\sim 65$. In 2001 , the number of people in that age suffering from sporadic AD was estimated to be approximately 24 million worldwide. Studies further predict a global increase of about 80 million patients suffering from AD in the year 2040 (196, 197). Thus, solving fundamental mechanisms and developing promising therapeutics is inevitable. 
For PHF - that are the matter of this work - several facts were revealed already: Tau PHF can be structurally divided into two regions, (i) a rigid amyloid core and (ii) a highly flexible fuzzy coat of more than 200 residues that transiently attaches to the amyloid core (198). Protease digestion and solvent accessibility studies indicated that the core of PHF is mainly built from amino acids belonging to the repeats R2 (present only in 4R isoforms) and R3 (199, 200). Furthermore, CD (circular dichroism) spectropolarimetry, FTIR (Fourier transform infrared) spectroscopy, together with Xray diffraction and selected area electron diffraction have indicated the presence of cross- $\beta$ structure, where $\beta$-strands run roughly perpendicular to the fiber axis (201-203). In addition, EPR (electron paramagnetic resonance) studies have suggested that within tau fibrils, $\beta$-strands are arranged in-register and parallel $(151,152)$.

Because the tau construct K19 is relatively short (99 aa), compared to htau40 (Figure 6), and features all known residues that are essential for fibril formation, it recently has become object to investigations using solid-state NMR. A previous study by Andronesi et al. has shown that K19 fibrils consist of a rigid core surrounded by regions of higher flexibility. The most rigid, water-inaccessible part of the fibrils was found to be formed by repeat R3, whereas R1 and R4 are more water-accessible (204). Nevertheless, detailed information about the tau PHF core residues and their structural arrangement are still missing. 


\subsection{Purpose of this work}

Despite all improvements in understanding the principles of tau fibril formation, a detailed insight into the residue-specific structural arrangement of $\beta$-strands formed by the amino acids in R2 and R3 is still not available. In this regard, MAS solid-state NMR spectroscopy constitutes a powerful method to obtain structural information on insoluble PHF assembled in vitro from the 99 aa tau construct K19 (Figure 6). It corresponds to the juvenile htau23 isoform of tau, containing a 3R version of the MTbinding domain. In a recently performed study on these fibrils, a pronounced structural heterogeneity resulting in substantial line broadening hampered the determination of the exact arrangement of the $\beta$-structure within the core (204). Based on improved sample preparation and an extensive labeling strategy we aimed for a detailed solid-state NMR analysis of the K19 core structure.

This thesis is based on:

Daebel V, et al. (2012) $\beta$-sheet core of tau paired helical filaments revealed by solidstate NMR. J Am Chem Soc 134:13982-9. 


\section{Materials and Methods}

\subsection{Sample preparation and characterization}

Recombinant expression, purification, aggregation and characterization of all tau samples were performed by Mandelkow et al., based until middle of 2011 at the Max Planck Unit for Structural Molecular Biology, 22607 Hamburg, Germany and since then in the "German Center for Neurodegenerative Diseases" (DZNE) and the CAESAR Research Center in 53175 Bonn, Germany. A detailed description of materials and methods has been published in 2005 by Barghorn et al. (205). A brief overview focusing on labeling schemes and aggregation is following in this Chapter.

\subsubsection{Chemical reagents and proteins}

Heparin (average molecular weight of 5,000 Da or 3,000 Da; see Table 3) and thioflavine S (ThS) were purchased from Sigma-Aldrich (Munich, Germany). Labeled ${ }^{15} \mathrm{NH}_{4} \mathrm{Cl}$, $\left[{ }^{13} \mathrm{C}\right]$-glucose and selectively $\left[{ }^{13} \mathrm{C}\right]$-labeled glycerol were obtained from Euriso-Top GmbH (Saarbrücken, Germany). All tau constructs were expressed in the pNG2 vector in E. coli strain BL21 (DE3) and purified by heat treatment and FPLC (fast performance liquid chromatography) Mono S chromatography (GE Healthcare, Freiburg, Germany) as described previously (205).

\subsubsection{Labeling schemes for solid-state NMR samples}

Uniform isotopic labeling of $\mathrm{K} 19$ protein with ${ }^{15} \mathrm{~N}$ and ${ }^{13} \mathrm{C}$ was achieved by expressing $\mathrm{K} 19$ in M9 minimal medium containing $1 \mathrm{~g} \mathrm{~L}^{-1}$ of ${ }^{15} \mathrm{NH}_{4} \mathrm{Cl}$ and $4 \mathrm{~g} \mathrm{~L}^{-1}$ of $\left[{ }^{13} \mathrm{C}\right]$-glucose. Selectively labeled protein was obtained by growing bacteria exclusively on $\left[2-{ }^{13} \mathrm{C}\right]$ glycerol or $\left[1,3-{ }^{13} \mathrm{C}\right]$ glycerol as carbon source $(6,40,79)$.

Reverse labeling of specific residues was accomplished by adding natural abundance amino acids in excess to the M9 minimal medium, containing ${ }^{15} \mathrm{NH}_{4} \mathrm{Cl}$ and $\left[{ }^{13} \mathrm{C}\right]-$ 
glucose $(22,80)$. Using an analogous method, $\left[{ }^{13} \mathrm{C}\right]$-labeled residues were incorporated into an otherwise natural abundance protein (forward labeling).

To get a mixed labeled K19 PHF sample, equimolar ratios of $\left[{ }^{13} \mathrm{C}\right]$-labeled $\mathrm{K} 19$ monomers and $\left[{ }^{15} \mathrm{~N}\right]$-labeled K19 monomers were combined for aggregation. The monomers were expressed using either ${ }^{15} \mathrm{NH}_{4} \mathrm{Cl}$ and $\left[{ }^{12} \mathrm{C}\right]$-glucose, or ${ }^{14} \mathrm{NH}_{4} \mathrm{Cl}$ and $\left[{ }^{13} \mathrm{C}\right]$-glucose, respectively, in the growth medium (206).

An overview about the different labeling approaches can be found in Table 3 .

\subsubsection{PHF assembly}

Aggregation was initiated by incubating soluble monomeric tau protein, typically in the concentration range of $50 \mu \mathrm{M}$ and in the volume range of $100-150 \mu \mathrm{l}$, in the presence of the anionic cofactor heparin for $\sim 3$ days at $310 \mathrm{~K}$. The buffer contained $20 \mathrm{mM}$ BES, $25 \mathrm{mM} \mathrm{NaCl}, \mathrm{pH} 7.4$ and a protein to heparin ratio of $4: 1$. The polymerized solution was then centrifuged at $160,000 \times \mathrm{g}$ for $40 \mathrm{~min}$. In some cases, the pellet was stored at $277 \mathrm{~K}$ and the supernatant was complemented again with heparin for another incubation time of 3-5 days (see Table 3). The reaction was then pelleted at $160,000 \times \mathrm{g}$ for $40 \mathrm{~min}$. Pellets were pooled and washed once with $50 \mathrm{mM}$ sodium phosphate, $\mathrm{pH} 6.8$, containing $0.1 \% \mathrm{NaN}_{3}$. (204)

Table 3. Overview about K19 PHF samples.

\begin{tabular}{|c|c|c|c|c|}
\hline Sample & Labeling & $\begin{array}{c}\text { Molecular Weight } \\
\text { Heparin } \\
\text { [Da] }\end{array}$ & $\begin{array}{l}2^{\text {nd }} \text { Incubation } \\
\text { Time [d] }\end{array}$ & $\begin{array}{l}\text { Yield } \\
{[\mathrm{mg}]}\end{array}$ \\
\hline uK19 old & uniformly- $\left[{ }^{13} \mathrm{C},{ }^{15} \mathrm{~N}\right]$ & 5,000 & none & 22 \\
\hline K19 ${ }_{\text {Krev }}$ & uniformly- $\left[{ }^{13} \mathrm{C},{ }^{15} \mathrm{~N}\right]$; except Lys- $\left[{ }^{12} \mathrm{C} ;{ }^{14} \mathrm{~N}\right]$ & 5,000 & 3 & 24 \\
\hline K19 $_{1: 1}$ & $(1: 1)-\left(\left[{ }^{13} \mathrm{C},{ }^{14} \mathrm{~N}\right]:\left[\left[{ }^{12} \mathrm{C},{ }^{15} \mathrm{~N}\right]\right)\right.$ & 5,000 & 3 & 10 \\
\hline K19 ${ }_{\text {KFLVrev }}$ & $\begin{array}{c}\text { uniformly- }\left[{ }^{13} \mathrm{C},{ }^{15} \mathrm{~N}\right] ; \text { except (Lys, Phe, Leu, Val)- } \\
{\left[{ }^{12} \mathrm{C} ;{ }^{14} \mathrm{~N}\right]}\end{array}$ & 5,000 & 3 & 60 \\
\hline K19 ${ }_{\text {2glyc }}$ & {$\left[2-{ }^{13} \mathrm{C}\right]$-glycerol- and uniformly- $\left[{ }^{15} \mathrm{~N}\right]$} & 5,000 & 3 & 40 \\
\hline K19 $1,3 \mathrm{glyc}$ & {$\left[1,3-{ }^{13} \mathrm{C}\right]$-glycerol- and uniformly- $\left[{ }^{15} \mathrm{~N}\right]$} & 5,000 & none & 33 \\
\hline uK19 & uniformly- $\left[{ }^{13} \mathrm{C},{ }^{15} \mathrm{~N}\right]$ & 5,000 & none & 41 \\
\hline uK19CA & uniformly- $\left[{ }^{13} \mathrm{C},{ }^{15} \mathrm{~N}\right]$ & 3,000 & 3 & 28 \\
\hline${\mathrm{K} 19 C A_{2 g l y c}}$ & {$\left[2-{ }^{13} \mathrm{C}\right]$-glycerol- and uniformly- $\left[{ }^{15} \mathrm{~N}\right]$} & 3,000 & 4 & 22 \\
\hline $\mathrm{K1}_{19 A_{1,3 g l y c}}$ & {$\left[1,3-{ }^{13} \mathrm{C}\right]$-glycerol- and uniformly- $\left[{ }^{15} \mathrm{~N}\right]$} & 3,000 & 5 & 45 \\
\hline K19 & $\begin{array}{c}\text { uniformly- }\left[{ }^{12} \mathrm{C},{ }^{14} \mathrm{~N}\right] ; \text { except (Cys, Tyr, Leu)- } \\
{\left[{ }^{13} \mathrm{C} ;{ }^{15} \mathrm{~N}\right]}\end{array}$ & 5,000 & none & 30 \\
\hline
\end{tabular}


The formation of aggregates was monitored by $\mathrm{ThS}$ fluorescence and the morphology of filaments was analyzed by electron microscopy. Samples were sent to Göttingen as pellets covered with buffer at room temperature and stored at $277 \mathrm{~K}$ afterwards.

\subsubsection{ThS fluorescence}

The binding and subsequent increase in ThS fluorescence is specific for the cross- $\beta$ structure, which is typical for amyloid aggregates $(95,96) .5 \mu 1$ of PHF reaction mixture was added to $45 \mu \mathrm{l}$ of $50 \mathrm{mM} \mathrm{NH}_{4} \mathrm{Ac}(\mathrm{pH}$ 7) containing $20 \mu \mathrm{M}$ ThS. ThS fluorescence was measured in a Tecan spectrofluorimeter (Crailsheim, Germany) with an excitation wavelength of $440 \mathrm{~nm}$ and an emission wavelength of $521 \mathrm{~nm}$ (slit width $2.5 \mathrm{~nm}$ each) in a 384 well plate (black microtiter 384 plate round well; ThermoLab Systems, Dreieich, Germany). Measurements were carried out at $298 \mathrm{~K}$ and the background fluorescence from $\mathrm{ThS}$ alone was subtracted. Measurements were carried out in triplicates. (167)

\subsubsection{Electron microscopy}

The protein samples were diluted to $1-10 \mu \mathrm{M}$ and placed on 600 mesh carbon coated copper grids for 45 seconds, washed twice with $\mathrm{H}_{2} \mathrm{O}$, and negatively stained with $2 \%$ uranyl acetate for 45 seconds. The specimens were examined with a Philips CM12 electron microscope at $80 \mathrm{kV}$.

\subsection{Structural biology}

\subsubsection{Solid-state NMR spectroscopy}

Prior to filling of MAS rotors, the protein pellets were ultra-centrifuged for $45 \mathrm{~min}$ at 60,000 rpm in a Beckman TLA100.3 rotor (Beckman Instruments $\mathrm{GmbH}$, München, Germany). MAS rotors were stored at $277 \mathrm{~K}$.

All solid-state NMR experiments were conducted on aggregated tau K19 PHF samples using 4 or $3.2 \mathrm{~mm}$ triple-resonance $\left({ }^{1} \mathrm{H},{ }^{13} \mathrm{C},{ }^{15} \mathrm{~N}\right)$ MAS probes at static magnetic fields of 20, 18.8, and 14.1 T (Bruker Biospin, Karlsruhe, Germany) corresponding to ${ }^{1} \mathrm{H}$ resonance frequencies of 850,800 , and $600 \mathrm{MHz}$, respectively. ${ }^{13} \mathrm{C}$ 
and ${ }^{15} \mathrm{~N}$ chemical shifts were calibrated either with Adamantane as an external reference or with DSS as an internal reference (207). In the latter case the temperature-dependent position of the water proton resonance was used to calculate the temperature inside the MAS rotor (208). Typical proton field strength for $90^{\circ}$ pulses and SPINAL-64 (209) high-power ${ }^{1} \mathrm{H}-{ }^{13} \mathrm{C}$ decoupling was $83 \mathrm{kHz}$.

For the detection of flexible regions within the protein, ${ }^{13} \mathrm{C}-{ }^{13} \mathrm{C}$ correlation spectra were measured at a spinning frequency of $8.33 \mathrm{kHz}$ using INEPT-based ${ }^{1} \mathrm{H}-{ }^{13} \mathrm{C}$ transfer (68) and TOBSY-mixing times of $6 \mathrm{~ms}$ (Figure A3) (69). For these experiments, GARP (53) decoupling with a field strength of $2.5 \mathrm{kHz}$ was applied on protons.

DREAM (Figure A4) (66) and PAIN-CP (Figure A5) (88) experiments were recorded at $18 \mathrm{kHz}$, all other spectra were acquired at a spinning frequency of $11 \mathrm{kHz}$. An initial ramped cross-polarization $(\mathrm{CP})$ was used to transfer magnetization from ${ }^{1} \mathrm{H}$ to ${ }^{13} \mathrm{C}$ or ${ }^{15} \mathrm{~N}$ with contact times between 700 and $1200 \mu \mathrm{s} .{ }^{13} \mathrm{C}-{ }^{13} \mathrm{C}$ transfer was achieved via PDSD (63) with mixing times of 20, 150, and $500 \mathrm{~ms}$ to obtain intra-residue, sequential, and medium- and long-range correlations, respectively (Figure A6). Sequential assignments were also obtained by means of NCACX and NCOCX experiments (Figure A7 and Figure A8). ${ }^{15} \mathrm{~N}$ to ${ }^{13} \mathrm{C} \alpha$ transfer utilized SPECIFIC-CP (62) for a contact time of 2.5-3.5 ms. In these experiments, PDSD or DARR (65) elements were used for homonuclear ${ }^{13} \mathrm{C}-{ }^{13} \mathrm{C}$ transfer. Intermolecular ${ }^{15} \mathrm{~N}$ to aliphatic ${ }^{13} \mathrm{C}$ transfer was achieved with PAIN-CP and a contact time of $5 \mathrm{~ms}$. Inter-scan delays were set to 2-2.5 s. All NMR spectra were processed using Topspin (version 2.1, Bruker Biospin, Karlsruhe, Germany) and analyzed using Sparky (version 3.100, T. D. Goddard \& D.G. Kneller, University of California).

A detailed list of experimental conditions can be found in Table A1.

\subsubsection{NMR-detected solvent protection of K18 and K19 filaments}

This part of the study has been performed in collaboration with Zweckstetter et al., based in the Department of NMR-based Structural Biology at the Max Planck Institute for Biophysical Chemistry in Göttingen. 
${ }^{15} \mathrm{~N}$-labeled recombinant $\mathrm{K} 19$ and $\mathrm{K} 18$ constructs were expressed, purified, and their fibrillation was achieved as described in Chapter 2.1 - additionally for the aggregation of K18 DTT was added to prevent intramolecular disulfide bond formation.

To determine the level of protection from amide proton exchange in the fibrillar state, a previously developed protocol (210) was applied. To remove residual monomeric protein and buffer, K18 and K19 filaments were subjected to three consecutive steps of centrifugation for 30 minutes at $25,000 \times \mathrm{g}$. For forward amide proton exchange, the resulting pellet ( $8.5 \mathrm{mg} \mathrm{K} 19$ and $7.2 \mathrm{mg} \mathrm{K} 18)$ was then incubated for a total of 36 hours in $200 \mu 199.9 \% \mathrm{D}_{2} \mathrm{O}$ at $278 \mathrm{~K}$. Next, the filaments were pelleted as described above and dissolved in $50 \% \mathrm{D}_{2} \mathrm{O} / 50 \% \mathrm{H}_{2} \mathrm{O}, 0.04 \%$ formic acid, $\mathrm{pH} 2.34$ and $2 \mathrm{M}$ GuSCN. The backward amide proton exchange was then assessed by a series of two-dimensional ${ }^{1} \mathrm{H}-{ }^{15} \mathrm{~N}$ HSQC spectra recorded at $278 \mathrm{~K}$ on Bruker NMR spectrometers with ${ }^{1} \mathrm{H}$ resonance frequencies of $600 \mathrm{MHz}(14.1 \mathrm{~T}$; K19 PHF) and $700 \mathrm{MHz}$ (16.45 T; K18 PHF) equipped with a $5 \mathrm{~mm}$ triple-resonance, pulsed-field zgradient cryogenic probe. Spectra were recorded with 4 transients and 256 increments in the ${ }^{15} \mathrm{~N}$ dimension, resulting in a total experimental time of 47 or 42 minutes, respectively. The delay time between the dissolvation of the PHF and the start of the first experiment was approximately 14 or 10 minutes, respectively. Exchange curves were fitted using IgorPro 5.01. The deuterium incorporation was calculated as described previously (210).

For sequential assignment of K18 in the denatured state, three-dimensional TOCSYHSQC (F1:132 x F2:128 x F3:2K total points) and NOESY-HSQC (F1:144 x F2:144 x F3:2K total points) experiments were acquired in $2 \mathrm{M} \mathrm{GuSCN}, \mathrm{pH} 2.34,0.04 \%$ formic acid, and $50 \% \mathrm{D}_{2} \mathrm{O} / 50 \% \mathrm{H}_{2} \mathrm{O}$ at $700 \mathrm{MHz}$ on a room-temperature $5 \mathrm{~mm}$ tripleresonance, pulsed-field z-gradient probe. Together with previously established assignments of K19 and K18 (177) as well as full-length tau (150) in phosphate buffer, the spectra enabled unambiguous assignment of the backbone signals of K18. Taking advantage of the sequence identity of K18 and K19, K19 was assigned based on chemical shift similarities in the HSQC spectra relative to K18. All spectra were processed and analyzed using NMRPipe (211) and CcpNmr Analysis (212). 


\section{Results and Discussion}

\subsection{High resolution spectra obtained with solid-state NMR}

We applied two-dimensional solid-state NMR spectroscopy to assign the resonances of PHF formed by the construct K19. In order to reduce spectral overlap and to unambiguously assign the observed residues we investigated not only a uniformly $\left[{ }^{13} \mathrm{C}\right.$, ${ }^{15} \mathrm{~N}$ ]-labeled sample (uK19), but in addition samples with different labeling schemes. Furthermore, we studied a uniformly $\left[{ }^{13} \mathrm{C}\right.$, $\left.{ }^{15} \mathrm{~N}\right]$-labeled K19C322A PHF sample (K19CA) as well as sparsely labeled mutants using [1, 3- $\left.{ }^{13} \mathrm{C}\right]-$ and $\left[2-{ }^{13} \mathrm{C}\right]-$ labeled glycerol. In K19, the mutation of the only cysteine, C322, to an alanine avoids intermolecular disulfide bond (DSB) formation.

The average ${ }^{13} \mathrm{C}$ line width in the spectra of K19 PHF (e.g. Figure 11 and Figure 13) was found to be around 0.5-0.8 ppm. This narrow line width reflects a higher degree of structural order in the fibrils and much better resolved resonances than seen in the previous solid-state NMR study on K19 PHF by Andronesi et al. (204) and may be the result of optimized hydration (see Chapter 1.3.3). Differences in the identified core region (that will be discussed below) could also suggest that the samples investigated in the previous study were of a different polymorph than the samples of the present study. This can be rationalized by small differences in the sample preparation (e.g. different people who prepared the sample, different batches of heparin used, etc.). In contrast, the spectra of wild type K19 samples (prepared with different labeling schemes) presented in this work overlay well with each other (differences $<0.5 \mathrm{ppm}$ ), indicating that all these samples are of the same polymorph.

An overview about the different samples and abbreviations can be found in Table 3, spectra that were used for the assignment process are given in the Appendix. 


\subsection{Flexible regions of tau K19 PHF in R1 and R4}

In order to detect the flexible segments of K19 PHF, which do not belong to the rigid core, we performed INEPT-based CC-TOBSY solid-state NMR experiments (Figure A3) (68-70). In the resulting spectra only resonances of residues with increased mobility (on the ps to ns time scale) are observed.

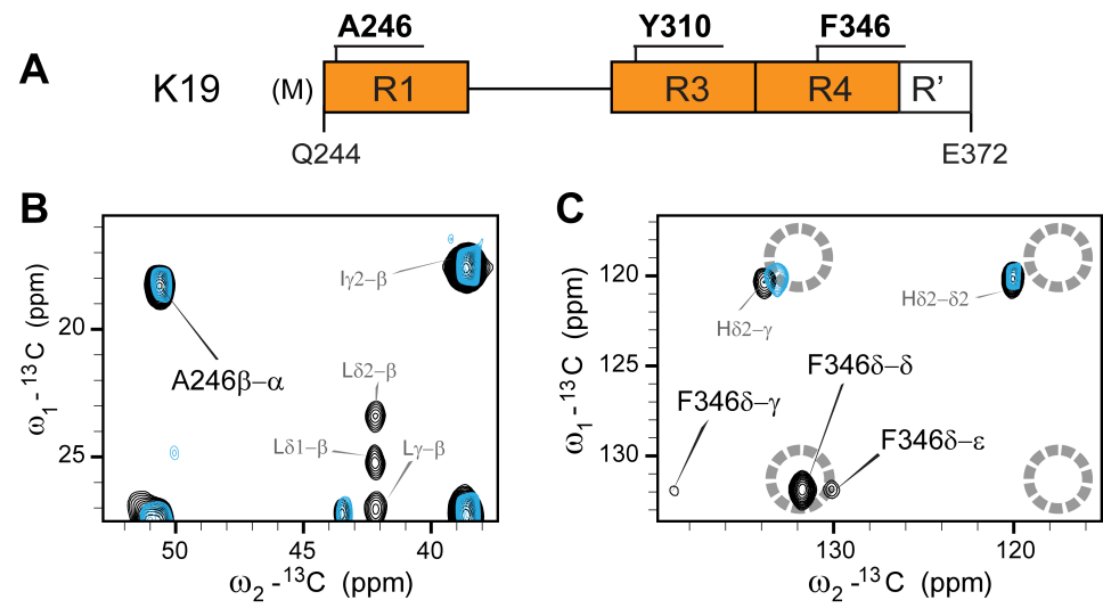

Figure 9. Dynamic segments of K19 PHF. (A) Positions of the three unique residues A246 (in repeat R1), Y310 (in R3), and F346 (in R4). (B, C) Overlay of $2 \mathrm{D}\left[{ }^{13} \mathrm{C},{ }^{13} \mathrm{C}\right]$-INEPT-CC-TOBSY ( $\mathrm{t}_{\text {mix }}=6 \mathrm{~ms}$ ) spectra of K19 ${ }_{\text {Krev }}$

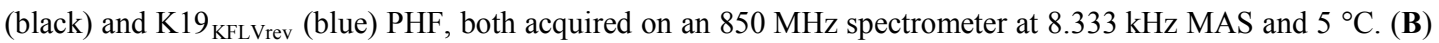
An alanine peak is present in the aliphatic region and $(\mathbf{C})$ phenylalanine resonances are visible in the aromatic region of the spectra. The dashed circles indicate positions where tyrosine resonances should appear if Y310 was flexible enough. Notice the absence of phenylalanine resonances in the reverse-labeled K19 $9_{\text {KFLVrev }}$ spectrum, thus validating the F346 assignment. Peaks marked with single letters (e.g. L) were not sequentially assigned.

The K19 sequence features three unique aa, A246 in R1, Y310 in R3, and F346 in R4 (Figure 9A), with distinct chemical shifts that can be easily identified. While the INEPT-CC-TOBSY spectra exhibit resonances with unambiguous random coil chemical shifts of alanine (Figure 9B) and phenylalanine (Figure 9C, black spectrum), tyrosine resonances are clearly absent (Figure 9C, dashed circles).

To unequivocally validate that the signal in Figure $9 \mathrm{C}$ originates from phenylalanine, we repeated the experiment on the K19 KFLVrev sample. Since phenylalanine is not $\left[{ }^{13} \mathrm{C},{ }^{15} \mathrm{~N}\right]$-labeled, the corresponding peaks vanish in the spectrum.

The appearance of F346 and A246 as well as the absence of Y310 in the INEPT-CCTOBSY spectra show that R1 and R4 are much more flexible than R3. Furthermore, the 
absence of the Y310 signals implies that the resonances in the spectra do not originate from soluble, monomeric K19 protein. In this case, the INEPT-CC-TOBSY spectra would contain signals from all residues of the molecule.

\subsection{Solid-state NMR studies on K19 PHF identify a well- defined rigid fibril core}

${ }^{13} \mathrm{C}-{ }^{13} \mathrm{C}$ correlations for residues of the rigid fibril core were obtained using PDSD experiments (63) with mixing times of 20,150, and $500 \mathrm{~ms}$ to gain intra-residue, sequential, together with medium- and long-range correlations, respectively (Figure A6).

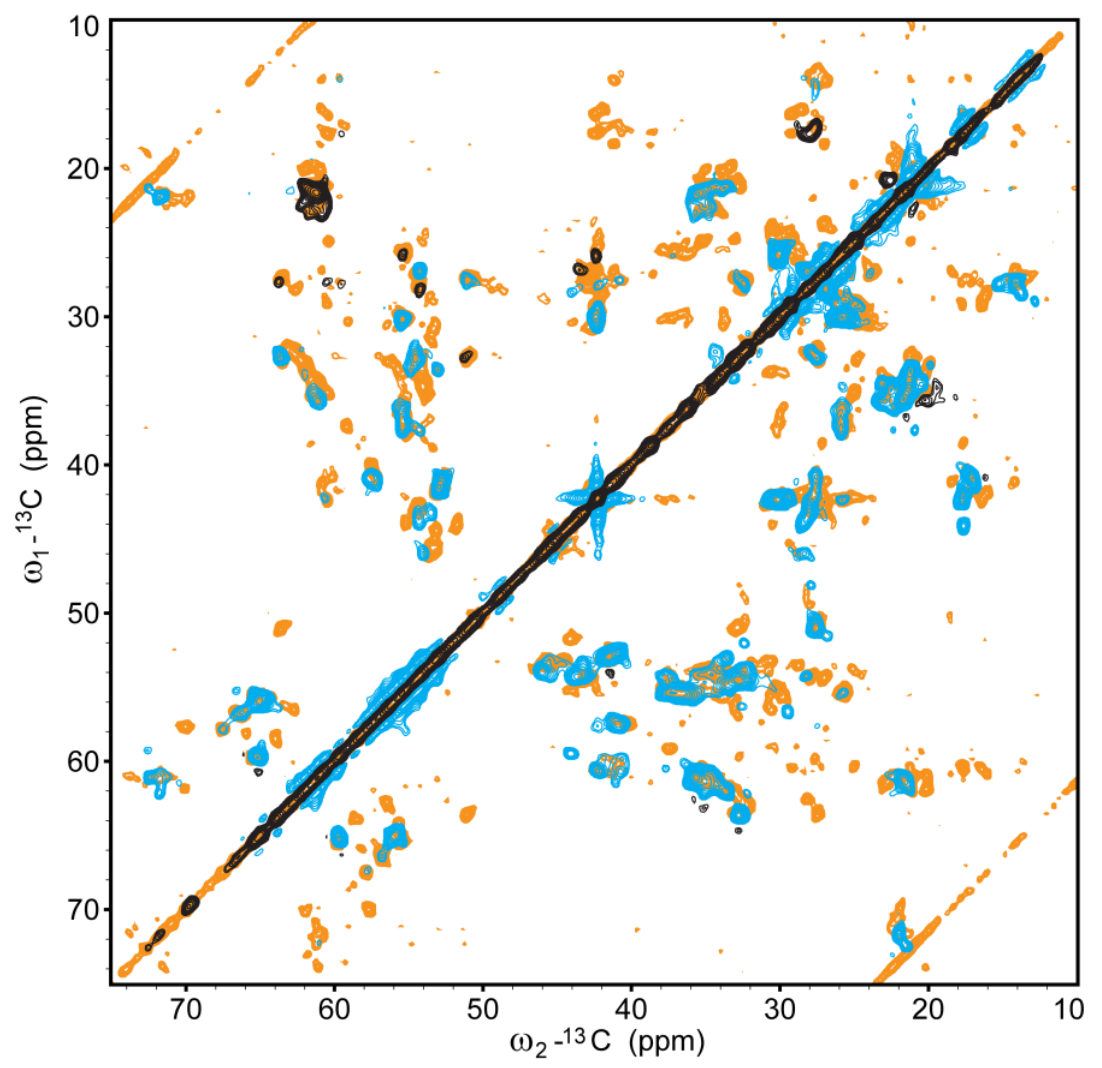

Figure 10. ${ }^{13} \mathrm{C}-{ }^{13} \mathrm{C}$ correlation experiments with different transfer schemes. Overlay of PDSD (orange; $\mathrm{t}_{\text {mix }}=20 \mathrm{~ms}$; recorded on an $850 \mathrm{MHz}$ spectrometer at $11 \mathrm{kHz}$ MAS at $7^{\circ} \mathrm{C}$ ) and DREAM (black: positive contours; blue: negative contours; $\mathrm{t}_{\mathrm{mix}}=3 \mathrm{~ms}$; recorded on an $800 \mathrm{MHz}$ spectrometer at $18 \mathrm{kHz} \mathrm{MAS}$ at $7^{\circ} \mathrm{C}$ ) spectra of uniformly $\left[{ }^{13} \mathrm{C},{ }^{15} \mathrm{~N}\right]$-labeled K19 PHF. 

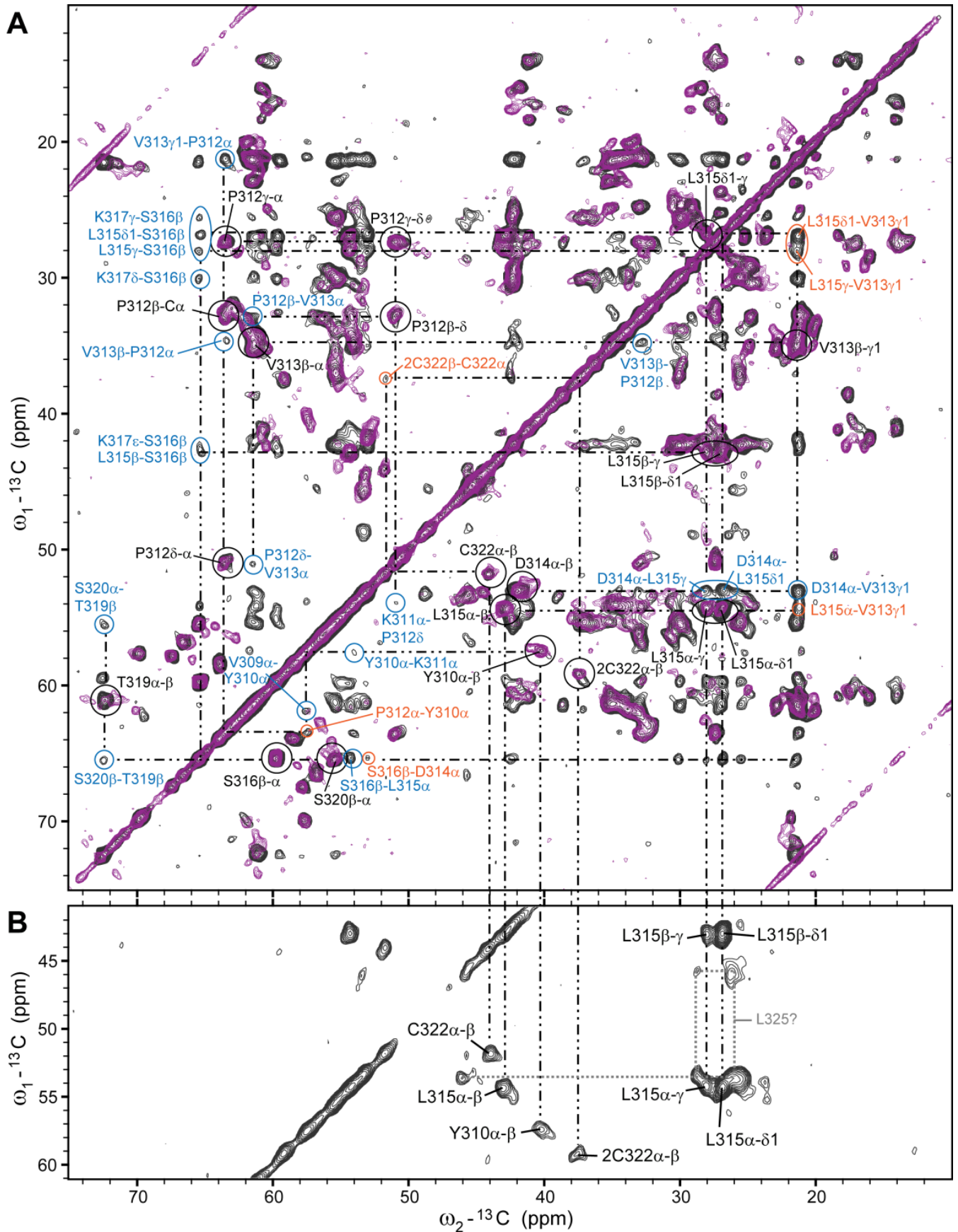

Figure 11. Sequential resonance assignment of the rigid core of K19 PHF. (A) Overlay of $2 \mathrm{D}\left[{ }^{13} \mathrm{C}\right.$, $\left.{ }^{13} \mathrm{C}\right]-\mathrm{PDSD}$ spectra (black: $\mathrm{t}_{\text {mix }}=150 \mathrm{~ms}$; purple: $\mathrm{t}_{\text {mix }}=20 \mathrm{~ms}$ ) measured on the $\mathrm{uK} 19$ sample on an $850 \mathrm{MHz}$ spectrometer at $11 \mathrm{kHz}$ MAS and $7{ }^{\circ} \mathrm{C}$. Intraresidual (black), sequential (blue), medium- and long-range (orange) connections are highlighted to exemplify the sequential assignment. Resonance assignments for V306 to S324 (in repeat R3) could be obtained. (B) $2 \mathrm{D}\left[{ }^{13} \mathrm{C},{ }^{13} \mathrm{C}\right]$-PDSD spectrum $\left(\mathrm{t}_{\text {mix }}=500 \mathrm{~ms}\right)$ of the $\mathrm{K} 19_{\mathrm{CYLfw}}$ sample acquired on a $600 \mathrm{MHz}$ spectrometer at $11 \mathrm{kHz}$ MAS at $7{ }^{\circ} \mathrm{C}$. Noteworthy is the presence of two cysteine resonances, both in an oxidized form (as seen by the chemical shifts), although cysteine is unique in the K19 sequence (C322). Further experimental details are given in Table A1. 
Other experiments were performed as well (e.g. DREAM, see Figure 10 and Figure A4), but the maximum number of spin systems could be observed in the PDSD experiments (Figure 11). Sequential assignments were also obtained by means of NCACX and NCOCX experiments (Figure A12 and Figure A8) (62).

As expected from the previous study by Andronesi et al. (204), the measured resonances cover only a subset of the 99 aa of the entire K19 sequence. With V306 to S324 (see Table 4), in total 18 residues are assigned to the rigid K19 PHF core. These residues belong to the repeat $\mathrm{R} 3$, which corroborates the results from the INEPT-based experiments.

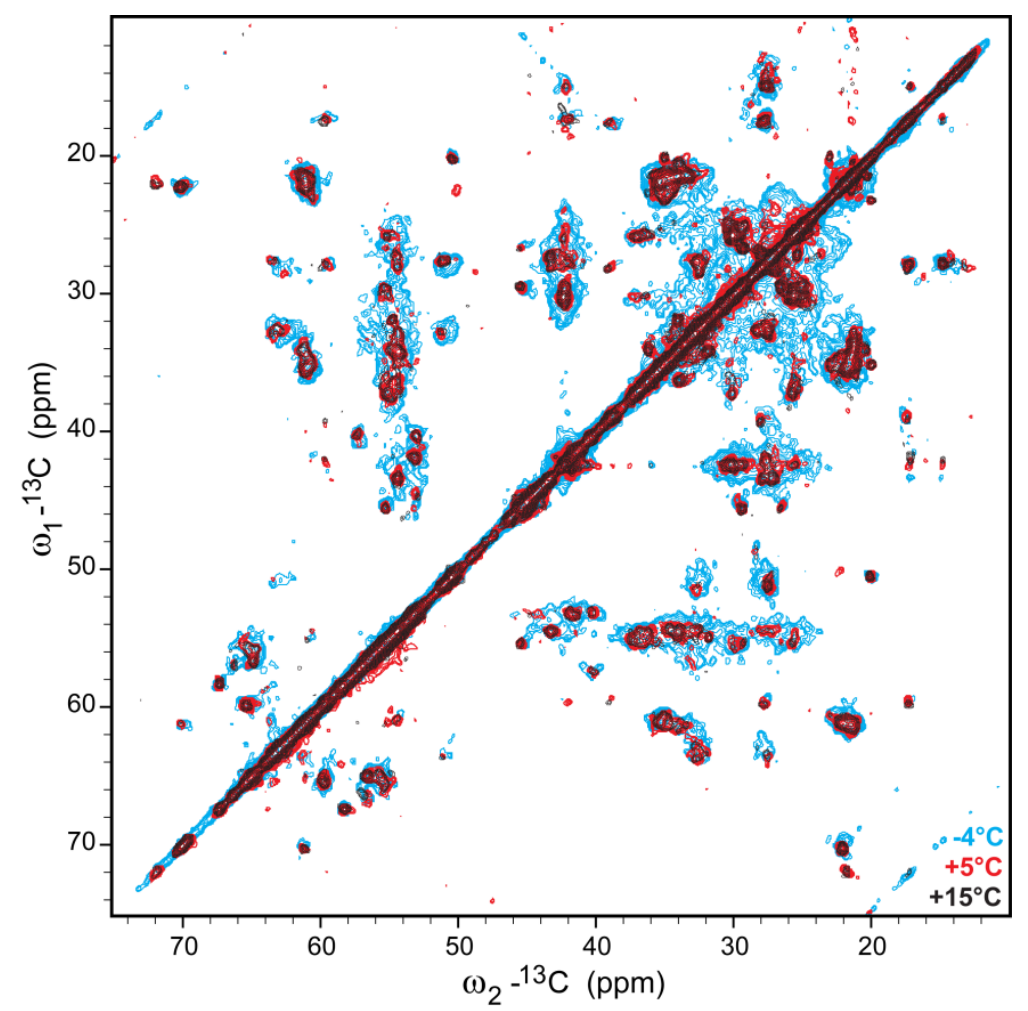

Figure 12. Variable temperature measurements. Overlay of PDSD spectra $\left(t_{\text {mix }}=20 \mathrm{~ms}\right)$ of K19CA PHF recorded on an $800 \mathrm{MHz}$ spectrometer at $11 \mathrm{kHz}$ MAS at different temperatures (blue: $-4{ }^{\circ} \mathrm{C}$; red: $+5{ }^{\circ} \mathrm{C}$; black: $+15^{\circ} \mathrm{C}$ ).

To probe the missing $\sim 80 \%$ of the K19 sequence we conducted PDSD experiments $\left(\mathrm{t}_{\text {mix }}=20 \mathrm{~ms}\right)$ at variable temperatures of $-4,5$ and $15^{\circ} \mathrm{C}$ (Figure 12). While the spectra recorded at 5 and $15{ }^{\circ} \mathrm{C}$ resemble each other in peak intensity and resolution, spectra recorded at $-4{ }^{\circ} \mathrm{C}$ exhibit significantly increased signal intensity and broader lines as well as a large number of additional peaks. 
Table 4. Chemical shift assignment for the rigid core of K19 PHF. For residues V306-S324, 94\% of all backbone and side chain ${ }^{13} \mathrm{C}$ atoms could be assigned. Chemical shifts are given in ppm.

\begin{tabular}{|c|c|c|c|c|c|c|c|c|c|c|c|}
\hline Residue & N & C & CA & CB & CG/CG1 & CG2 & CD/CD1 & CD2 & CE/CE1 & CE2 & CZ \\
\hline V306 & 124.7 & - & 60.38 & 35.17 & 24.99 & 21.25 & & & & & \\
\hline Q307 & 125.1 & 174.7 & 54.05 & 34.08 & 34.78 & & 178.9 & & & & \\
\hline I308 & 124.8 & 174.6 & 60.52 & 42.37 & 29.12 & 17.7 & 16.36 & & & & \\
\hline V309 & 128.3 & 173.0 & 61.87 & 33.81 & 21.2 & 20.1 & & & & & \\
\hline Y310 & 132.2 & 172.9 & 57.52 & 40.24 & 127.7 & & 134.5 & 133.7 & 118.8 & 118.2 & 157.3 \\
\hline K311 & 125.2 & 171.2 & 54.08 & 33.05 & 24.79 & & 30.53 & & 42.05 & & \\
\hline P312 & 134.8 & 175.5 & 63.58 & 32.85 & 27.44 & & 51.02 & & & & \\
\hline V313 & 119.4 & 174.8 & 61.42 & 34.66 & $21.35 *$ & & & & & & \\
\hline D314 & 128.2 & 174.1 & 53.07 & 41.79 & 179.5 & & & & & & \\
\hline L315 & 129.0 & 177.1 & 54.34 & 42.89 & 28.0 & & $26.91 *$ & & & & \\
\hline S316 & 119.8 & 174.1 & 59.78 & 65.37 & & & & & & & \\
\hline K317 & 116.4 & 176.2 & 55.27 & 37.09 & 25.65 & & 30.05 & & 42.36 & & \\
\hline V318 & 127.2 & 175.5 & 61.48 & 35.24 & 22.92 & 21.52 & & & & & \\
\hline T319 & 124.0 & 172.9 & 61.08 & 72.44 & & 21.4 & & & & & \\
\hline S320 & 119.6 & 173.9 & 55.5 & 65.44 & & & & & & & \\
\hline K321 & 124.4 & - & 54.1 & 34.2 & - & & - & & - & & \\
\hline C322 & 115.3 & 174.1 & 51.72 & 44.08 & & & & & & & \\
\hline G323 & 111.9 & - & 45.79 & & & & & & & & \\
\hline S324 & 114.3 & 173.3 & 56.8 & 66.63 & & & & & & \\
\hline
\end{tabular}

$\cdots$

\begin{tabular}{|c|c|c|c|c|c|c|c|c|c|c|c|}
\hline 2K321 & 123.6 & 174.7 & 55.79 & 33.9 & 25.41 & & 29.91 & & 42.3 & & \\
\hline $\mathbf{2 C 3 2 2}$ & 123.6 & 173.7 & 59.17 & 37.44 & & & & & & & \\
\hline $\mathbf{2 G 3 2 3}$ & 112.8 & - & 45.05 & & & & & & & & \\
\hline $\mathbf{2 S 3 2 4}$ & 121.3 & 173.7 & 57.88 & 67.53 & & & & & & & \\
\hline
\end{tabular}

- indicates unassigned resonances.

* indicates $\mathrm{C} \gamma 1 / \mathrm{C} \gamma 2$ or $\mathrm{C} \delta 1 / \mathrm{C} \delta 2$ resonances with identical chemical shift.

Thus, when aggregated into PHF, $\sim 80 \%$ of the K19 residues are highly dynamic and become only sufficiently rigid to be observed in dipolar-based solid-state NMR experiments when the sample is frozen.

This result is reminiscent of observations by Jaroniec and coworkers who found that signals from approximately 100 residues (i.e., $\sim 80 \%$ of all residues) of human $\operatorname{PrP}(23-$ 144) amyloid fibrils are not detected above approximately $-20{ }^{\circ} \mathrm{C}$ in dipolar-based solidstate NMR experiments (115). 


\subsection{Spectra of K19 PHF reveal two conformations for residues K321-S324}

Surprisingly, in PDSD spectra of a sample, where only cysteine, tyrosine and leucine are $\left[{ }^{13} \mathrm{C}\right.$, $\left.{ }^{15} \mathrm{~N}\right]$-labeled (K19 $\mathrm{CYLfw}$; Figure 11B), we unambiguously detected two cysteine resonances - despite the fact that only one, C322, is present in the K19 sequence (Figure 6). Both resonances (in the following: $\mathrm{C} 322$ and 2C322), exhibit chemical shifts typical for oxidized cysteines involved in DSB formation $(55,213)$.

To exclude chemical exchange (on a time scale of $\mu$ s) of the cysteine resonances, we recorded a CHHC experiment. Due to the short ${ }^{1} \mathrm{H}-{ }^{1} \mathrm{H}$ mixing time $(250 \mu \mathrm{s})$, a cross peak between the two cysteines would not be expected if the different cysteine conformations were due to chemical exchange. Indeed, a C322-2C322 signal was observed (Figure A10). Furthermore, the presence of two conformationally different cysteines in the fibril core could be confirmed by PDSD experiments on a sparsely labeled K19 ${ }_{2 \text { glyc }}$ sample (Figure 13), where we observed two sets of resonances for residues K321 to S324 (set 1: K321 to S324 shown in green and set 2: 2K321 to 2S324 shown in blue; Table 4).

Notably, not only sequential and medium-range connections within the sets (Figure 13A) were observed, but five long-range correlations between the two sets as well (C322-2K321, C322-2C322, C322-2S324, 2C322-S324, S324-2G323; Figure 13B). Furthermore, both sets are sequentially connected to the preceding residues - that are observed only once - indicating a structural difference only in the C-terminal part of the PHF core.

To unequivocally assure that the splitting of residues K321 to S324 is due to the presence of an intermolecular DSB, we mutated C322 to alanine. The NCA spectrum of K19CA PHF clearly reveals a simplified resonance pattern compared to K19 wild type (WT; Figure 14) with two interesting findings: (i) Instead of two cysteine resonances, one strong alanine signal is observed - with chemical shifts indicative of $\beta$-sheet structure. Also residues K321-S324 do not give rise to two sets of signals with equal intensity any more. 


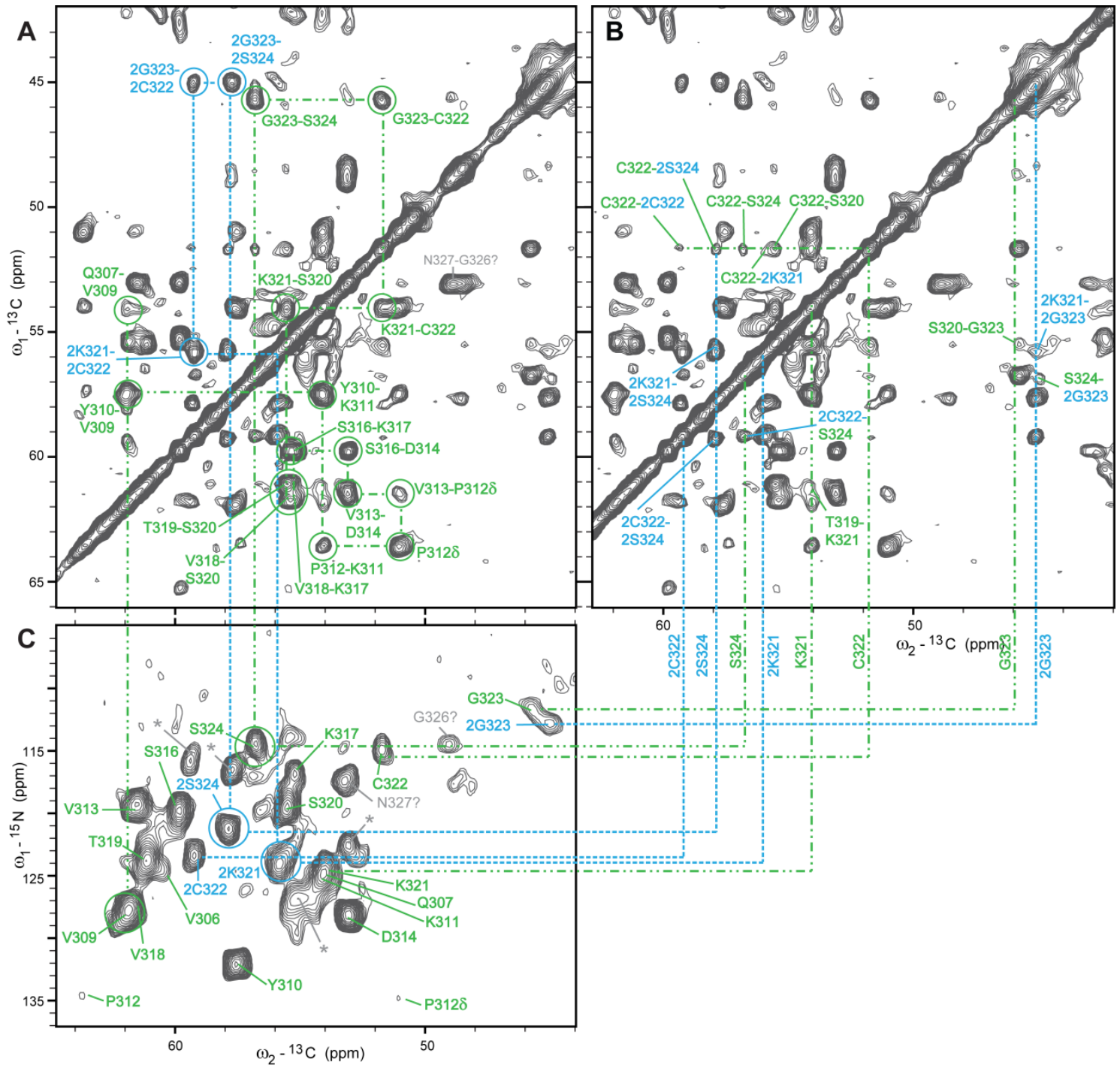

Figure 13. Sequential assignment of residues with two sets of resonances. (A, B) $2 \mathrm{D}\left[{ }^{13} \mathrm{C},{ }^{13} \mathrm{C}\right]-\mathrm{PDSD}$ spectrum of $\mathrm{K} 19_{2 \text { glyc }} \mathrm{PHF}\left(\mathrm{t}_{\text {mix }}=500 \mathrm{~ms}\right.$ ) recorded on an $850 \mathrm{MHz}$ spectrometer at $11 \mathrm{kHz}$ MAS at $11^{\circ} \mathrm{C}$. Sequential correlations of resonance sets 1 (green) and 2 (blue) (A), and medium-range as well as inter-set correlations (B) are indicated. (C) $2 \mathrm{D}\left[{ }^{15} \mathrm{~N},{ }^{13} \mathrm{C}\right]-\mathrm{NCA}$ spectrum of $\mathrm{K} 19_{2 \text { glyc }}$ acquired on an $800 \mathrm{MHz}$ spectrometer at $11 \mathrm{kHz}$ MAS and $5{ }^{\circ} \mathrm{C}$. Note, that Leu $\mathrm{C} \alpha$ is not labeled in the $\mathrm{K} 19_{\text {2glyc }}$ sample. Correlations labeled in gray could not be assigned unambiguously.

Nevertheless, peak doubling still occurs to a small extent, as seen e.g. by a second weak alanine signal (2A322 in Figure 14). (ii) In the WT spectra, some peaks appear that do not show sequential correlations and therefore could not be assigned (marked with asterisks in Figure 13C and Figure 14). These resonances may arise from additional peak doubling due to multiple conformations in the K19 WT. In contrast, they are absent or occur only weakly in spectra of K19CA PHF. Thus, further 
investigations on the K19CA mutant seem promising (see Outlook). However, in this study we focused on the WT K19 construct.

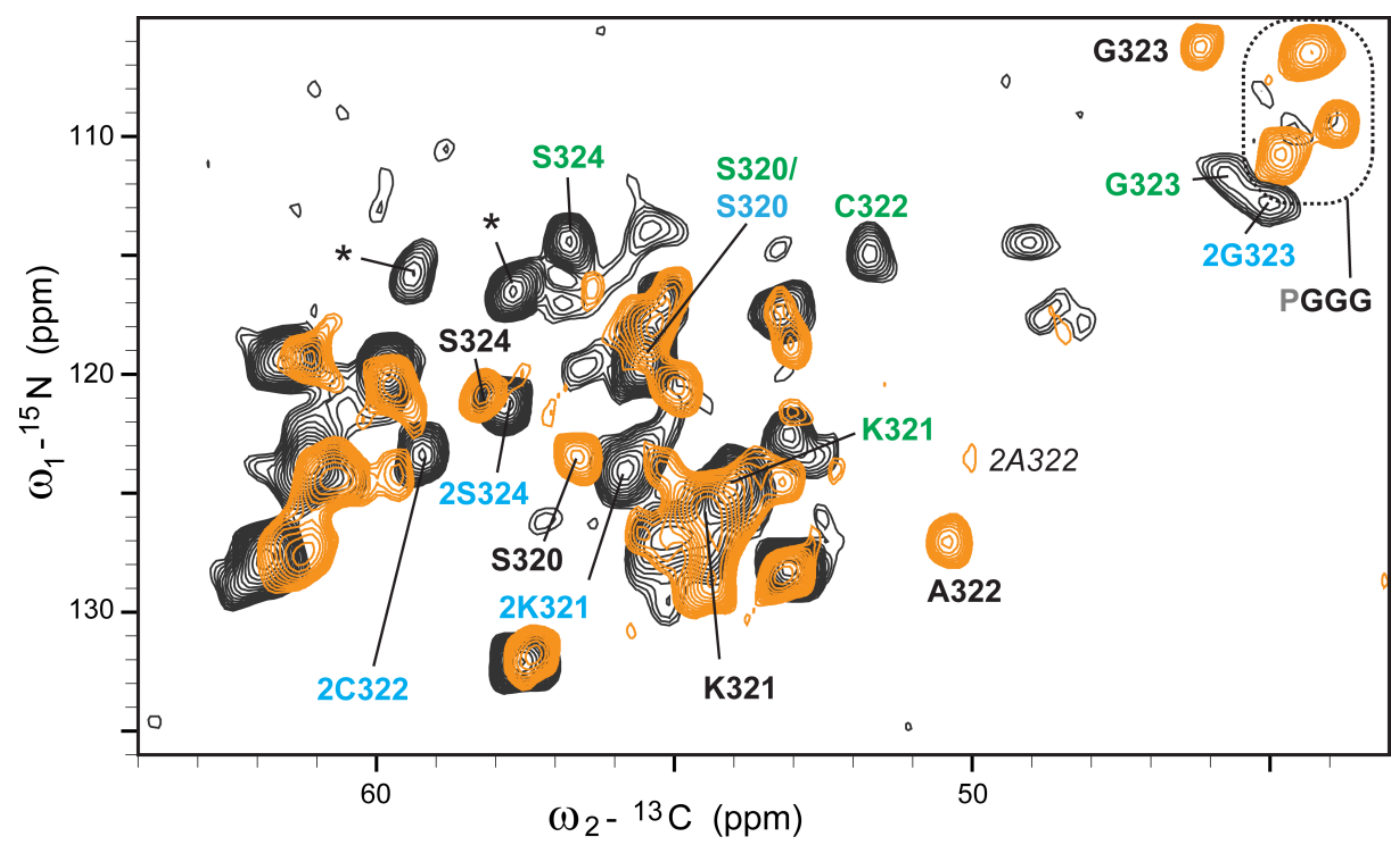

Figure 14. Effect of disulfide bond formation on solid-state NMR spectra. Comparison of $2 \mathrm{D}\left[{ }^{15} \mathrm{~N},{ }^{13} \mathrm{C}\right]-\mathrm{NCA}$

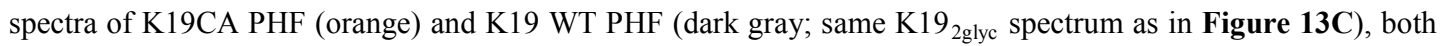
recorded on an $800 \mathrm{MHz}$ spectrometer at $11 \mathrm{kHz}$ MAS and $5{ }^{\circ} \mathrm{C}$. Resonance assignments of set 1 (green) and 2 (blue) are based on $\mathrm{K} 19_{2 \text { glyc }}$, while black assignment labels are for the mutant. For the sake of clarity, only assignments for S320 to S324 are shown. Residues in the dashed box belong to glycines of the ${ }^{332} \mathrm{PGGG}^{335}$ motif that is only visible for the K19CA PHF sample. The correlations marked with asterisks could not be assigned in K19 WT, but occur only weakly in the mutant in the noise.

\subsection{Secondary structure analysis of the K19 PHF core residues}

In Figure 15A and B, secondary chemical shifts (SCS) - indicative of the secondary structure (56) - for residues V306 to S320 (gray) as well as the two sets K321 to S324 and $2 \mathrm{~K} 321$ to $2 \mathrm{~S} 324$ are depicted. 


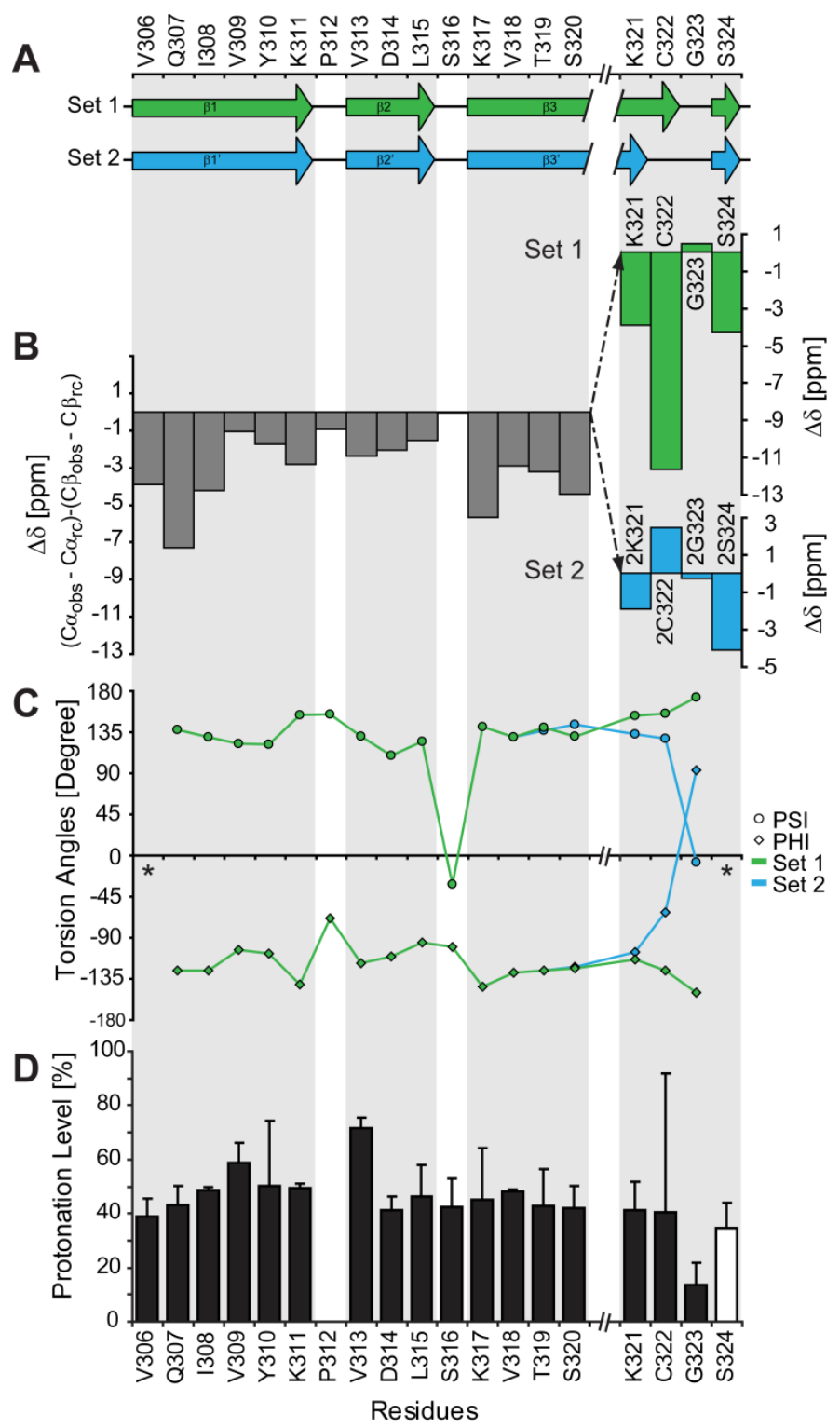

Figure 15. Analysis of secondary chemical shifts (SCS). (A) Cartoon representation of the secondary structure of the two sets (set 1: green; set 2: blue). (B) Consecutive negative values indicate a $\beta$-strand conformation, discontinuities in the negative values a kink between $\beta$-strands. The SCS reveal the presence of three $\beta$-strands interrupted by kinks at P312, a known $\beta$-strand breaker, and S316. The first $\beta$-strand is formed by the hexapeptide motif ${ }^{306}$ VQIVYK $^{311}$. From K321 to S324 the sequence is split into two sets of resonances. (C) A TALOS+ analysis, predicting Phi (rhombs) and Psi (circles) dihedral torsion angles for set 1 (green) and 2 (blue), corroborates the results from the SCS analysis. (All predictions are classified by TALOS+ as "good", except for 2G323.) (D) Protonation levels of the assigned rigid core of K19 filaments after 36 hours forward-exchange to $\mathrm{D}_{2} \mathrm{O}$ as a function of residue number. The open bar is an averaged value from overlapped residues (see also Figure 16). 
Based on our chemical shift assignment, and in line with the previous solid-state NMR study (204) the fibril core is predominantly found in $\beta$-strand conformation. This is further corroborated by backbone dihedral angle predictions obtained from the program TALOS+ (59) (Figure 15C; predictions for all residues were classified as "good", except for 2G323). A Ramachandran plot of the predictions is given in the Appendix (Figure A1).

Exceptions to $\beta$-sheet conformation occur for residues P312, S316, G323, as well as $2 \mathrm{C} 322$ and 2G323. The SCS of these residues indicate the presence of kinks that disrupt the $\beta$-strands (Figure 15) and might change the characteristic inside-outside order of side chains observed in a fully extended conformation.

Previous studies have shown that the hexapeptide ${ }^{306} \mathrm{VQIVYK}^{311}$ in R3 displays $\beta$ sheet propensity in disordered full-length tau and is furthermore able to self-assemble into fibrils by itself $(159,177,214,215)$. Consistently, SCS identify the first $\beta$-strand from V306 to K311. At P312 a kink is probably formed, because proline is a known $\beta$ strand breaker and the $\mathrm{C} \alpha$ chemical shift of P312 is larger than the random coil value, indicating a non- $\beta$-strand conformation. P312 is followed by a second, short $\beta$-strand, V313 to L315, and another kink located at residue S316. In molecules belonging to set 1 the third strand extends from K317 to C322 followed by a further kink at G323. In set 2 molecules, the third $\beta$-strand comprises only residues $\mathrm{K} 317$ to $2 \mathrm{~K} 321$, and a larger kink is formed by $2 \mathrm{C} 322$ and $2 \mathrm{G} 323$.

Bibow et al. have recently shown that a spin label attached to C322 in tau PHF can be quenched by the reducing agent DTT, indicating that the side chain of Cys 322 is not fully buried in the fibril core (198) - in line with formation of a kink at C322.

Downstream of this kink, S324 as well as 2S324 chemical shifts indicate $\beta$-strand structure. However, as there is no unambiguous assignment for the consecutive residues, it is not clear whether a fourth $\beta$-strand follows.

While deletion of the C-terminus of full-length tau tends to enhance fibril formation, the deletion of residues D314 to S320 abrogates fibrillation (216), probably as it eliminates strands $\beta 2$ and $\beta 3$. Interestingly, ${ }^{314} \operatorname{DLSK}^{317}$ shows conformational propensity for a turn in natively unfolded tau in solution as well as in chemical denaturant, as observed by secondary chemical shift and residual dipolar coupling 
analysis $(177,217)$. This indicates that the turn conformation might be a precursor to fibril conformation similar to the hexapeptide motif.

\subsection{H/D exchange experiments}

To probe the accessibility of the residues forming the core of PHF, we conducted H/D exchange experiments, a technique to identify solvent-protected backbone amide protons, using solution NMR (210).

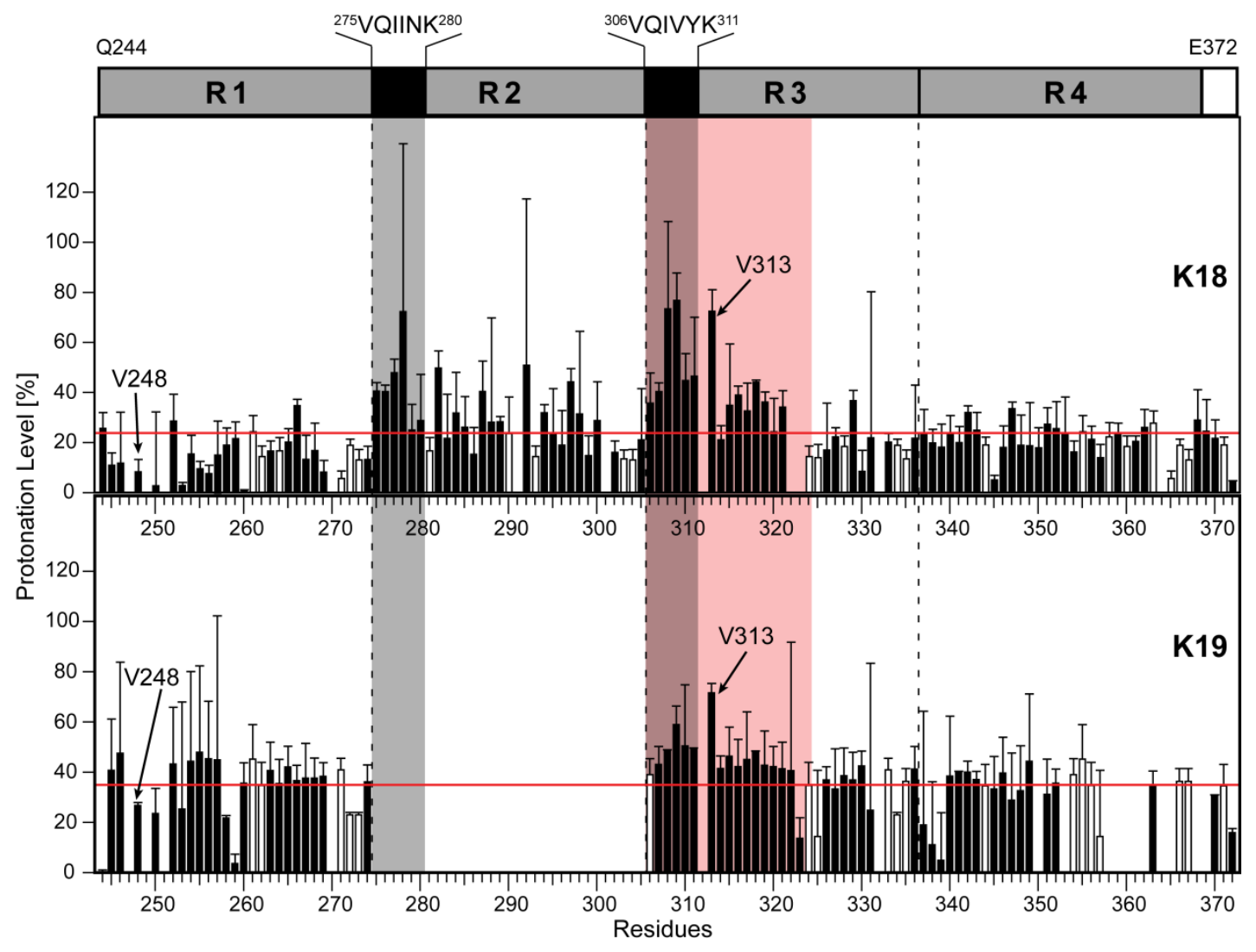

Figure 16. Protonation levels of K18 and K19 filaments after 36 hours forward-exchange to $D_{2} O$ as a function of residue number. Horizontal red lines indicate the average protonation of all residues. Gaps arise from either proline residues or residues that could not be detected. Open bars are averaged values from overlapped residues. On top, the domain orientation of K18 is shown, with the vertical gray bars highlighting the two hexapeptide motifs and the red bar marking the rigid core of K19 PHF. Interestingly, residues identified by the solid-state NMR study to be within the core region of K19 show the strongest protonation levels in K18 as well, indicating that this region is of central importance also to K18 PHF. 

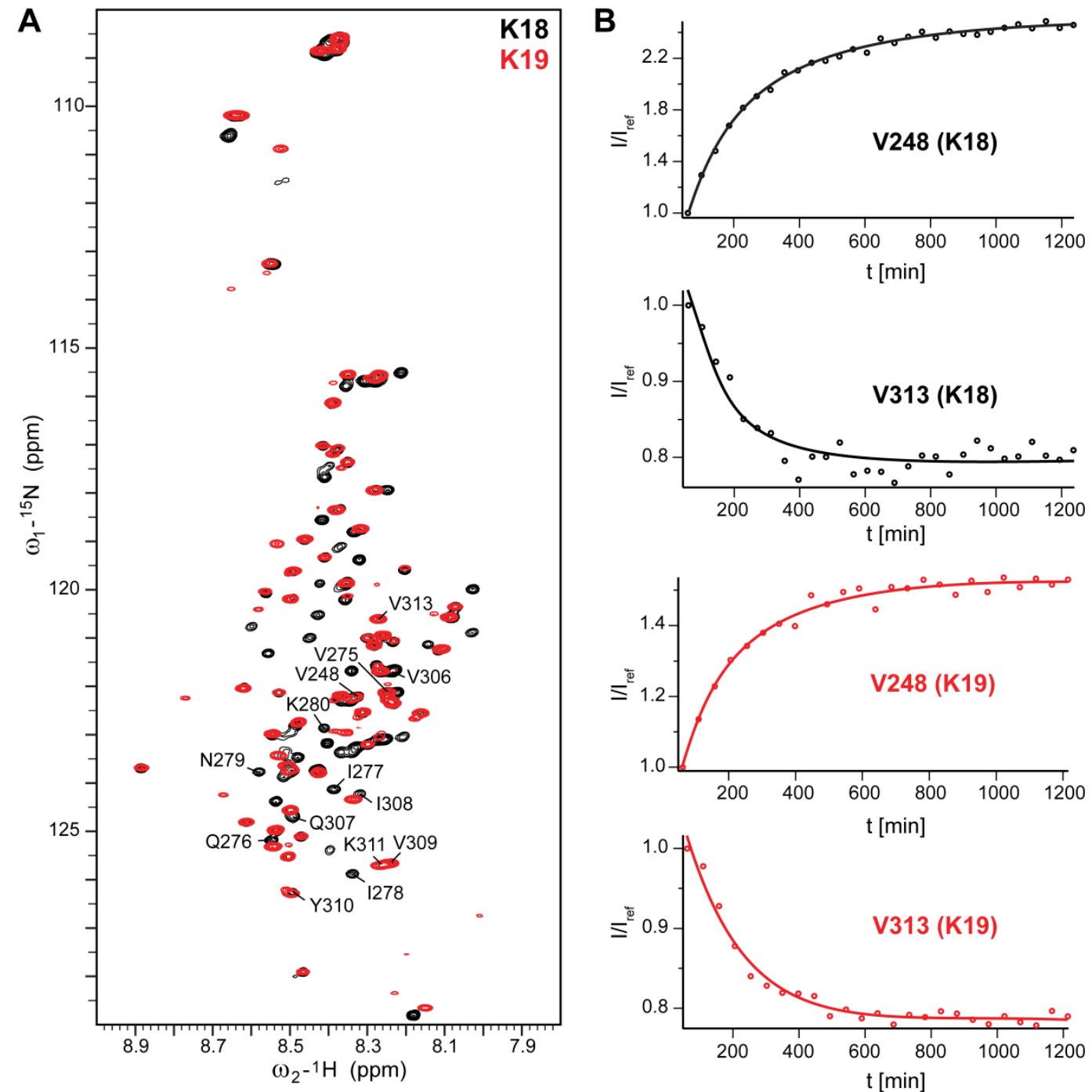

Figure 17. H/D exchange data of K19 and K18. (A) Superposition of $\left[{ }^{1} \mathrm{H},{ }^{15} \mathrm{~N}\right]-\mathrm{HSQC}$ spectra of K18 (black; acquired on a $700 \mathrm{MHz}$ spectrometer at $5^{\circ} \mathrm{C}$ ) and $\mathrm{K} 19$ (red, acquired on a $600 \mathrm{MHz}$ spectrometer at $5^{\circ} \mathrm{C}$ ) monomers in $2 \mathrm{M} \mathrm{GuSCN}, 0.04 \%$ formic acid, $\mathrm{pH} 2.34$ and $50 \% \mathrm{H}_{2} \mathrm{O} / 50 \% \mathrm{D}_{2} \mathrm{O}$ showing that resonances overlay well. Selected residues, in particular of the two hexapeptide motifs ${ }^{275}{ }^{V Q I I N K}{ }^{280}$ (K18) and ${ }^{306}$ VQIVYK $^{311}$ (K18 and K19), are marked. Note, that V306 in K19 and V275 in K18 are surrounded by a similar chemical environment due to the same sequence motif (GKVQI). For this reason, V306 in K19 is shifted with respect to V306 in K18, but overlays well with V275, which itself is not present in K19. (B) Time dependence of the HSQC cross-peak intensities of two selected residues, V248 (outside the core region) and V313 (within the core region) of K18 (black) and K19 (red) during backward-exchange are depicted. Intensities are normalized to the intensity of the first spectrum. In both constructs V313 in PHF is protected while V248 is not.

In these experiments, residues that are protected from solvent exhibit high protonation levels, while solvent-exposed residues do not. 
Although the H/D data for K19 PHF do not exhibit a large variation due to a fast exchange rate, a trend can be found in the protonation levels that are in agreement with the solid-state NMR results (Figure 15D): The most protected region in K19 PHF belongs to residues I308 to V313, with a certain degree of protection visible for residues D314 to K321 as well. In contrast, residues of R1 and R4 are solvent-exposed to a higher extent (Figure 16).

Furthermore, we probed how repeat R2 contributes to the fibril core using PHF that were formed by K18 monomers. Since the exchange rate of K18 was much slower compared to K19 PHF, the protonation levels are more variable than for K19 (Figure 16). The H/D exchange behavior is similar for K19 and K18 (Figure 17) and the most protected region in both constructs is repeat R3 (Figure 16). The protective environment provided by the fibril core in R3 might explain why residue Y310 is the only tyrosine in tau that is nearly resistant to chemical modification by site-specific nitration (218) and that gives the most extensive shift changes in fluorescence spectra even in full-length tau during PHF aggregation (199). K18 residues of repeat R2 are also protected from exchange with solvent (Figure 16). In particular, the hexapeptide ${ }^{275} \mathrm{VQIINK}^{280}$ at the N-terminus of R2 is highly protected, indicating its involvement in the rigid fibril core of $\mathrm{K} 18 \mathrm{PHF}$.

\subsection{Aggregation behavior of K19 single mutants}

The $\beta$-strand $\beta 1$ of the PHF core corresponds to the hexapeptide ${ }^{306}$ VQIVYK $^{311}$ that has been studied extensively $(159,202,214,219,220)$.

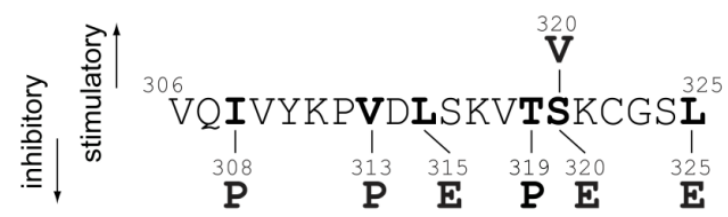

Figure 18. Overview of the K19 single point mutations within the assigned PHF core region. $\beta$-strand breaking proline mutants: I308P, V313P, and T319P. K19 inhibitory mutants: L315E, S320E, and L325E. K19 stimulatory mutant: S320V. 
It was shown that $\beta$-strand breaking proline point mutations within this motif, e.g. I308P, abrogate PHF formation (202). On the other hand, the influence of strands $\beta 2$ and $\beta 3$ (corresponding to V313 to $\mathrm{C} 322 / \mathrm{V} 313$ to $2 \mathrm{~K} 321$ ) on fibril formation and stability is largely unknown. Hence, in the current study we introduced single point mutations in this part of the K19 core (Figure 18) and followed the aggregation behavior of the mutant proteins. Kinetics of aggregation was monitored fluorimetrically using the ThS assay (Figure 19). The presence and morphology of PHF were monitored by electron microscopy (Figure 20).

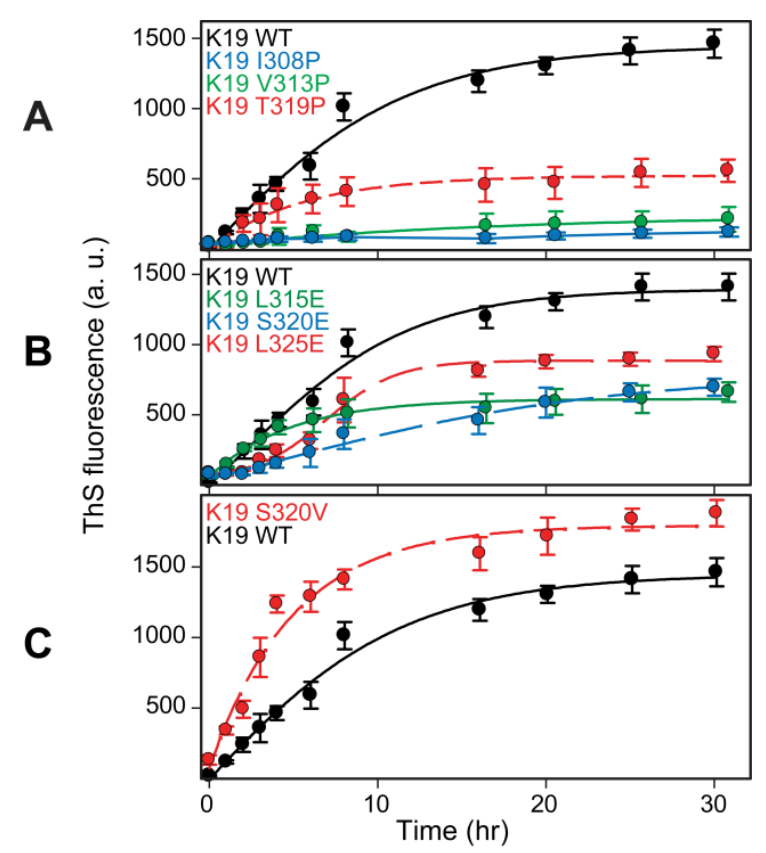

Figure 19. PHF assembly of different K19 single mutants monitored by ThS fluorescence. (A) K19 WT and $\beta$ strand breaking proline mutants I308P, V313P, and T319P. (B) K19 inhibitory mutants L315E, S320E, and L325E, and (C) K19 stimulatory mutant S320V.

First, K19 proline mutants were designed, which were expected to be inhibitory for aggregation by disrupting the $\beta$-strands $\beta 1, \beta 2$, and $\beta 3$, respectively (Figure 19A and Figure 20). As expected, the mutations V313P and T319P disrupt the $\beta$-strands and prevent fibril formation. The most pronounced inhibition was observed for V313P, which leads to nearly complete abrogation of aggregation, comparable to the previously described I308P mutation. 
Furthermore, we generated the mutations L315E within $\beta 2$ and S320E as part of $\beta 3$, but also L325E, which is just outside of the assigned region (Figure 19B). These mutations disrupt PHF formation to different degrees. The furthest C-terminal mutation, L325E, shows the least drastic effect.

With S320V, a hydrophilic serine is replaced by a hydrophobic valine. Figure 19C illustrates the aggregation kinetics of S320V, which is even faster than of the WT.

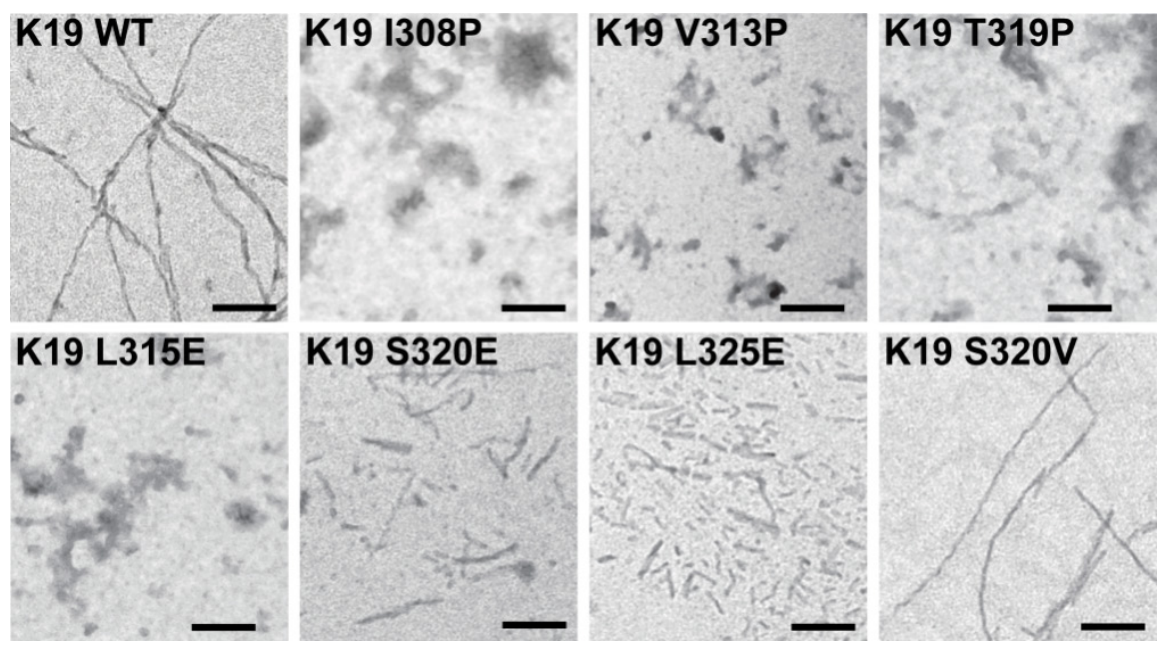

Figure 20. Electron micrographs of the different K19 mutants. In the presence of heparin (scale bars $=200 \mathrm{~nm})$.

Figure 20 summarizes the fibril structures of WT and mutants observed by negative stain EM. The control sample of K19 WT PHF shows abundant long filaments, predominantly with twisted substructure. The morphology of K19 S320V fibrils is indistinguishable from PHF of K19 WT. In the remaining micrographs we can distinguish between two different morphologies: (i) fragmented short filaments formed by the mutants S320E, and L325E and (ii) amorphous deposits without filaments for the mutants I308P, V313P, L315E, and T319P.

In summary, the aggregation behavior of the proline mutants provides evidence that the $\beta$-structure is highly important for fibril formation in the overall region of residues 306 to 325 .

A hydrophobic influence on the stability of the PHF core was probed by mutating hydrophobic to charged residues. These mutations abrogate WT-like fibril formation. In contrast, replacing S320 by a more hydrophobic valine (S320V) actually leads to an 
enhancement of fibrillation, indicating hydrophobic interactions to be a substantial stabilizing factor for K19 PHF. 


\subsection{Supramolecular arrangement of K19 molecules within the fibril core}

\subsubsection{Intermolecular stacking}

To elucidate the intermolecular arrangement of tau K19 molecules in the cross- $\beta$ structure, a two-dimensional $\left[{ }^{15} \mathrm{~N}-{ }^{13} \mathrm{C}\right]-\mathrm{PAIN}-\mathrm{CP}(88)$ spectrum of the K19 $1: 1$ sample was measured.

A
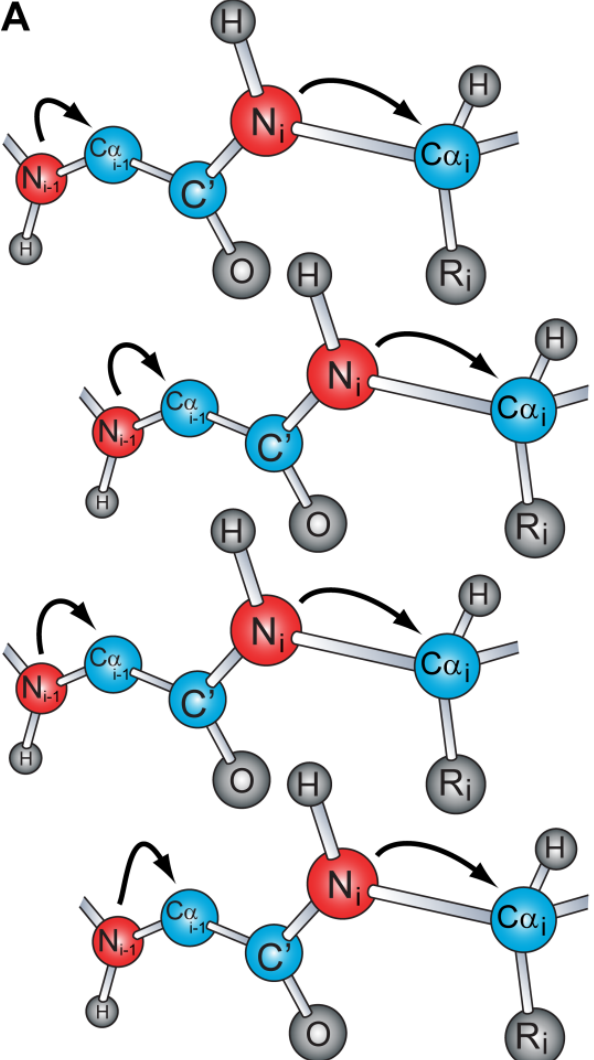

B

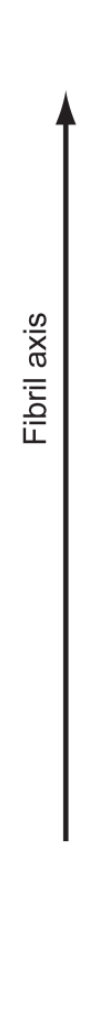

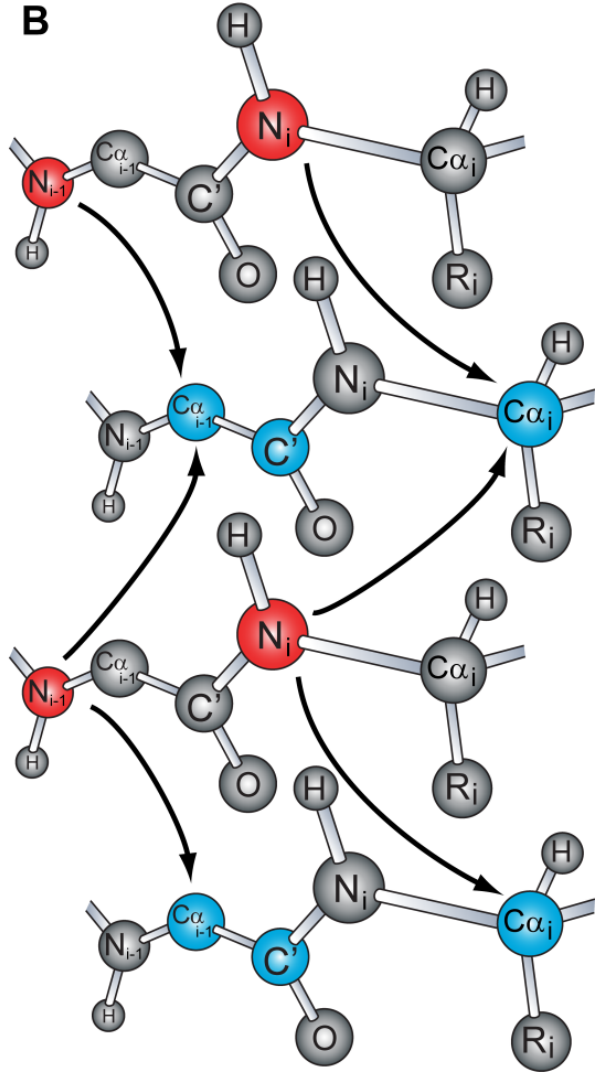

Figure 21. Comparison of magnetization transfers in NCA and PAIN-CP experiments. (A, B) Indicated is a protofilament with an in-register and parallel stacking of four molecules along the fibril axis. $\left[{ }^{15} \mathrm{~N}\right]$-labeled and $\left[{ }^{13} \mathrm{C}\right]$-labeled nuclei are shown in red and blue, respectively. Unlabeled nuclei are depicted in gray. While the ${ }^{15} \mathrm{~N}(\mathrm{i}){ }^{13} \mathrm{C} \alpha(\mathrm{i})$ polarization transfer is mainly intramolecular in $\mathrm{NCA}$ experiments (A), only intermolecular magnetization transfer is responsible for the correlations seen in PAIN-CP spectra (B).

These PHF were aggregated from an equimolar mixture of $\left[{ }^{15} \mathrm{~N}\right]$-labeled and $\left[{ }^{13} \mathrm{C}\right]-$ labeled K19 protein. Since no ${ }^{15} \mathrm{~N}-{ }^{13} \mathrm{C}$-spin pairs are present within one K19 molecule of such mixed-labeled fibrils, ${ }^{15} \mathrm{~N}(\mathrm{i})-{ }^{13} \mathrm{C} \alpha(\mathrm{i})$ correlations obtained in a PAIN-CP 
spectrum must be intermolecular (206) (Figure 21). The spectrum overlays well with an NCA spectrum of the uK19 sample (Figure 22) revealing a parallel, in-register arrangement of the $\beta$-strands along the fibril axis, in line with previous EPR studies $(151,152)$.

Notably, no intermolecular ${ }^{15} \mathrm{~N}(\mathrm{i})-{ }^{13} \mathrm{C} \alpha(\mathrm{i})$ correlations are detected for residues within each of the two sets (K321 to S324/ 2K321 to 2S324; orange circles in Figure 22), indicating that this part is either not stacked parallel, in-register or that set 1 and set 2 molecules are stacked in an alternating arrangement, which would result in a different resonance pattern (see discussion in the next Chapter).

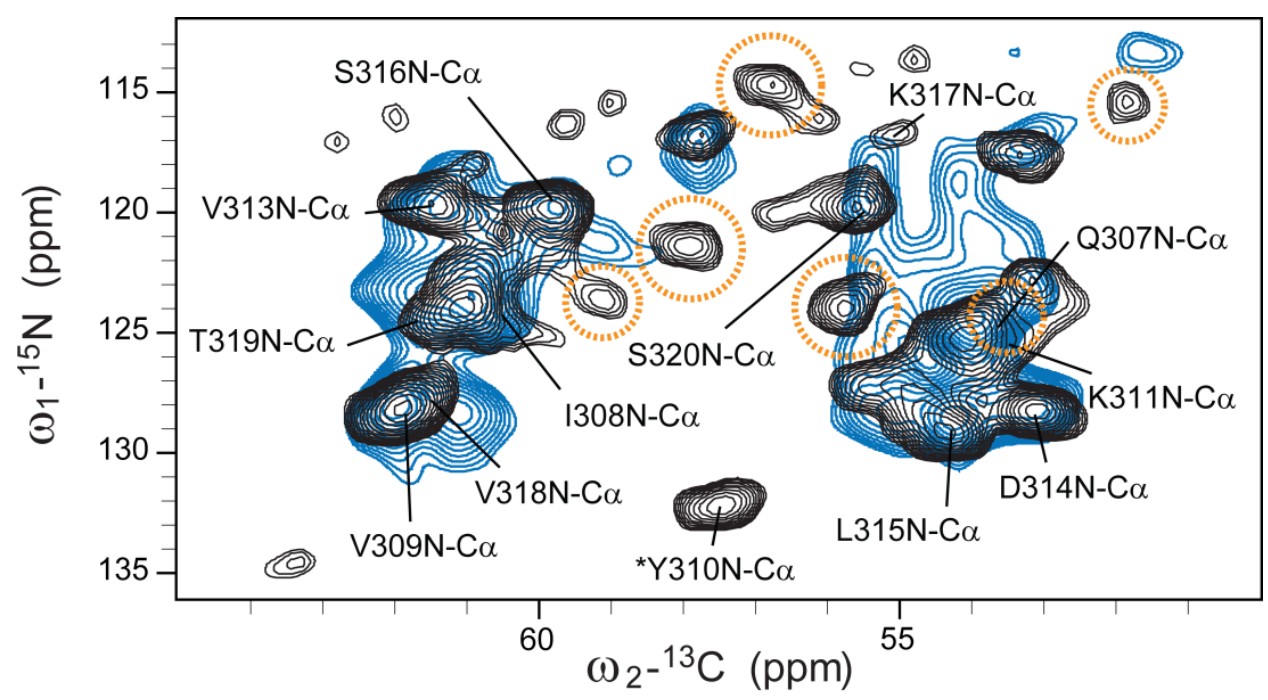

Figure 22. Intermolecular stacking of tau K19 PHF. Overlay of a $2 \mathrm{D}\left[{ }^{15} \mathrm{~N},{ }^{13} \mathrm{C}\right]-\mathrm{PAIN}-\mathrm{CP}$ correlation spectrum (blue; $\mathrm{t}_{\mathrm{mix}}=5 \mathrm{~ms}$ ) of PHF containing a 1:1 mixture of $\mathrm{u}-\left[{ }^{13} \mathrm{C}\right]-$ and $\mathrm{u}-\left[{ }^{15} \mathrm{~N}\right]$-labeled $\mathrm{K} 19$ molecules $\left(\mathrm{K} 19_{1: 1}\right)$ acquired on an $850 \mathrm{MHz}$ spectrometer at $18 \mathrm{kHz}$ MAS at $5{ }^{\circ} \mathrm{C}$ with a $2 \mathrm{D}\left[{ }^{15} \mathrm{~N},{ }^{13} \mathrm{C}\right]-\mathrm{NCA}$ spectrum (black) of uK19 recorded on an $850 \mathrm{MHz}$ spectrometer at $11 \mathrm{kHz}$ MAS at $7^{\circ} \mathrm{C}$. The labeled resonances indicate that the $\beta$ strands are arranged in-register and parallel. Note, that all resonances in the NCA spectrum belonging to the doubled region (K321-S324 / 2K321-2S324) do not appear in the PAIN-CP spectrum (orange circles). * The $\mathrm{Y} 310 \mathrm{~N}-\mathrm{C} \alpha$ correlation appears in the noise of the PAIN-CP spectrum.

\subsubsection{Intermolecular disulfide bonds}

All investigated samples were prepared under oxidizing conditions in which DSB formation can occur. The chemical shifts of the two assigned cysteines (C322 and $2 \mathrm{C} 322$ ) show that this happens indeed. Importantly, five long-range restraints 
correlating the two sets were detected in the PDSD $500 \mathrm{~ms}$ spectrum of the K19 ${ }_{2 \mathrm{glyc}}$ sample (Figure 13).

Because cysteine is a unique amino acid within the K19 sequence (Figure 6), the DSB must be formed intermolecular (Figure 23). In principle, two possibilities are conceivable: (i) an intermolecular DSB within one protofilament along the fibril axis (Figure 23A), which is possible because of the parallel, in-register arrangement (221, 222), and (ii) an inter-protofilament DSB or rather a DSB formed by symmetrically non-equivalent (as indicated by the different chemical shifts) monomers in a lateral dimer within one protofilament (Figure 23B) $(223,224)$.

The possible arrangements can be expected to show characteristic ${ }^{15} \mathrm{~N}(\mathrm{i})-{ }^{13} \mathrm{C} \alpha(\mathrm{i})$ correlations. For an intra-filamentous DSB, only correlations between the two sets are possible ("inter-set", Figure 23A), whereas for a laterally formed DSB, the spectrum should be dominated by correlations within the two different sets ("intra-set"; Figure 23B). Nevertheless, cross peaks predicted from the assignment are absent for both intraand inter-set correlations (Figure A2). Thus, for the moment we can neither exclude nor favor a model, due to missing unambiguous spectral data.

A

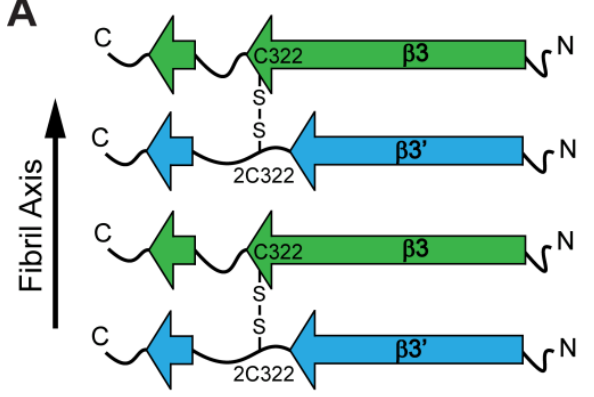

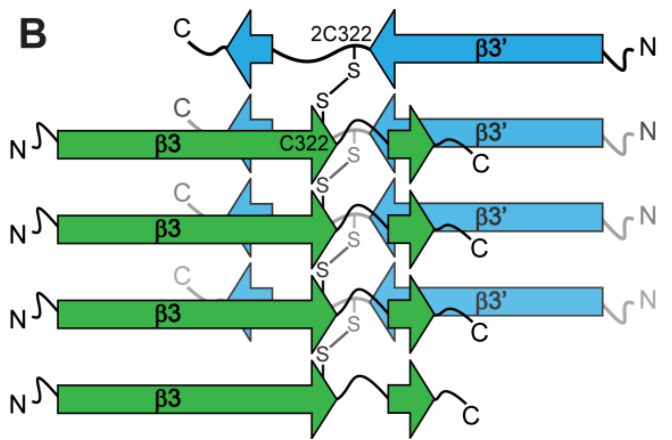

Figure 23. Models for cysteine disulfide bond (DSB) formation within K19 PHF. The molecules shown in green and blue relate to the two observed resonance sets for the residues close to C322. (A) DSB formation along the fibril axis within one protofilament. (B) Laterally formed DSB.

Nevertheless, intermolecular DSB must be an important factor for fast and stable aggregation of K19 PHF, not least because DSB-linked tau dimers are known to successfully seed PHF aggregation (225). Moreover, aggregation assays on K19 molecules under reducing conditions using DTT investigated by ThS and EM reveal that K19 is still able to form PHF, but at a much slower rate (226). 


\section{K19CA - an Outlook}

\subsection{Partial Assignment of the K19CA PHF core}

As observed from the NCA spectrum in Figure 14, a spectral simplification by using K19CA instead of WT PHF is a promising approach for solid-state NMR studies that aim for structure determination of the K19 PHF fibril core. Therefore, we recently performed further experiments necessary for the assignment process. Here, we present and discuss preliminary results.

Again, ${ }^{13} \mathrm{C}-{ }^{13} \mathrm{C}$ correlations for residues of the rigid fibril core of the $\mathrm{C} 322 \mathrm{~A}$ mutant were obtained using PDSD experiments (Figure A17), while sequential ${ }^{15} \mathrm{~N}-{ }^{13} \mathrm{C}$ correlations were gained from NCC spectra (Figure A18).

As already described in Chapter 3.4, one strong alanine signal is observed instead of two cysteine resonances. Furthermore, the strong splitting of residues K321 to S324 converted to a small extent into peak doubling for a variety of residues as indicated e.g. for the second alanine (2A322) that shows $\beta$-strand propensity. Due to a less polymorphic nature than K19 PHF, in the K19CA PHF spectra the observed resonances are extended C-terminally. Partial resonance assignment from Q307 to E338 was obtained so far (Table 5).

Table 5. Partial chemical shift assignment for the rigid core of K19CA PHF. For most residues of Q307 to E338, a preliminary assignment was obtained that needs to be refined and confirmed. Chemical shifts are given in ppm.

\begin{tabular}{|c|c|c|c|c|c|c|c|c|c|c|}
\hline Residue & N & C & CA & CB & CG/CG1 & CG2 & CD/CD1 & CD2 & CE/CE1 & CZ \\
\hline Q307 & - & 173.8 & 54,36 & 32.76 & 34.66 & & 179.4 & & & \\
\hline I308 & - & 174.2 & 59,70 & 42.34 & 27.62 & 17.06 & 14.77 & & & \\
\hline V309 & 128.7 & 173.2 & 61.45 & 34.15 & - & - & & & & \\
\hline Y310 & 132.1 & - & 57.54 & 40.22 & 128.0 & & - & - & - & 157.4 \\
\hline K311 & 125.7 & - & 54.28 & 35.31 & - & & - & & - & \\
\hline P312 & - & - & 63.82 & 32.63 & 27.46 & & 51.32 & & & \\
\hline
\end{tabular}




\begin{tabular}{|c|c|c|c|c|c|c|c|c|c|c|}
\hline Residue & $\mathbf{N}$ & C & $\mathbf{C A}$ & CB & CG/CG1 & CG2 & CD/CD1 & CD2 & CE/CE1 & $\mathrm{CZ}$ \\
\hline V313 & 119.6 & - & 61.12 & 35.35 & 21.34 & 21.84 & & & & \\
\hline D314 & 128.7 & 174,1 & 53.27 & 41.70 & 180.6 & & & & & \\
\hline L315 & 129.1 & 177.2 & 54.49 & 43.28 & 27.86 & & - & - & & \\
\hline S316 & 120.5 & 174,23 & 59.80 & 65.34 & & & & & & \\
\hline K317 & 116.7 & - & 55.30 & 36.90 & 25.67 & & 30.06 & & 42.44 & \\
\hline V318 & - & - & - & - & - & - & & & & \\
\hline T319 & 127.3 & 174.1 & 61.27 & 70.26 & & 21.96 & & & & \\
\hline S320 & 123.4 & 172.8 & 56.74 & 64.93 & & & & & & \\
\hline K321 & - & - & 54.61 & 36.23 & - & & - & & - & \\
\hline A322 & 127.2 & 175.8 & 50.62 & 19.96 & & & & & & \\
\hline G323 & 106.2 & 173.9 & 46.20 & & & & & & & \\
\hline S324 & 121.0 & 171.7 & 58.39 & 67.39 & & & & & & \\
\hline L325 & 118.0 & 175.9 & 55.44 & 45.45 & 29.44 & & - & 26.55 & & \\
\hline G326 & 106.6 & 173.7 & 44.25 & & & & & & & \\
\hline N327 & 118.6 & 174.1 & 53.21 & 40.22 & 177.0 & & & & & \\
\hline I328 & - & - & 59.55 & 39.00 & 27.91 & 17.35 & - & & & \\
\hline H329 & - & - & - & - & - & & & - & - & \\
\hline H330 & - & - & 55.50 & - & - & & & - & 137.1 & \\
\hline K331 & - & - & - & - & - & & - & & - & \\
\hline P332 & - & 177.3 & 62.83 & - & 28.33 & & - & & & \\
\hline G333 & 110.6 & 174.6 & 45.08 & & & & & & & \\
\hline G334 & 109.5 & 174.2 & 43.90 & & & & & & & \\
\hline G335 & 106.6 & 172.8 & 44.65 & & & & & & & \\
\hline Q336 & - & - & 54.87 & 31.82 & 34.10 & & 180.1 & & & \\
\hline V337 & 124.5 & 174.3 & 60.59 & 34.98 & 19.95 & 22.98 & & & & \\
\hline E338 & 127.3 & - & 54.55 & 33.94 & 36.21 & & 182.0 & & & \\
\hline $2 A 322$ & 123.3 & & 50.25 & 22.19 & & & & & & \\
\hline
\end{tabular}

- indicates unassigned resonances.

Residues V306, V318, H329, and K331 as well as most side chain assignments are omitted due to spectral overlap and limited time for a complete analysis of all recorded spectra. In contrast to K19 WT, the assigned residues belong to almost the whole repeat R3 and the very beginning of R4.

As in K19 WT fibrils (Figure 15), SCS analysis of the partially assigned K19CA resonances (Figure 24) reveal the presence of the first three $\beta$-strands ( $\beta 1-3)$ interrupted by kinks at P312 and S316. No splitting such as in the K19 WT occurs; rather $\beta 3$ is 
formed by K317 to A322, followed by a kink formed at G323. A fourth $\beta$-strand that was assumed in K19 WT PHF is in agreement with the K19CA SCS (S324 to I328). The consecutive three residues (H329 to K331) are not or only partially assigned. Because of the aa sequence, the formation of a turn of residues P332 to G335 is likely and in agreement with the SCS (177). Residues Q336 to E338 show a clear $\beta$-strand propensity.

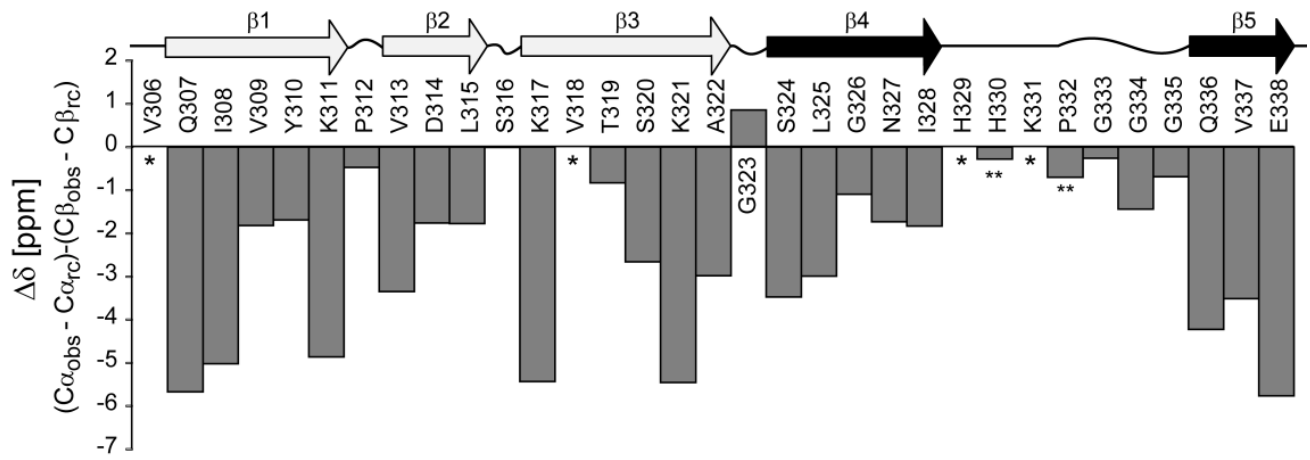

Figure 24. Analysis of preliminary SCS of core residues in K19CA PHF. Consecutive negative values indicate a $\beta$-strand conformation, discontinuities in the negative values a kink between $\beta$-strands. SCS suggest the presence of the three $\beta$-strands ( $\beta 1-3$, white arrows) interrupted by kinks at P312, a known $\beta$-strand breaker, and S316. Strand $\beta 3$ is formed by K317 to A322, followed by a kink at G323 and a fourth $\beta$-strand ( $\beta 4$, black arrow). Likely, the ${ }^{332} \mathrm{PGGG}^{335}$ motif forms a turn, while residues Q336 to E338 show a clear $\beta$-strand propensity ( $\beta 5$, black arrow). On top of the diagram a cartoon representation of the secondary structure elements is shown. * Not assigned so far. ** Missing $\mathrm{C} \beta$ assignment.

Next to completing the assignments of the rigid core of K19CA fibrils, it will be reasonable to perform temperature-dependent as well as INEPT-CC-TOBSY measurements to probe the missing $\sim 67 \%$ residues of the K19 sequence - as has been done for K19 WT (Figure 9 and Figure 12).

\subsection{Possible arrangements of $\beta$-strands $\beta 1$ to $\beta 3$ in the K19 PHF core}

Although assignments for V306 and V318 are missing, SCS analysis of the partially assigned K19CA resonances suggests a secondary structure in the region of Q307 to A322 that is conserved in WT and mutant K19 PHF (white arrows in Figure 24). Due 
to the missing DSB formation, the core of the mutant PHF is less polymorphic, resulting in only one major set of resonances, which especially influences $\beta$-strand three (K317 to A322).

A

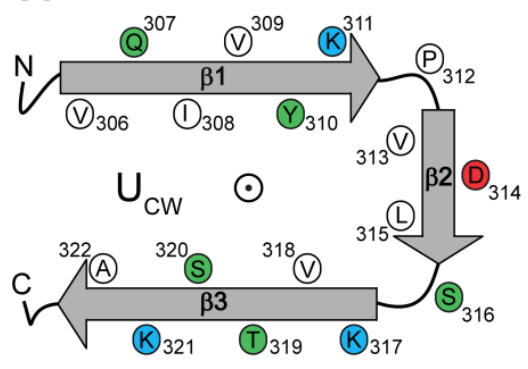

B

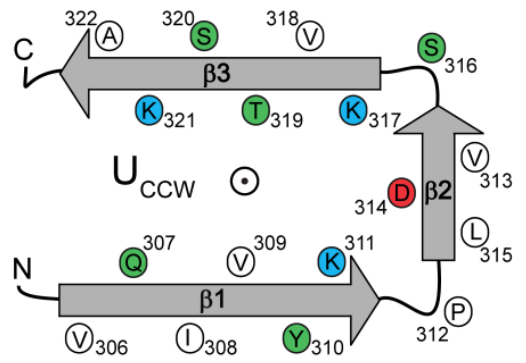

C

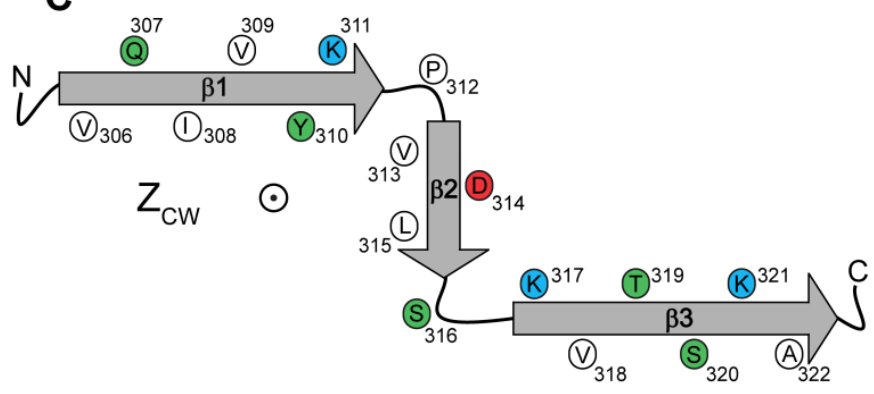

D

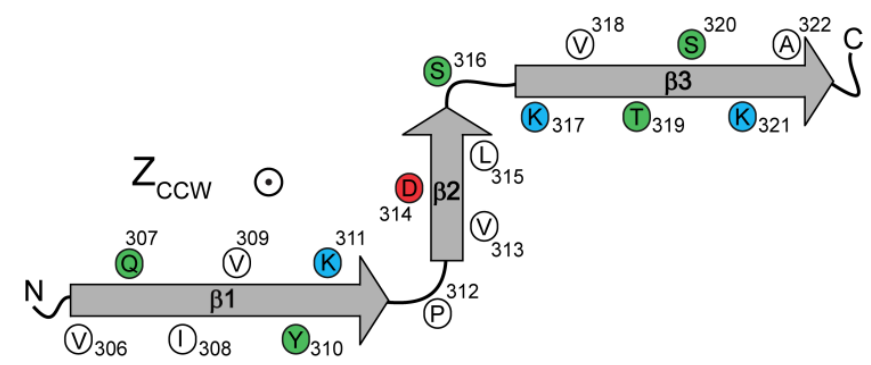

Figure 25. Different schematic models for the orientation of the three $\beta$-strands within the core of K19 PHF (using the K19CA aa sequence) based on the SCS analysis. (A-D) Positively charged residues are colored in blue, negatively charged ones in red, hydrophilic ones in green and hydrophobic ones in white. (A) Clockwise Ushape arrangement of the three $\beta$-strands leads to the formation of a hydrophobic core $\left(\mathrm{U}_{\mathrm{CW}}\right)$. (B) Counterclockwise U-shape arrangement with charged and hydrophilic residues inside the core $\left(\mathrm{U}_{\mathrm{CCW}}\right)$. (C, D) Z-shape arrangements with the first kink turning either clockwise $\left(\mathbf{C} ; \mathrm{Z}_{\mathrm{CW}}\right)$ or counter-clockwise $\left(\mathbf{D} ; \mathrm{Z}_{\mathrm{CCW}}\right)$.

Based on the analysis of K19 WT, consistent with the K19CA data, we have generated different models for the orientation of the conserved three $\beta$-strands of one K19 molecule within the rigid core of PHF. As there are two one-residue-kinks between the three $\beta$-strands, four general models are conceivable (Figure 25; For the sake of clarity regarding $\beta 3$ we used the aa sequence of the K19CA mutant), all characterized by a typical inside-outside arrangement of the side chains within each $\beta$-strand: (i) A clockwise U-shape arrangement of the $\beta$-strands $\left(\mathrm{U}_{\mathrm{CW}}\right)$, (ii) a counter-clockwise Ushape arrangement $\left(\mathrm{U}_{\mathrm{CCW}}\right)$, (iii) a Z-shape arrangement with the first kink turning clockwise $\left(Z_{C W}\right)$, and (iv) a Z-shape arrangement with the first kink turning counterclockwise $\left(\mathrm{Z}_{\mathrm{CCW}}\right)$. 
The $\mathrm{U}_{\mathrm{CW}}$ model features two consecutive side chains pointing outward at the kinks (K311/ P312 and S316/ K317, respectively). The side chains of all charged and most hydrophilic residues point outward, while most hydrophobic residues point to the inside of the U-shape resulting in a hydrophobic core made up of side chains from residues V306, I308, Y310, V313, L315, V318, S320, and A322. The proposed $\mathrm{U}_{\mathrm{CW}}$ model of K19 PHF is reminiscent of the Amyloid $\beta_{1-40}$ model put forward by Tycko and coworkers (28). This model consists of two extended $\beta$-strands connected by a turn, which results in the formation of a hydrophobic cluster of side chains.

In contrast, the $\mathrm{U}_{\mathrm{CCW}}$ model buries the side chains of all charged and most hydrophilic residues inside the core (Q307, V309, K311, D314, K317, T319, and K321). The resulting electrostatic repulsion of the three positively charged lysine side chains (K311, K317, and K321) makes the $\mathrm{U}_{\mathrm{CCW}}$ arrangement seem unlikely.

Furthermore, two extended Z-shape arrangements of the $\beta$-strands with different kink directions are conceivable. Without sizeable contacts between $\beta$-strands one and three, such arrangements would not be stable by themselves. In this case, stability may be provided by a lateral growth of the fibers.

Unfortunately, unambiguous long-range correlations supporting any model could not be obtained so far, neither in the K19 WT nor in the mutant PHF. However, when revisiting the results of the mutation study from Chapter 3.7, stabilizing effects on PHF assembly by hydrophobic interactions were shown. In detail, replacing hydrophobic residues, such as L315, S320 and L325 by a negatively charged glutamic acid, disruption of fibril aggregation was observed (revisit Figure 20). The degree of disturbance was the strongest for L315E, while S320E and L325E formed short filamentous aggregates. Finally, by replacing S320 by a more hydrophobic valine, the assembly efficiency was increased compared to K19 WT (Figure 19).

When comparing the mutation sites with the suggested models, a $U_{\mathrm{CW}}$-shaped arrangement is in perfect agreement with our results. L315 as well as S320 would be buried inside a suspected hydrophobic core. Replacing these residues by charged ones would cause disruption of fibril formation, while substitution with a more hydrophobic residue would further stabilize the hydrophobic effects.

Due to electrostatic repulsion of three positively charged lysine side chains (K311, K317 and K321/2K321) pointing inward and a hydrated environment surrounding the 
core, an $\mathrm{U}_{\mathrm{CCW}}$ arrangement seems unfavorable and less probable. Additionally, the mutagenesis data that demonstrate the importance of hydrophobic interactions on the core stability (e.g. the stimulatory mutant K19S320V) are in contradiction to an $\mathrm{U}_{\mathrm{CCW}}$ arrangement.

Nevertheless, solid-state NMR distance restraints are still missing. In a $\mathrm{U}_{\mathrm{CW}}$ model, $\beta$-strands one and three should be in close proximity to each other featuring observable long-range correlations. In light of the extended core assignment of K19CA PHF, a larger hydrophobic U-shape model with more than three $\beta$-strands is conceivable. This could explain why no long-range restraints between $\beta 1$ and $\beta 3$ are observed. Additionally, due to the disulfide bond in K19 WT PHF, assignment downstream of S324 was impossible. Thus, assignment of further $\beta$-strands required for obtaining distance information was unfeasible.

Another possibility are the extended Z-shape arrangements that cannot be excluded either and would not lead to plenty of long-range correlations, not least because of the parallel and in-register arrangement of the K19 molecules along the fibril axis.

Fortunately, sparsely labeled samples of K19 CA PHF exhibit well-resolved spectra and appear to be promising on the way towards structure determination of the rigid core of K19 PHF (Figure A19). 


\section{Conclusion}

As tau aggregation into PHF is one of the hallmarks of $\mathrm{AD}$, it is important to understand structural features of the fibril core as well as the fibrillation process itself. Our site-specific solid-state NMR study on K19 PHF reveals a well-defined rigid core (V306 to S324; from R3), composed of three $\beta$-strands. Our data unambiguously disclose a parallel, in-register supramolecular arrangement, including the presence of intermolecular disulfide bonds between tau monomer units. The occurrence of DSB leads to polymorphism in solid-state NMR spectra. Consistently, we found that PHF formed from the tau mutant K19CA exhibits solid-state NMR spectra with less polymorphism. Ongoing research is aimed at the collection of long-range distance restraints for K19CA PHF that will be essential for the determination of an atomic model of tau PHF. 


\section{Bibliography}

1. Cavanagh JF, W. J.; Palmer III, A. G.; Rance, M.; Skelton, N. J. (2007) Protein NMR Spectroscopy. Principles and Practice (Elsevier Academic Press Inc) 2. Ed.

2. Billeter M, Wagner G, \& Wuthrich K (2008) Solution NMR structure determination of proteins revisited. $J$ Biomol NMR 42:155-158.

3. Kay LE (2011) Solution NMR spectroscopy of supra-molecular systems, why bother? A methyl-TROSY view. J Magn Reson 210:159-170.

4. McDermott AE (2004) Structural and dynamic studies of proteins by solid-state NMR spectroscopy: rapid movement forward. Curr Opin Struct Biol 14:554-561.

5. Lesage A (2009) Recent advances in solid-state NMR spectroscopy of spin $\mathrm{I}=1 / 2$ nuclei. Phys Chem Chem Phys 11:6876-6891.

6. Castellani F, et al. (2002) Structure of a protein determined by solid-state magic-angle-spinning NMR spectroscopy. Nature 420:98-102.

7. McDermott A, et al. (2000) Partial NMR assignments for uniformly (13C, 15N)-enriched BPTI in the solid state. J Biomol NMR 16:209-219.

8. Franks WT, et al. (2005) Magic-angle spinning solid-state NMR spectroscopy of the beta1 immunoglobulin binding domain of protein G (GB1): $15 \mathrm{~N}$ and $13 \mathrm{C}$ chemical shift assignments and conformational analysis. $J$ Am Chem Soc 127:12291-12305.

9. Bockmann A, et al. (2003) Solid state NMR sequential resonance assignments and conformational analysis of the $2 \times 10.4 \mathrm{kDa}$ dimeric form of the Bacillus subtilis protein Crh. J Biomol NMR 27:323-339.

10. Marulanda D, Tasayco ML, Cataldi M, Arriaran V, \& Polenova T (2005) Resonance assignments and secondary structure analysis of E. coli thioredoxin by magic angle spinning solid-state NMR spectroscopy. $J$ Phys Chem B 109:18135-18145.

11. Seidel K, Etzkorn M, Heise H, Becker S, \& Baldus M (2005) High-resolution solid-state NMR studies on uniformly [13C,15N]-labeled ubiquitin. Chembiochem : a European journal of chemical biology 6:16381647 .

12. Pintacuda G, et al. (2007) Solid-state NMR spectroscopy of a paramagnetic protein: assignment and study of human dimeric oxidized CuII-ZnII superoxide dismutase (SOD). Angew Chem Int Ed Engl 46:1079-1082.

13. Bertini I, et al. (2011) Solid-state NMR of proteins sedimented by ultracentrifugation. Proc Natl Acad Sci U S A 108:10396-10399.

14. Habenstein B, et al. (2011) Extensive de novo solid-state NMR assignments of the $33 \mathrm{kDa}$ C-terminal domain of the Ure2 prion. $J$ Biomol NMR 51:235-243.

15. Ketchem RR, Lee KC, Huo S, \& Cross TA (1996) Macromolecular structural elucidation with solid-state NMR-derived orientational constraints. J Biomol NMR 8:1-14.

16. McDermott A (2009) Structure and dynamics of membrane proteins by magic angle spinning solid-state NMR. Annual review of biophysics 38:385-403. 
17. Schneider R, et al. (2010) The native conformation of the human VDAC1 N terminus. Angew Chem Int Ed Engl 49:1882-1885.

18. Tycko R (2006) Molecular structure of amyloid fibrils: insights from solid-state NMR. Quart Rev Biophys 39:1-55.

19. Jaroniec CP, MacPhee CE, Astrof NS, Dobson CM, \& Griffin RG (2002) Molecular conformation of a peptide fragment of transthyretin in an amyloid fibril. Proc Natl Acad Sci USA 99:16748-16753.

20. Parthasarathy S, et al. (2011) Molecular-level examination of $\mathrm{Cu} 2+$ binding structure for amyloid fibrils of 40-residue Alzheimer's beta by solid-state NMR spectroscopy. J Am Chem Soc 133:3390-3400.

21. Nielsen JT, et al. (2009) Unique identification of supramolecular structures in amyloid fibrils by solid-state NMR spectroscopy. Angew Chem Int Ed Engl 48:2118-2121.

22. Heise H, et al. (2005) Molecular-level secondary structure, polymorphism, and dynamics of full-length $\alpha$ synuclein fibrils studied by solid-state NMR. Proc Natl Acad Sci USA 102:15871-15876.

23. Wasmer C, et al. (2008) Amyloid fibrils of the HET-s(218-289) prion form a $\beta$ solenoid with a triangular hydrophobic core. Science 319:1523-1526.

24. Iwata K, et al. (2006) 3D structure of amyloid protofilaments of $\beta_{2}$-microglobulin fragment probed by solidstate NMR. Proc Natl Acad Sci USA 103:18119-18124.

25. Ferguson N, et al. (2006) General structural motifs of amyloid protofilaments. Proc Natl Acad Sci USA 103:16248-16253.

26. Vilar M, et al. (2008) The fold of alpha-synuclein fibrils. Proc Natl Acad Sci U S A 105:8637-8642.

27. Bertini I, Gonnelli L, Luchinat C, Mao J, \& Nesi A (2011) A New Structural Model of Abeta(40) Fibrils. J Am Chem Soc.

28. Petkova AT, Yau WM, \& Tycko R (2006) Experimental constraints on quaternary structure in Alzheimer's beta-amyloid fibrils. Biochemistry 45:498-512.

29. Helmus JJ, Surewicz K, Surewicz WK, \& Jaroniec CP (2010) Conformational flexibility of Y145Stop human prion protein amyloid fibrils probed by solid-state nuclear magnetic resonance spectroscopy. J Am Chem Soc 132:2393-2403.

30. Comellas G, et al. (2011) Structured regions of alpha-synuclein fibrils include the early-onset Parkinson's disease mutation sites. J Mol Biol 411:881-895.

31. Kloepper KD, Hartman KL, Ladror DT, \& Rienstra CM (2007) Solid-state NMR spectroscopy reveals that water is nonessential to the core structure of alpha-synuclein fibrils. J Phys Chem B 111:13353-13356.

32. Loquet A, Lv G, Giller K, Becker S, \& Lange A (2011) 13C spin dilution for simplified and complete solidstate NMR resonance assignment of insoluble biological assemblies. J Am Chem Soc 133:4722-4725.

33. Gath J, et al. (2012) Solid-state NMR sequential assignments of alpha-synuclein. Biomolecular NMR assignments 6:51-55.

34. Loquet AS, N.G.; Gupta, R.; Giller, K.; Riedel, D.; Goosmann, C.; Griesinger, C.; Kolbe, M.; Baker, D.; Becker, S.; Lange, A. (2012) Atomic model of the type III secretion system needle. Nature.

35. Chen B \& Tycko R (2010) Structural and dynamical characterization of tubular HIV-1 capsid protein assemblies by solid state nuclear magnetic resonance and electron microscopy. Protein Sci 19:716-730.

36. Krabben L, et al. (2009) Loop 3 of short neurotoxin II is an additional interaction site with membrane-bound nicotinic acetylcholine receptor as detected by solid-state NMR spectroscopy. J Mol Biol 390:662-671. 
37. Lange A, et al. (2006) Toxin-induced conformational changes in a potassium channel revealed by solid-state NMR. Nature 440:959-962.

38. Higman VA, et al. (2009) Assigning large proteins in the solid state: a MAS NMR resonance assignment strategy using selectively and extensively 13C-labelled proteins. J Biomol NMR 44:245-260.

39. Loquet A, Giller K, Becker S, \& Lange A (2010) Supramolecular interactions probed by 13C-13C solid-state NMR spectroscopy. J Am Chem Soc 132:15164-15166.

40. Hong M (1999) Determination of multiple $\Phi$-torsion angles in proteins by selective and extensive ${ }^{13} \mathrm{C}$ labeling and two-dimensional solid-state NMR. J Magn Reson 139:389-401.

41. Zhou DH, Graesser DT, Franks WT, \& Rienstra CM (2006) Sensitivity and resolution in proton solid-state NMR at intermediate deuteration levels: quantitative linewidth characterization and applications to correlation spectroscopy. J Magn Reson 178:297-307.

42. Reif B, Jaroniec CP, Rienstra CM, Hohwy M, \& Griffin RG (2001) 1H-1H MAS correlation spectroscopy and distance measurements in a deuterated peptide. J Magn Reson 151:320-327.

43. Reif B, et al. (2003) Characterization of (1)H-(1)H distances in a uniformly (2)H,(15)N-labeled SH3 domain by MAS solid-state NMR spectroscopy (section sign). J Am Chem Soc 125:1488-1489.

44. Morcombe CR, Gaponenko V, Byrd RA, \& Zilm KW (2005) 13C CPMAS spectroscopy of deuterated proteins: CP dynamics, line shapes, and T1 relaxation. J Am Chem Soc 127:397-404.

45. Linser R, et al. (2011) Proton-detected solid-state NMR spectroscopy of fibrillar and membrane proteins. Angew Chem Int Ed Engl 50:4508-4512.

46. Franks WT, Kloepper KD, Wylie BJ, \& Rienstra CM (2007) Four-dimensional heteronuclear correlation experiments for chemical shift assignment of solid proteins. J Biomol NMR 39:107-131.

47. Duer MJ (2002) Solid-state NMR Spectroscopy. Principles and Applications (Blackwell Science Ltd) 1. Ed.

48. Laws DD, Bitter HM, \& Jerschow A (2002) Solid-state NMR spectroscopic methods in chemistry. Angew Chem Int Ed Engl 41:3096-3129.

49. Nielsen NC, Strasso LA, \& Nielsen AB (2012) Dipolar recoupling. Topics in current chemistry 306:1-45.

50. Schmidt-Rohr KS, H. W. (1994) Multidimensional Solid-State NMR and Polymers (Academic Press Inc).

51. Wylie BJ \& Rienstra CM (2008) Multidimensional solid state NMR of anisotropic interactions in peptides and proteins. J Chem Phys 128:052207.

52. Andrew ERB, A.; Eades, R.G. (1958) Nuclear Magnetic Resonance Spectra from a Crystal rotated at High Speed. Nature 182.

53. Shaka AJ, Barker PB, \& Freeman R (1985) Computer-optimized decoupling scheme for wideband applications and low-level Operation. J Magn Reson 64:547-552.

54. Wishart DS \& Sykes BD (1994) The 13C chemical-shift index: a simple method for the identification of protein secondary structure using $13 \mathrm{C}$ chemical-shift data. J Biomol NMR 4:171-180.

55. Wang Y \& Jardetzky O (2002) Probability-based protein secondary structure identification using combined NMR chemical-shift data. Protein Sci 11:852-861.

56. Luca S, et al. (2001) Secondary chemical shifts in immobilized peptides and proteins: A qualitative basis for structure refinement under magic angle spinning. J Biomol NMR 20:325-331.

57. Ulrich EL, et al. (2008) BioMagResBank. Nucleic acids research 36:D402-408.

58. Berman HM, et al. (2000) The Protein Data Bank. Nucleic acids research 28:235-242. 
59. Shen Y, Delaglio F, Cornilescu G, \& Bax A (2009) TALOS+: a hybrid method for predicting protein backbone torsion angles from NMR chemical shifts. J Biomol NMR 44:213-223.

60. Cheung MS, Maguire ML, Stevens TJ, \& Broadhurst RW (2010) DANGLE: A Bayesian inferential method for predicting protein backbone dihedral angles and secondary structure. J Magn Reson 202:223-233.

61. Lange A, Seidel K, Verdier L, Luca S, \& Baldus M (2003) Analysis of proton-proton transfer dynamics in rotating solids and their use for 3D structure determination. J Am Chem Soc 125:12640-12648.

62. Baldus M, Petkova AT, Herzfeld J, \& Griffin RG (1998) Cross polarization in the tilted frame: assignment and spectral simplification in heteronuclear spin systems. Mol Phys 95:1197-1207.

63. Szeverenyi NM, Sullivan MJ, \& Maciel GE (1982) Observation of spin exchange by two-dimensional fourier transform 13C cross polarization-magic-angle spinning. J Magn Reson (1969) 47:462-475.

64. Pines AG, M.G.; Waugh, J.S. (1973) Proton-enhanced NMR of dilute spins in solids. J Chem Phys 59:22.

65. Takegoshi K, Nakamura S, \& Terao $\mathrm{T}(2001){ }^{13} \mathrm{C}-{ }^{1} \mathrm{H}$ dipolar-assisted rotational resonance in magic-angle spinning NMR. Chem Phys Lett 344:631-637.

66. Verel R, Baldus M, Ernst M, \& Meier BH (1998) A homonuclear spin-pair filter for solid-state NMR based on adiabatic-passage techniques. Chem Phys Lett 287:421-428.

67. Nielsen NCB, H.; Jakobsen, H. J.; Levitt, M. H. (1994) Double-quantum homonuclear rotary resonance: Efficient dipolar recovery in magic-angle spinning nuclear magnetic resonance. $J$ Chem Phys 101:8.

68. Burum DP \& Ernst RR (1980) Net polarization transfer via a J-ordered state for signal enhancement of lowsensitivity nuclei. J Magn Reson (1969) 39:163-168.

69. Baldus M \& Meier BH (1996) Total correlation spectroscopy in the solid state. The use of scalar couplings to determine the through-bond connectivity. J Magn Reson, Series A 121:65-69.

70. Andronesi OC, et al. (2005) Determination of membrane protein structure and dynamics by magic-anglespinning solid-state NMR spectroscopy. J Am Chem Soc 127:12965-12974.

71. Chevelkov V, et al. (2005) Detection of dynamic water molecules in a microcrystalline sample of the SH3 domain of alpha-spectrin by MAS solid-state NMR. J Biomol NMR 31:295-310.

72. Van Melckebeke H, et al. (2011) Probing water accessibility in HET-s(218-289) amyloid fibrils by solid-state NMR. J Mol Biol 405:765-772.

73. Lesage A \& Bockmann A (2003) Water-protein interactions in microcrystalline crh measured by $1 \mathrm{H}-13 \mathrm{C}$ solid-state NMR spectroscopy. J Am Chem Soc 125:13336-13337.

74. Lesage A, et al. (2008) Polarization transfer over the water-protein interface in solids. Angew Chem Int Ed Engl 47:5851-5854.

75. Lesage A, Emsley L, Penin F, \& Bockmann A (2006) Investigation of dipolar-mediated water-protein interactions in microcrystalline Crh by solid-state NMR spectroscopy. J Am Chem Soc 128:8246-8255.

76. Nadaud PS, Helmus JJ, Hofer N, \& Jaroniec CP (2007) Long-range structural restraints in spin-labeled proteins probed by solid-state nuclear magnetic resonance spectroscopy. J Am Chem Soc 129:7502-7503.

77. Nadaud PS, Helmus JJ, Kall SL, \& Jaroniec CP (2009) Paramagnetic ions enable tuning of nuclear relaxation rates and provide long-range structural restraints in solid-state NMR of proteins. J Am Chem Soc 131:81088120 .

78. Pintacuda G \& Kervern G (2012) Paramagnetic Solid-State Magic-Angle Spinning NMR Spectroscopy. Topics in current chemistry. 
79. LeMaster DM \& Kushlan DM (1996) Dynamical mapping of E-coli thioredoxin via ${ }^{13} \mathrm{C}$ NMR relaxation analysis. J Am Chem Soc 118:9255-9264.

80. Vuister GW, Kim SJ, Wu C, \& Bax A (1994) 2D and 3D NMR-study of phenylalanine residues in proteins by reverse isotopic labeling. $J$ Am Chem Soc 116:9206-9210.

81. Lange A, Luca S, \& Baldus M (2002) Structural constraints from proton-mediated rare-spin correlation spectroscopy in rotating solids. $J$ Am Chem Soc 124:9704-9705.

82. Bertini I, et al. (2010) High-resolution solid-state NMR structure of a $17.6 \mathrm{kDa}$ protein. J Am Chem Soc 132:1032-1040.

83. Lange A, et al. (2005) A concept for rapid protein-structure determination by solid-state NMR spectroscopy. Angew Chem Int Ed Engl 44:2089-2092.

84. Zhang Y, et al. (2010) Resonance assignment and three-dimensional structure determination of a human alpha-defensin, HNP-1, by solid-state NMR. J Mol Biol 397:408-422.

85. Loquet A, et al. (2008) 3D structure determination of the Crh protein from highly ambiguous solid-state NMR restraints. J Am Chem Soc 130:3579-3589.

86. Manolikas T, Herrmann T, \& Meier BH (2008) Protein structure determination from 13C spin-diffusion solid-state NMR spectroscopy. J Am Chem Soc 130:3959-3966.

87. De Paepe G, Lewandowski JR, Loquet A, Bockmann A, \& Griffin RG (2008) Proton assisted recoupling and protein structure determination. J Chem Phys 129:245101-245121.

88. Lewandowski JR, De Paepe G, \& Griffin RG (2007) Proton assisted insensitive nuclei cross polarization. $J$ Am Chem Soc 129:728-729.

89. Lewandowski JR, van der Wel PC, Rigney M, Grigorieff N, \& Griffin RG (2011) Structural complexity of a composite amyloid fibril. J Am Chem Soc 133:14686-14698.

90. Virchow R (1854) Über den Gang der amyloiden Degeneration. Virch Arch 8:364-368.

91. Sipe JD \& Cohen AS (2000) Review: history of the amyloid fibril. Journal of structural biology 130:88-98

92. Bennhold H (1922) Eine specifische Amyloidfärbung mit Kongorot. Münch Med Wochenschr 69:2.

93. Divry PF, M. (1927) Sur les propriétées optiques de l'amyloide. CR Soc Biol (Paris) 97:3.

94. Putchler HS, F.; Levine, M. (1962) On the binding of Congo red by amyloid. J Histochem Cytochem 10:10.

95. Naiki H, Higuchi K, Hosokawa M, \& Takeda T (1989) Fluorometric determination of amyloid fibrils in vitro using the fluorescent dye, thioflavin T1. Analytical biochemistry 177:244-249.

96. Ban T, Hamada D, Hasegawa K, Naiki H, \& Goto Y (2003) Direct observation of amyloid fibril growth monitored by thioflavin T fluorescence. J Biol Chem 278:16462-16465.

97. Lee VMY, Balin BJ, Otvos L, Jr., \& Trojanowski JQ (1991) A68: A major subunit of paired helical filaments and derivatized forms of normal tau. Science 251:675-678.

98. Lin CY, et al. (2007) Toxic human islet amyloid polypeptide (h-IAPP) oligomers are intracellular, and vaccination to induce anti-toxic oligomer antibodies does not prevent h-IAPP-induced beta-cell apoptosis in h-IAPP transgenic mice. Diabetes 56:1324-1332.

99. Serpell LC, Berriman J, Jakes R, Goedert M, \& Crowther RA (2000) Fiber diffraction of synthetic alphasynuclein filaments shows amyloid-like cross-beta conformation. Proc Natl Acad Sci U S A 97:4897-4902.

100. Sipe JD (2005) Amyloid proteins. The Beta Sheet Conformation and Disease (Wiley-VCH) p 799. 
101. Nelson R \& Eisenberg D (2006) Recent atomic models of amyloid fibril structure. Curr Opin Struct Biol $16: 260-265$.

102. Shirahama T \& Cohen AS (1967) High-resolution electron microscopic analysis of the amyloid fibril. J. Cell Biol. 33:679-708.

103. Shirahama T \& Cohen AS (1967) Reconstitution of amyloid fibrils from alkaline extracts. J. Cell Biol. 35:459-464.

104. Serpell LC, et al. (2000) The protofilament substructure of amyloid fibrils. J Mol Biol 300:1033-1039.

105. Fandrich M (2007) On the structural definition of amyloid fibrils and other polypeptide aggregates. Cellular and molecular life sciences: CMLS 64:2066-2078.

106. Eanes ED \& Glenner GG (1968) X-ray diffraction studies on amyloid filaments. J Histochem Cytochem 16:673-677.

107. Bonar L, Cohen AS, \& Skinner MM (1969) Characterization of the amyloid fibril as a cross-beta protein. Proc Soc Exp Biol Med 131:1373-1375.

108. Kirschner DA, Abraham C, \& Selkoe DJ (1986) X-ray diffraction from intraneuronal paired helical filaments and extraneuronal amyloid fibers in Alzheimer disease indicates cross-beta conformation. Proc Natl Acad Sci $U S A$ 83:503-507.

109. Serpell LC, Fraser PE, \& Sunde M (1999) X-ray fiber diffraction of amyloid fibrils. Methods in enzymology 309:526-536

110. Sunde M \& Blake C (1997) The structure of amyloid fibrils by electron microscopy and X-ray diffraction. Advances in protein chemistry 50:123-159.

111. Sunde M \& Blake CC (1998) From the globular to the fibrous state: protein structure and structural conversion in amyloid formation. Quarterly reviews of biophysics 31:1-39.

112. Makin OS, Atkins E, Sikorski P, Johansson J, \& Serpell LC (2005) Molecular basis for amyloid fibril formation and stability. Proc Natl Acad Sci US A 102:315-320.

113. Kryndushkin DS, Wickner RB, \& Tycko R (2011) The core of Ure2p prion fibrils is formed by the Nterminal segment in a parallel cross-beta structure: evidence from solid-state NMR. J Mol Biol 409:263-277.

114. Habenstein B, et al. (2012) A Native-Like Conformation for the C-Terminal Domain of the Prion Ure2p Within its Fibrillar Form. Angew Chem Int Ed Engl.

115. Helmus JJ, Surewicz K, Nadaud PS, Surewicz WK, \& Jaroniec CP (2008) Molecular conformation and dynamics of the Y145Stop variant of human prion protein in amyloid fibrils. Proc Natl Acad Sci U S A 105:6284-6289.

116. Petkova AT, et al. (2005) Self-propagating, molecular-level polymorphism in Alzheimer's beta-amyloid fibrils. Science 307:262-265.

117. Paravastu AK, Leapman RD, Yau WM, \& Tycko R (2008) Molecular structural basis for polymorphism in Alzheimer's beta-amyloid fibrils. Proc Natl Acad Sci U S A 105:18349-18354.

118. Luhrs T, et al. (2005) 3D structure of Alzheimer's amyloid-beta(1-42) fibrils. Proc Natl Acad Sci U S A 102:17342-17347.

119. Anfinsen CB (1973) Principles that govern the folding of protein chains. Science 181:223-230.

120. Hartl FU \& Hayer-Hartl M (2009) Converging concepts of protein folding in vitro and in vivo. Nat Struct Mol Biol 16:574-581. 
121. Fersht AR (2008) From the first protein structures to our current knowledge of protein folding: delights and scepticisms. Nature reviews. Molecular cell biology 9:650-654.

122. Onuchic JN \& Wolynes PG (2004) Theory of protein folding. Curr Opin Struct Biol 14:70-75.

123. Chiti F \& Dobson CM (2006) Protein misfolding, functional amyloid, and human disease. Annual review of biochemistry 75:333-366.

124. Modler AJ, et al. (2004) Polymerization of proteins into amyloid protofibrils shares common critical oligomeric states but differs in the mechanisms of their formation. Amyloid : the international journal of experimental and clinical investigation : the official journal of the International Society of Amyloidosis $11: 215-231$.

125. Petty SA \& Decatur SM (2005) Intersheet rearrangement of polypeptides during nucleation of \{beta $\}$-sheet aggregates. Proc Natl Acad Sci U S A 102:14272-14277.

126. Serio TR, et al. (2000) Nucleated conformational conversion and the replication of conformational information by a prion determinant. Science 289:1317-1321.

127. Lomakin A, Chung DS, Benedek GB, Kirschner DA, \& Teplow DB (1996) On the nucleation and growth of amyloid beta-protein fibrils: detection of nuclei and quantitation of rate constants. Proc Natl Acad Sci U S A 93:1125-1129.

128. Leopold PE, Montal M, \& Onuchic JN (1992) Protein folding funnels: a kinetic approach to the sequencestructure relationship. Proc Natl Acad Sci U S A 89:8721-8725.

129. Makin OS \& Serpell LC (2005) Structures for amyloid fibrils. FEBS J 272:5950-5961.

130. Maji SK, et al. (2009) Functional amyloids as natural storage of peptide hormones in pituitary secretory granules. Science 325:328-332.

131. Berson JF, Harper DC, Tenza D, Raposo G, \& Marks MS (2001) Pmel17 initiates premelanosome morphogenesis within multivesicular bodies. Molecular biology of the cell 12:3451-3464.

132. Theos AC, Truschel ST, Raposo G, \& Marks MS (2005) The Silver locus product Pmel17/gp100/Silv/ME20: controversial in name and in function. Pigment cell research / sponsored by the European Society for Pigment Cell Research and the International Pigment Cell Society 18:322-336.

133. Fowler DM, et al. (2006) Functional amyloid formation within mammalian tissue. PLoS Biol 4:e6.

134. McGlinchey RP, et al. (2011) Repeat domains of melanosome matrix protein Pmel17 orthologs form amyloid fibrils at the acidic melanosomal pH. J Biol Chem 286:8385-8393.

135. Wasmer C, et al. (2009) The molecular organization of the fungal prion HET-s in its amyloid form. $J$ Mol Biol 394:119-127.

136. Balguerie A, et al. (2003) Domain organization and structure-function relationship of the HET-s prion protein of Podospora anserina. The EMBO journal 22:2071-2081.

137. Coustou V, Deleu C, Saupe S, \& Begueret J (1997) The protein product of the het-s heterokaryon incompatibility gene of the fungus Podospora anserina behaves as a prion analog. Proc Natl Acad Sci U S A 94:9773-9778

138. Blinder D, Coschigano PW, \& Magasanik B (1996) Interaction of the GATA factor Gln3p with the nitrogen regulator Ure2p in Saccharomyces cerevisiae. Journal of bacteriology 178:4734-4736.

139. Thual C, et al. (1999) Structural characterization of Saccharomyces cerevisiae prion-like protein Ure2. J Biol Chem 274:13666-13674.

140. Bousset L, Thomson NH, Radford SE, \& Melki R (2002) The yeast prion Ure2p retains its native alphahelical conformation upon assembly into protein fibrils in vitro. The EMBO journal 21:2903-2911. 
141. Sunde M, et al. (1997) Common core structure of amyloid fibrils by synchrotron X-ray diffraction. J Mol Biol 273:729-739.

142. Ohta S, et al. (2009) Defining lipid-binding regions of human serum amyloid A using its fragment peptides. Chemistry and physics of lipids 162:62-68.

143. Poljak RJ, et al. (1973) Three-dimensional structure of the Fab' fragment of a human immunoglobulin at 2,8A resolution. Proc Natl Acad Sci U S A 70:3305-3310.

144. Bedrood S, et al. (2012) Fibril structure of human islet amyloid polypeptide. J Biol Chem 287:5235-5241.

145. Riek R, Guntert P, Dobeli H, Wipf B, \& Wuthrich K (2001) NMR studies in aqueous solution fail to identify significant conformational differences between the monomeric forms of two Alzheimer peptides with widely different plaque-competence, A beta(1-40)(ox) and A beta(1-42)(ox). Eur J Biochem 268:5930-5936.

146. Watson AA, Fairlie DP, \& Craik DJ (1998) Solution structure of methionine-oxidized amyloid beta-peptide (1-40). Does oxidation affect conformational switching? Biochemistry 37:12700-12706.

147. Balbach JJ, et al. (2002) Supramolecular structure in full-length Alzheimer's beta-amyloid fibrils: evidence for a parallel beta-sheet organization from solid-state nuclear magnetic resonance. Biophysical journal $83: 1205-1216$

148. Petkova AT, et al. (2004) Solid state NMR reveals a pH-dependent antiparallel beta-sheet registry in fibrils formed by a beta-amyloid peptide. J Mol Biol 335:247-260.

149. Mylonas E, et al. (2008) Domain conformation of tau protein studied by solution small-angle X-ray scattering. Biochemistry 47:10345-10353.

150. Mukrasch MD, et al. (2009) Structural polymorphism of 441-residue tau at single residue resolution. PLoS Biol 7:e34.

151. Margittai M \& Langen R (2004) Template-assisted filament growth by parallel stacking of tau. Proc Natl Acad Sci USA 101:10278-10283.

152. Margittai M \& Langen R (2006) Side chain-dependent stacking modulates tau filament structure. J Biol Chem 281:37820-37827.

153. Riek R, et al. (1996) NMR structure of the mouse prion protein domain $\operatorname{PrP}(121-231)$. Nature 382:180-182.

154. Govaerts C, Wille H, Prusiner SB, \& Cohen FE (2004) Evidence for assembly of prions with left-handed beta-helices into trimers. Proc Natl Acad Sci U S A 101:8342-8347.

155. Cohen FE (1999) Protein misfolding and prion diseases. J Mol Biol 293:313-320.

156. Thakur AK, et al. (2009) Polyglutamine disruption of the huntingtin exon $1 \mathrm{~N}$ terminus triggers a complex aggregation mechanism. Nat Struct Mol Biol 16:380-389.

157. Schneider R, et al. (2011) Structural characterization of polyglutamine fibrils by solid-state NMR spectroscopy. J Mol Biol 412:121-136.

158. Dobson CM (2001) The structural basis of protein folding and its links with human disease. Philosophical transactions of the Royal Society of London. Series B, Biological sciences 356:133-145.

159. Sawaya MR, et al. (2007) Atomic structures of amyloid cross- $\beta$ spines reveal varied steric zippers. Nature 447:453-457.

160. Gotz J, Eckert A, Matamales M, Ittner LM, \& Liu X (2011) Modes of Abeta toxicity in Alzheimer's disease. Cellular and molecular life sciences : CMLS 68:3359-3375.

161. Spires-Jones TL, Kopeikina KJ, Koffie RM, de Calignon A, \& Hyman BT (2011) Are tangles as toxic as they look? Journal of molecular neuroscience : MN 45:438-444. 
162. Pritchard SM, Dolan PJ, Vitkus A, \& Johnson GV (2011) The toxicity of tau in Alzheimer disease: turnover, targets and potential therapeutics. Journal of cellular and molecular medicine 15:1621-1635.

163. Labbadia J, et al. (2012) Suppression of protein aggregation by chaperone modification of high molecular weight complexes. Brain : a journal of neurology 135:1180-1196.

164. Cowan CM, et al. (2011) Modelling tauopathies in Drosophila: insights from the fruit fly. International journal of Alzheimer's disease 2011:598157.

165. Xi Y, Noble S, \& Ekker M (2011) Modeling neurodegeneration in zebrafish. Current neurology and neuroscience reports 11:274-282.

166. Weingarten MD, Lockwood AH, Hwo SY, \& Kirschner MW (1975) A protein factor essential for microtubule assembly. Proc Natl Acad Sci U S A 72:1858-1862.

167. Friedhoff P, Schneider A, Mandelkow E-M, \& Mandelkow E (1998) Rapid assembly of Alzheimer-like paired helical filaments from microtubule-associated protein tau monitored by fluorescence in solution. Biochemistry 37:10223-10230.

168. Goedert M, Wischik CM, Crowther RA, Walker JE, \& Klug A (1988) Cloning and sequencing of the cDNA encoding a core protein of the paired helical filament of Alzheimer disease: identification as the microtubuleassociated protein tau. Proc Natl Acad Sci U S A 85:4051-4055.

169. Neve RL, Harris P, Kosik KS, Kurnit DM, \& Donlon TA (1986) Identification of cDNA clones for the human microtubule-associated protein tau and chromosomal localization of the genes for tau and microtubuleassociated protein 2. Brain research 387:271-280.

170. Lee G, Cowan N, \& Kirschner M (1988) The primary structure and heterogeneity of tau-protein from mousebrain. Science 239:285-288.

171. Goedert M, Spillantini MG, Jakes R, Rutherford D, \& Crowther RA (1989) Multiple isoforms of human microtubule-associated protein tau: sequences and localization in neurofibrillary tangles of Alzheimer's disease. Neuron 3:519-526.

172. Couchie D, et al. (1992) Primary structure of high molecular weight tau present in the peripheral nervous system. Proc Natl Acad Sci U S A 89:4378-4381.

173. Goedert M, Spillantini MG, \& Crowther RA (1992) Cloning of a big tau microtubule-associated protein characteristic of the peripheral nervous system. Proc Natl Acad Sci U S A 89:1983-1987.

174. Ittner A, et al. (2011) Brief update on different roles of tau in neurodegeneration. IUBMB life 63:495-502.

175. Mazanetz MP \& Fischer PM (2007) Untangling tau hyperphosphorylation in drug design for neurodegenerative diseases. Nature reviews. Drug discovery 6:464-479.

176. Steiner B, et al. (1990) Phosphorylation of microtubule-associated protein tau: identification of the site for $\mathrm{Ca} 2(+)$-calmodulin dependent kinase and relationship with tau phosphorylation in Alzheimer tangles. The EMBO journal 9:3539-3544.

177. Mukrasch MD, et al. (2005) Sites of tau important for aggregation populate $\beta$-structure and bind to microtubules and polyanions. J Biol Chem 280:24978-24986.

178. Mandelkow EM \& Mandelkow E (2012) Biochemistry and cell biology of tau protein in neurofibrillary degeneration. Cold Spring Harbor perspectives in medicine 2:a006247.

179. Hirokawa N, Shiomura Y, \& Okabe S (1988) Tau proteins: the molecular structure and mode of binding on microtubules. J. Cell Biol. 107:1449-1459.

180. Clavaguera F, et al. (2009) Transmission and spreading of tauopathy in transgenic mouse brain. Nature cell biology 11:909-913. 
181. Fauquant C, et al. (2011) Systematic identification of tubulin-interacting fragments of the microtubuleassociated protein Tau leads to a highly efficient promoter of microtubule assembly. J Biol Chem 286:3335833368 .

182. Grundke-Iqbal I, et al. (1986) Abnormal phosphorylation of the microtubule-associated protein tau (tau) in Alzheimer cytoskeletal pathology. Proc Natl Acad Sci USA 83:4913-4917.

183. Mandelkow EM, et al. (1995) Tau domains, phosphorylation, and interactions with microtubules. Neurobiology of aging 16:355-362; discussion 362-353.

184. Fischer D, et al. (2009) Conformational changes specific for pseudophosphorylation at serine 262 selectively impair binding of tau to microtubules. Biochemistry 48:10047-10055.

185. Iqbal K, et al. (2005) Tau pathology in Alzheimer disease and other tauopathies. Biochim Biophys Acta, Mol Basis Dis 1739:198-210.

186. Lee VMY, Goedert M, \& Trojanowski JQ (2001) Neurodegenerative tauopathies. Annu Rev Neurosci 24:1121-1159.

187. Williams DR (2006) Tauopathies: classification and clinical update on neurodegenerative diseases associated with microtubule-associated protein tau. Internal medicine journal 36:652-660.

188. Bouchard M \& Suchowersky O (2011) Tauopathies: one disease or many? The Canadian journal of neurological sciences. Le journal canadien des sciences neurologiques 38:547-556.

189. Richardson JC, Steele J, \& Olszewski J (1963) Supranuclear Ophthalmoplegia, Pseudobulbar Palsy, Nuchal Dystonia and Dementia. A Clinical Report on Eight Cases of "Heterogenous System Degeneration". Transactions of the American Neurological Association 88:25-29.

190. Rebeiz JJ, Kolodny EH, \& Richardson EP, Jr. (1967) Corticodentatonigral degeneration with neuronal achromasia: a progressive disorder of late adult life. Transactions of the American Neurological Association 92:23-26.

191. Pick A (1892) Ueber die Beziehungen der senilen Hirnatrophie zur Aphasie. Prager Med Wochenschr 17:2.

192. Ittner LM \& Gotz J (2011) Amyloid-beta and tau--a toxic pas de deux in Alzheimer's disease. Nat Rev Neurosci 12:65-72.

193. Hampel H, et al. (2011) The future of Alzheimer's disease: the next 10 years. Progress in neurobiology 95:718-728.

194. Goedert M \& Spillantini MG (2006) A century of Alzheimer's disease. Science 314:777-781.

195. Salomone SCFL, G.M.; Fedotova, J.; Drago, F. (2011) New pharmacological strategies for treatment of Alzheimer's disease: focus on disease modifying drugs. Br J Clin Pharmacol 73:13.

196. Ferri CP, et al. (2005) Global prevalence of dementia: a Delphi consensus study. Lancet 366:2112-2117.

197. Reitz C, Brayne C, \& Mayeux R (2011) Epidemiology of Alzheimer disease. Nature reviews. Neurology 7:137-152.

198. Bibow S, et al. (2011) The dynamic structure of filamentous tau. Angew Chem Int Ed Engl 50:11520-11524.

199. Li L, von Bergen M, Mandelkow EM, \& Mandelkow E (2002) Structure, stability, and aggregation of paired helical filaments from tau protein and FTDP-17 mutants probed by tryptophan scanning mutagenesis. $J$ Biol Chem 277:41390-41400.

200. von Bergen M, et al. (2006) The core of tau-paired helical filaments studied by scanning transmission electron microscopy and limited proteolysis. Biochemistry 45:6446-6457. 
201. Berriman J, et al. (2003) Tau filaments from human brain and from in vitro assembly of recombinant protein show cross- $\beta$ structure. Proc Natl Acad Sci USA 100:9034-9038.

202. von Bergen M, et al. (2001) Mutations of tau protein in frontotemporal dementia promote aggregation of paired helical filaments by enhancing local $\beta$-structure. J Biol Chem 276:48165-48174.

203. Giannetti AM, et al. (2000) Fibers of tau fragments, but not full length tau, exhibit a cross $\beta$-structure: Implications for the formation of paired helical filaments. Prot Sci 9:2427-2435.

204. Andronesi OC, et al. (2008) Characterization of Alzheimer's-like paired helical filaments from the core domain of tau protein using solid-state NMR spectroscopy. J Am Chem Soc 130:5922-5928.

205. Barghorn S, Biernat J, \& Mandelkow E (2005) Purification of recombinant tau protein and preparation of Alzheimer-paired helical filaments in vitro. Methods Mol Biol 299:35-51.

206. Etzkorn M, Bockmann A, Lange A, \& Baldus M (2004) Probing molecular interfaces using 2D magic-anglespinning NMR on protein mixtures with different uniform labeling. J Am Chem Soc 126:14746-14751.

207. Morcombe CR \& Zilm KW (2003) Chemical shift referencing in MAS solid state NMR. J Magn Reson 162:479-486.

208. Bockmann A, et al. (2009) Characterization of different water pools in solid-state NMR protein samples. $J$ Biomol NMR 45:319-327.

209. Fung BM, Khitrin AK, \& Ermolaev K (2000) An improved broadband decoupling sequence for liquid crystals and solids. J Magn Reson 142:97-101.

210. Cho MK, Kim HY, Fernandez CO, Becker S, \& Zweckstetter M (2011) Conserved core of amyloid fibrils of wild type and A30P mutant alpha-synuclein. Protein Sci 20:387-395.

211. Delaglio F, et al. (1995) NMRPipe: a multidimensional spectral processing system based on UNIX pipes. $J$ Biomol NMR 6:277-293.

212. Vranken WF, et al. (2005) The CCPN data model for NMR spectroscopy: development of a software pipeline. Proteins 59:687-696.

213. Sharma D \& Rajarathnam K (2000) 13C NMR chemical shifts can predict disulfide bond formation. J Biomol NMR 18:165-171.

214. von Bergen M, et al. (2000) Assembly of tau protein into Alzheimer paired helical filaments depends on a local sequence motif $\left({ }^{306}\right.$ VQIVYK $\left.^{311}\right)$ forming $\beta$ structure. Proc Natl Acad Sci USA 97:5129-5134.

215. Sievers SA, et al. (2011) Structure-based design of non-natural amino-acid inhibitors of amyloid fibril formation. Nature 475:96-100.

216. Abraha A, et al. (2000) C-terminal inhibition of tau assembly in vitro and in Alzheimer's disease. $J$ Cell Sci 113:3737-3745.

217. Mukrasch MD, et al. (2007) Highly populated turn conformations in natively unfolded tau protein identified from residual dipolar couplings and molecular simulation. J Am Chem Soc 129:5235-5243.

218. Reynolds MR, Berry RW, \& Binder LI (2005) Site-specific nitration and oxidative dityrosine bridging of the $\tau$ protein by peroxynitrite: Implications for Alzheimer's disease. Biochemistry 44:1690-1700.

219. Goux WJ, et al. (2004) The formation of straight and twisted filaments from short tau peptides. $J$ Biol Chem 279:26868-26875

220. Meng SR, et al. (2012) Fibril-forming motifs are essential and sufficient for the fibrillization of human tau. PloS one 7:e38903. 
221. Almeida AM, Li R, \& Gellman SH (2011) Parallel $\beta$-sheet secondary structure is stabilized and terminated by interstrand disulfide cross-linking. J Am Chem Soc Epub 2011, Dec 8.

222. Choi JH, May BC, Wille H, \& Cohen FE (2009) Molecular modeling of the misfolded insulin subunit and amyloid fibril. Biophysical journal 97:3187-3195.

223. Schmidt M, et al. (2009) Comparison of Alzheimer Abeta(1-40) and Abeta(1-42) amyloid fibrils reveals similar protofilament structures. Proc Natl Acad Sci U S A 106:19813-19818.

224. Lopez Del Amo JM, et al. (2012) An Asymmetric Dimer as the Basic Subunit in Alzheimer's Disease Amyloid beta Fibrils. Angew Chem Int Ed Engl.

225. Wille H, Drewes G, Biernat J, Mandelkow EM, \& Mandelkow E (1992) Alzheimer-like paired helical filaments and antiparallel dimers formed from microtubule associated protein-tau in vitro. J. Cell Biol. 118:573-584.

226. Barghorn S \& Mandelkow E (2002) Toward a unified scheme for the aggregation of tau into Alzheimer paired helical filaments. Biochemistry 41:14885-14896.

227. Ramachandran GN, Ramakrishnan C, \& Sasisekharan V (1963) Stereochemistry of polypeptide chain configurations. J Mol Biol 7:95-99.

228. Morris AL, MacArthur MW, Hutchinson EG, \& Thornton JM (1992) Stereochemical quality of protein structure coordinates. Proteins 12:345-364. 


\section{Appendices}

\subsection{Experimental details}

Table A1. Details of experiments measured on K19 PHF samples.

\begin{tabular}{|c|c|c|c|c|c|c|c|c|c|c|}
\hline Sample & $\begin{array}{c}1 \mathrm{H} \\
\text { freq. } \\
{[\mathrm{MHz}]}\end{array}$ & $\begin{array}{c}v_{\mathrm{r}} \\
{[\mathrm{kHz}]}\end{array}$ & Experiment & $\begin{array}{c}\text { Mixing } \\
\text { time } \\
{[\mathrm{ms}]}\end{array}$ & $\begin{array}{c}\text { CP time } \\
{[\mu s]}\end{array}$ & $\mathbf{T D}_{1}$ & $\begin{array}{l}\mathrm{aq}_{1} \\
{[\mathrm{~ms}]}\end{array}$ & ns & $\begin{array}{c}\text { Total } \\
\text { time } \\
\text { [d; h] }\end{array}$ & $\begin{array}{l}\mathbf{T} \\
{ }^{\circ} \mathbf{C}\end{array}$ \\
\hline uK19 old & 800 & 18 & DREAM & 3 & 700 & 250 & 6.9 & 464 & $2 ; 17$ & 7 \\
\hline K19 $_{\text {Krev }}$ & 850 & 8.33 & $\begin{array}{c}\text { INEPT-CC- } \\
\text { TOBSY }\end{array}$ & $6\left(\mathrm{P9}^{3}{ }_{1}\right)$ & I & 1024 & 16 & 160 & $3 ; 0$ & 5 \\
\hline K19 1:1 & 850 & 18 & PAIN-CP* & 5 & 900 & 26 & 6.3 & 20352 & $12 ; 5$ & 5 \\
\hline K19 $_{\text {KFLVrev }}$ & 850 & 8.33 & $\begin{array}{c}\text { INEPT-CC- } \\
\text { TOBSY }\end{array}$ & $6\left(\mathrm{P9}^{3}{ }_{1}\right)$ & I & 896 & 14 & 112 & $1 ; 19$ & 5 \\
\hline \multirow[t]{5}{*}{ K19 ${ }_{\text {2glyc }}$} & 600 & 11 & PDSD & 100 & 700 & 854 & 10 & 256 & $5 ; 15$ & 7 \\
\hline & 600 & 11 & PDSD & 500 & 700 & 854 & 10 & 512 & $13 ; 9$ & 7 \\
\hline & 800 & 10.5 & PDSD & 700 & 1000 & 768 & 9.8 & 464 & $11 ; 6$ & 8 \\
\hline & 850 & 11 & PDSD & 500 & 1000 & 960 & 10.7 & 384 & $13 ; 0$ & 11 \\
\hline & 800 & 11 & $\mathrm{NCA}$ & / & $800 / 5000$ & 66 & 8.5 & 1392 & $2 ; 16$ & 5 \\
\hline \multirow[t]{3}{*}{ K19 ${ }_{1,3 \mathrm{glyc}}$} & 600 & 11 & PDSD & 100 & 700 & 684 & 8 & 320 & $5 ; 14$ & 7 \\
\hline & 600 & 11 & PDSD & 500 & 700 & 684 & 8 & 1168 & $23 ; 22$ & 7 \\
\hline & 850 & 11 & PDSD & 500 & 1000 & 1024 & 10.2 & 336 & $12 ; 6$ & 5 \\
\hline \multirow[t]{9}{*}{ uK19 } & 850 & 11 & PDSD & 20 & 900 & 880 & 9.8 & 112 & $2 ; 22$ & 7 \\
\hline & 850 & 11 & PDSD & 150 & 900 & 880 & 9.8 & 128 & $3 ; 12$ & 7 \\
\hline & 850 & 11 & $\mathrm{CHHC}$ & 0.25 & $1200 / 100 / 100$ & 360 & 10 & 1248 & $13 ; 0$ & 8 \\
\hline & 850 & 11 & $\begin{array}{c}\text { INEPT-CC- } \\
\text { TOBSY }\end{array}$ & $6\left(\mathrm{P9}^{3}{ }_{1}\right)$ & l & 964 & 15 & 64 & $1 ; 3$ & 6 \\
\hline & 850 & 11 & $\mathrm{NCA}$ & / & $900 / 3000$ & 56 & 8.1 & 832 & $1 ; 9$ & 7 \\
\hline & 850 & 11 & $\mathrm{NCA}$ & / & $900 / 3000$ & 146 & 7.1 & 224 & $0 ; 23$ & 7 \\
\hline & 850 & 11 & NCACX & $\begin{array}{c}50 \\
\text { (DARR) }\end{array}$ & $700 / 3500$ & 48 & 7 & 6528 & $7 ; 6$ & 7 \\
\hline & 850 & 11 & $\mathrm{NCOCX}$ & $\begin{array}{c}30 \\
\text { (DARR) }\end{array}$ & $900 / 3500$ & 48 & 6.9 & 4480 & $5 ; 2$ & 7 \\
\hline & 600 & 11 & PDSD & 150 & 1500 & 854 & 10 & 272 & $8 ; 4$ & 5 \\
\hline \multirow[t]{2}{*}{ K19CA } & 800 & 11 & PDSD & 20 & 900 & 784 & 10 & 160 & $3 ; 16$ & 5 \\
\hline & 800 & 11 & PDSD & 150 & 900 & 784 & 10 & 144 & $3 ; 12$ & 5 \\
\hline
\end{tabular}




\begin{tabular}{|c|c|c|c|c|c|c|c|c|c|c|}
\hline Sample & $\begin{array}{c}1 \mathrm{H} \\
\text { freq. } \\
{[\mathrm{MHz}]}\end{array}$ & $\begin{array}{c}\mathbf{v}_{\mathbf{r}} \\
{[\mathbf{k H z}]}\end{array}$ & Experiment & $\begin{array}{c}\text { Mixing } \\
\text { time } \\
{[\mathrm{ms}]}\end{array}$ & $\begin{array}{c}\text { CP time } \\
{[\mu s]}\end{array}$ & $\mathbf{T D}_{1}$ & $\begin{array}{l}\mathrm{aq}_{1} \\
{[\mathrm{~ms}]}\end{array}$ & ns & $\begin{array}{c}\text { Total } \\
\text { time } \\
\text { [d; h] }\end{array}$ & $\begin{array}{l}\mathbf{T} \\
{ }^{\circ} \mathbf{C}\end{array}$ \\
\hline & 600 & 11 & PDSD & 150 & 800 & 872 & 12 & 272 & $7 ; 19$ & 5 \\
\hline & 800 & 11 & $\mathrm{NCA}$ & I & $600 / 3000$ & 58 & 8.1 & 1088 & $1 ; 16$ & 5 \\
\hline & 800 & 11 & NCACX & $\begin{array}{c}50 \\
\text { (PDSD) }\end{array}$ & $600 / 3000$ & 52 & 8 & 3920 & $5 ; 9$ & 5 \\
\hline & 800 & 11 & NCOCX & $\begin{array}{c}50 \\
\text { (PDSD) }\end{array}$ & $600 / 4000$ & 52 & 8 & 5472 & $7 ; 14$ & 5 \\
\hline & 800 & 11 & PDSD & 20 & 900 & 784 & 10 & 48 & $1 ; 3$ & -4 \\
\hline & 800 & 11 & PDSD & 20 & 900 & 784 & 10 & 48 & $1 ; 3$ & 15 \\
\hline \multirow[t]{2}{*}{$\mathrm{K}_{19 C A_{2 g l y c}}$} & 850 & 11 & PDSD & 500 & 800 & 960 & 10.7 & 368 & $12 ; 11$ & 5 \\
\hline & 850 & 11 & NCA & I & $800 / 2500$ & 46 & 6.1 & 800 & $1 ; 2$ & 5 \\
\hline $\mathrm{K}_{19 C A_{1,3 g l y c}}$ & 850 & 11 & PDSD & 500 & 1000 & 960 & 10.7 & 336 & $11 ; 9$ & 6 \\
\hline \multirow[t]{2}{*}{ K19 $_{\text {CYLfw }}$} & 600 & 11 & PDSD & 50 & 1200 & 600 & 7 & 256 & $3 ; 19$ & 7 \\
\hline & 600 & 11 & PDSD & 500 & 1200 & 600 & 7 & 368 & $6 ; 13$ & 7 \\
\hline
\end{tabular}

* PAIN-CP-conditions: $73.4 \mathrm{kHz}$ on ${ }^{1} \mathrm{H}$ (pl13); $37.1 \mathrm{kHz}$ on ${ }^{13} \mathrm{C}$ (pl14); $27.3 \mathrm{kHz}$ on ${ }^{15} \mathrm{~N}$ (pl15). 


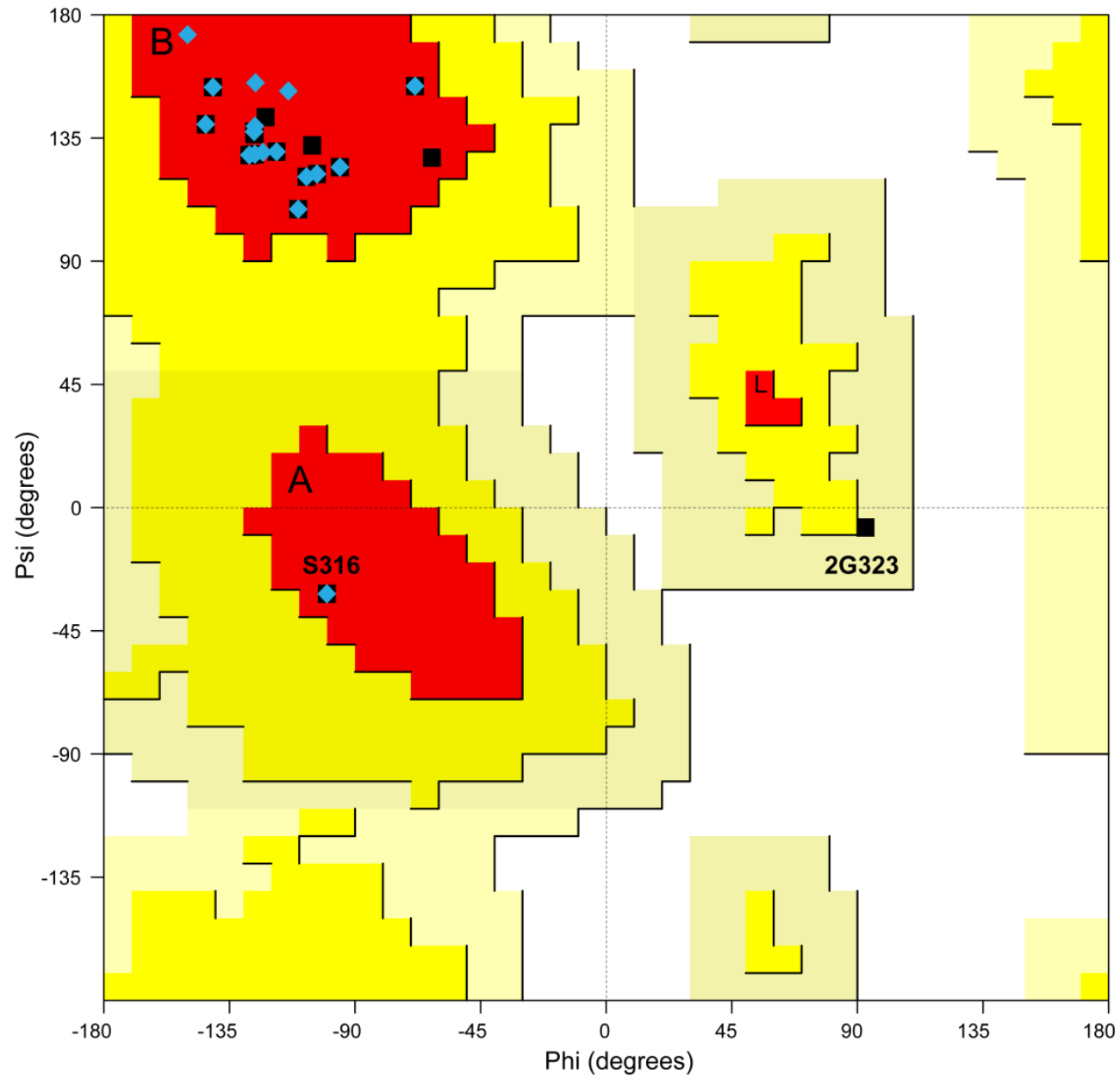

Figure A1. Ramachandran plot. Depicted are the TALOS+ dihedral angle (Phi, Psi) predictions for the set 1 (blue diamonds) and set 2 (black boxes) core residues of K19 PHF. The red, yellow and light yellow colors represent the favored, allowed and generously allowed regions, respectively $(\mathrm{B}=\beta$-sheet; $\mathrm{A}=\alpha$-helix; $\mathrm{L}=$ left-handed helix). Except for 2G323, all predictions are located in the allowed regions. Predictions for S316 dihedral angles are in both sets in the helical region "A". $(227,228)$ 


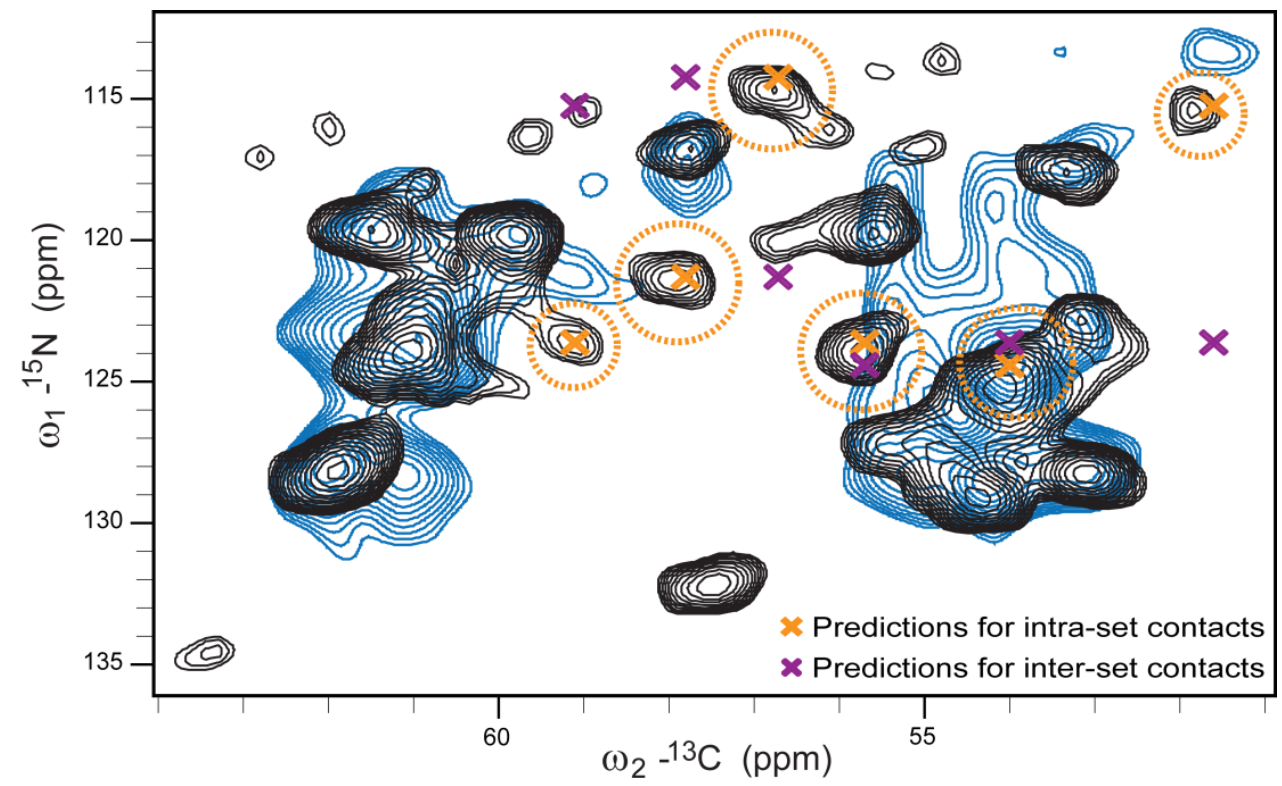

Figure A2. Predictions for the intermolecular DSB formation compared with experimental data. Overlay of a $2 \mathrm{D}\left[{ }^{15} \mathrm{~N},{ }^{13} \mathrm{C}\right]$-PAIN-CP correlation spectrum (blue; $\mathrm{t}_{\text {mix }}=5 \mathrm{~ms}$ ) of $\mathrm{K} 19_{1: 1}$ with a $2 \mathrm{D}\left[{ }^{15} \mathrm{~N},{ }^{13} \mathrm{C}\right]-\mathrm{NCA}$ spectrum (black) of uK19 (as in Figure 21). All resonances in the NCA spectrum belonging to the doubled region (K321S324 / 2K321-2S324) do not appear in the PAIN-CP spectrum (orange circles). On top of the spectra predictions of the doubled resonances are plotted for ${ }^{15} \mathrm{~N}(\mathrm{i})-{ }^{13} \mathrm{C}(\mathrm{i})$ intra-set contacts (orange crosses) and inter-set contacts (purple crosses) as would be expected for the formation of an intra-sheet DSB (as in Figure 23). 


\subsection{Pulse programs}

\subsubsection{INEPT-CC-TOBSY (Insensitive Nuclei Enhancement by} Polarization Transfer- ${ }^{13} \mathrm{C}-{ }^{13} \mathrm{C}$-Total Through-Bond-Correlation Spectroscopy)

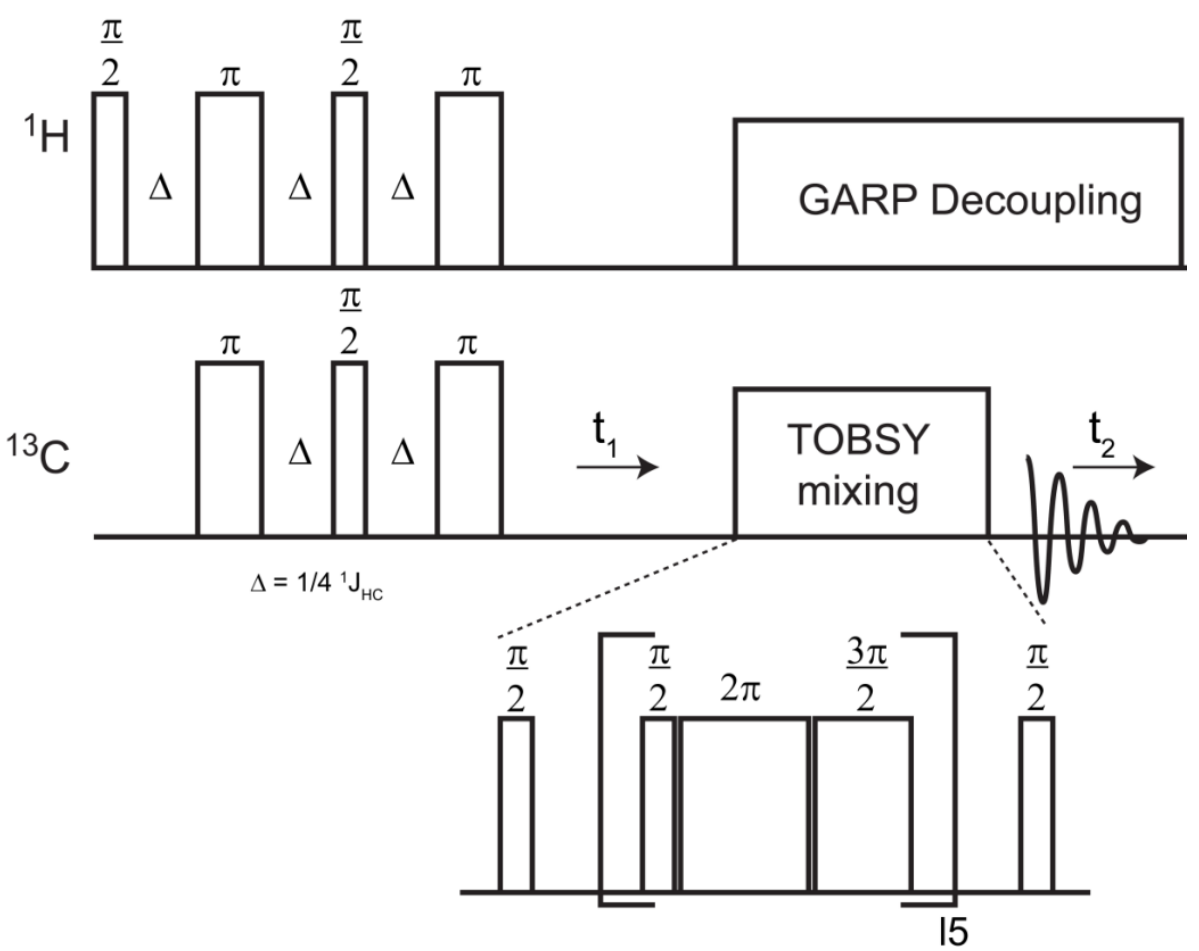

Figure A3. INEPT-CC-TOBSY pulse sequence $(68,69) . t_{1}=$ indirect dimension; $t_{2}=$ direct dimension.

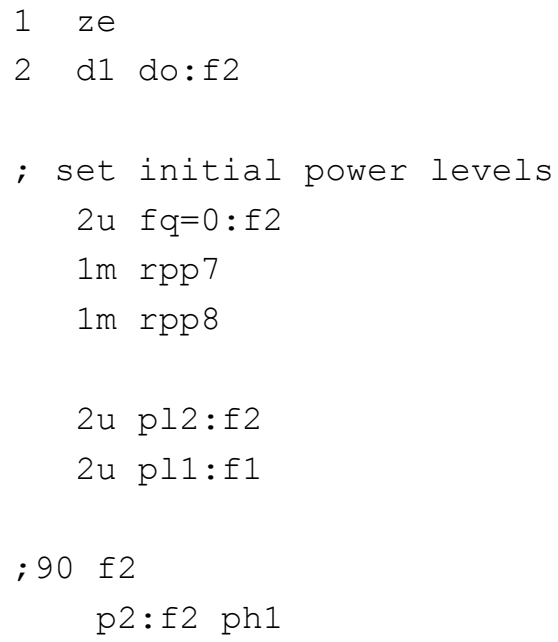




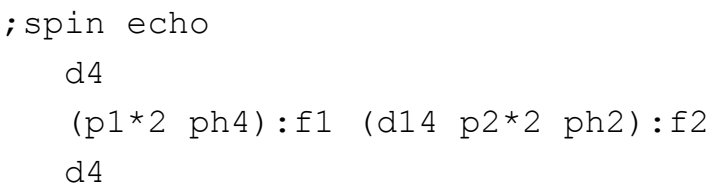




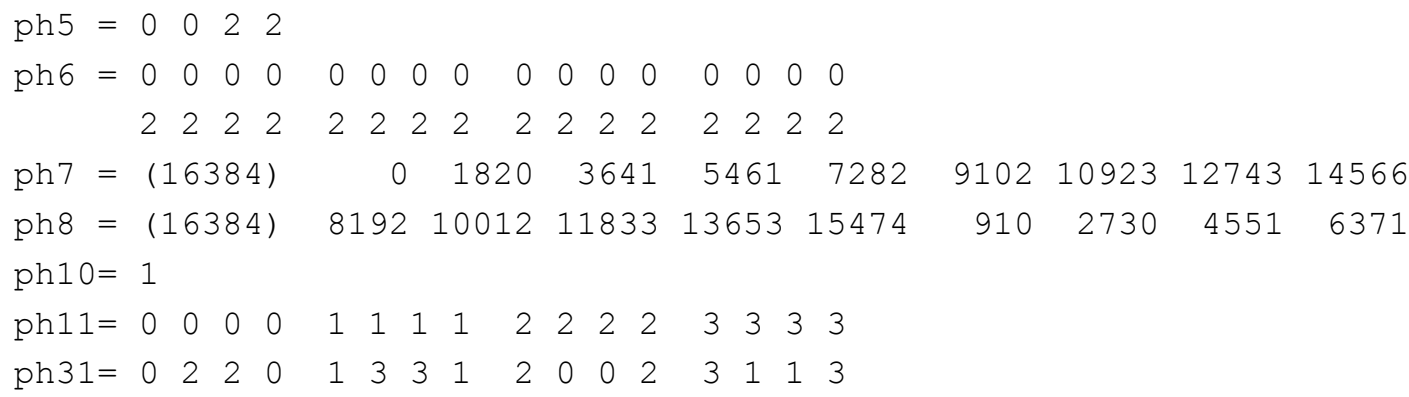




\subsubsection{DREAM (Dipolar Recoupling Enhancement through Amplitude Modulation)}

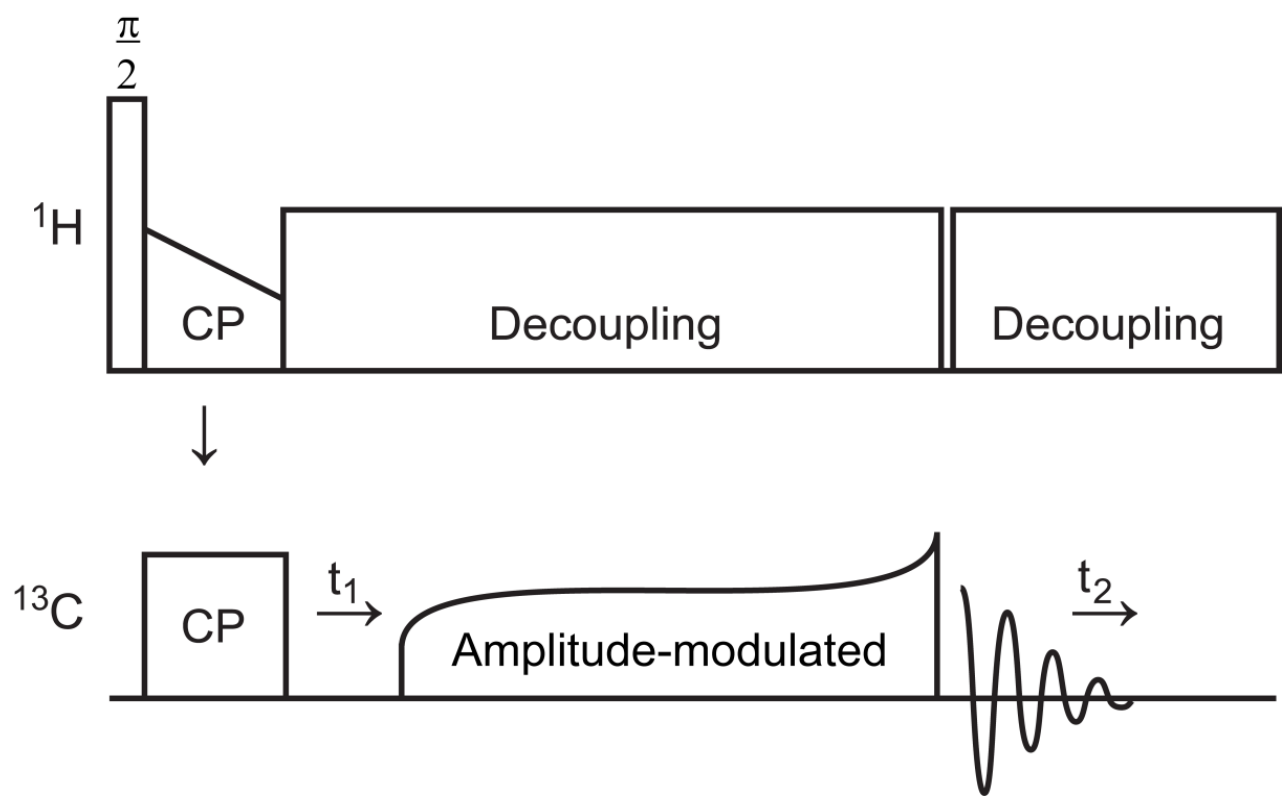

Figure A4. DREAM (Dipolar Recoupling Enhancement through Amplitude Modulation) pulse sequence (66). $\mathrm{CP}=$ cross polarization; $\mathrm{t}_{1}=$ indirect dimension; $\mathrm{t}_{2}=$ direct dimension.

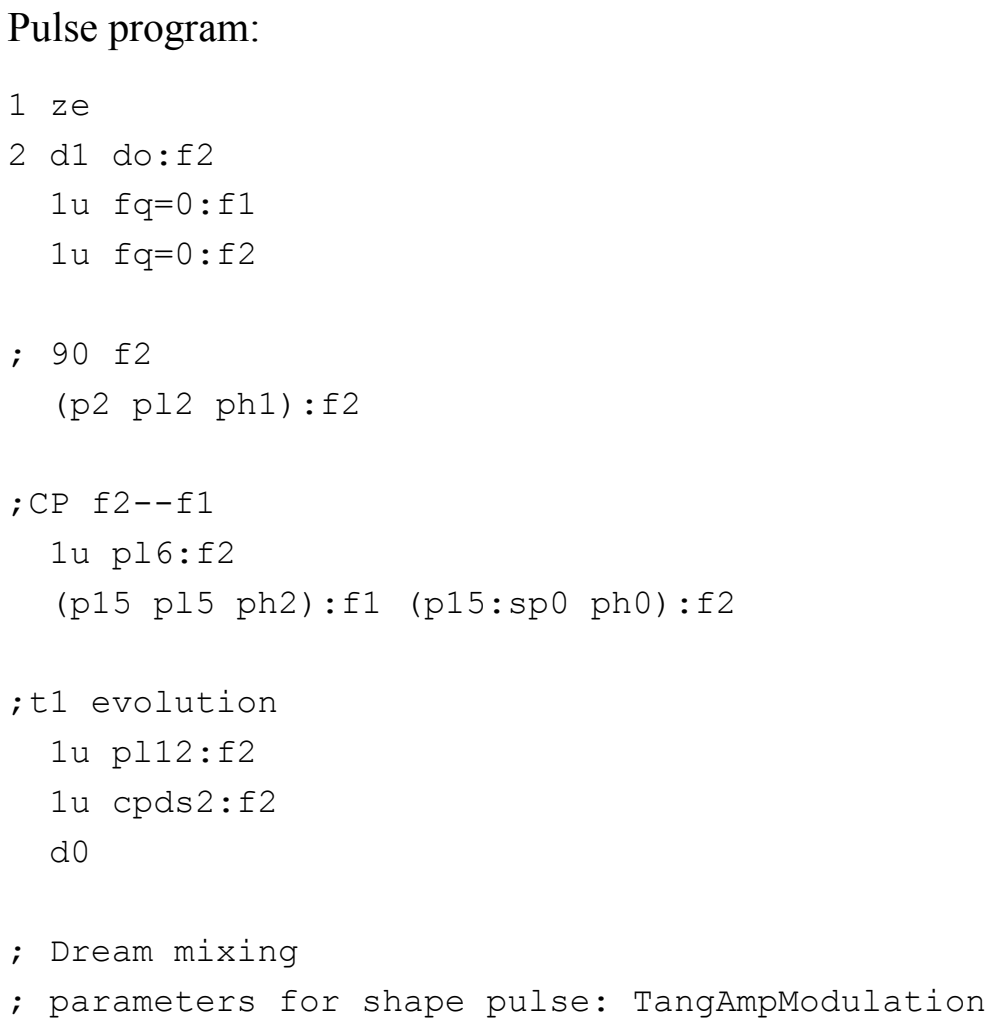




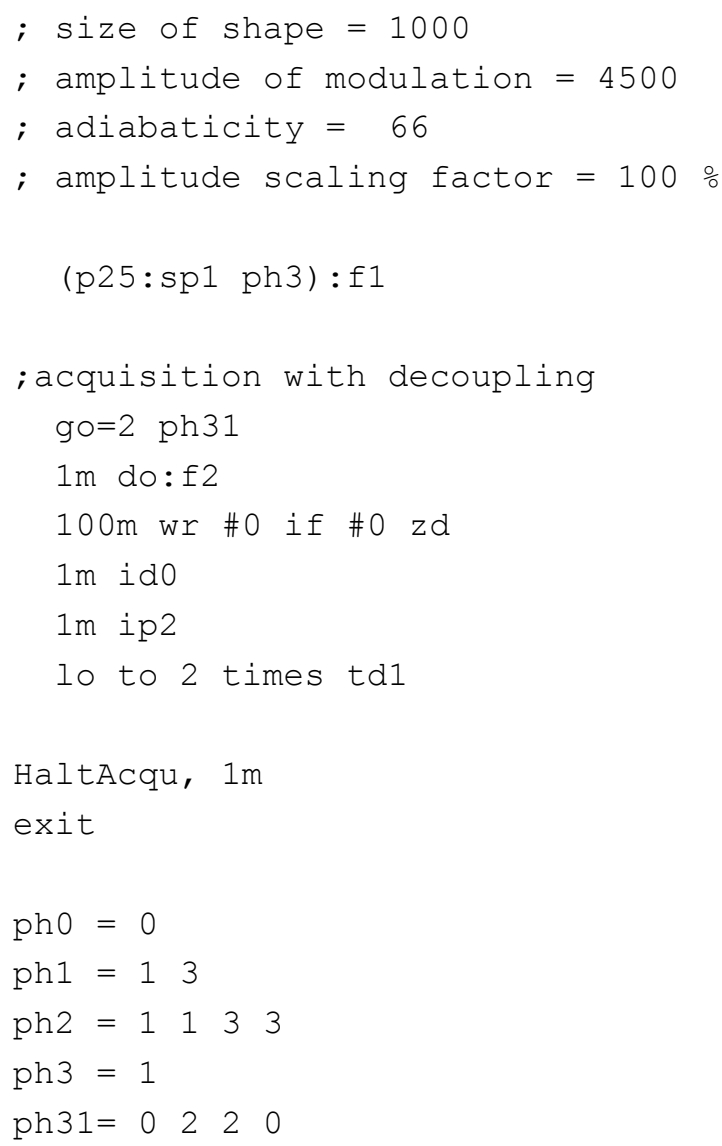




\subsubsection{PAIN-CP (Proton Assisted Insensitive Nuclei Cross}

\section{Polarization)}

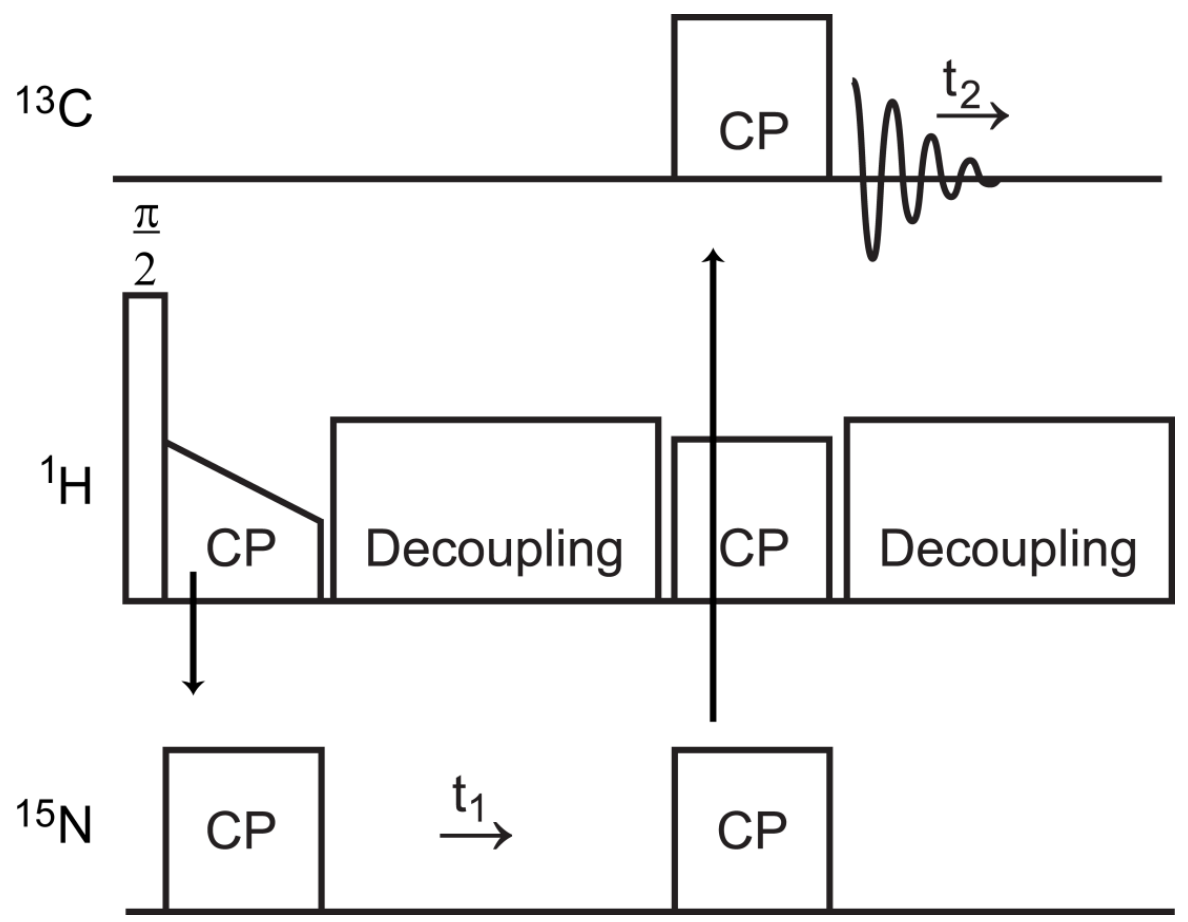

Figure A5. PAIN-CP (Proton Assisted Insensitive Nuclei Cross Polarization) pulse sequence (88). CP $=$ cross polarization; $\mathrm{t}_{1}=$ indirect dimension; $\mathrm{t}_{2}=$ direct dimension

Pulse program:

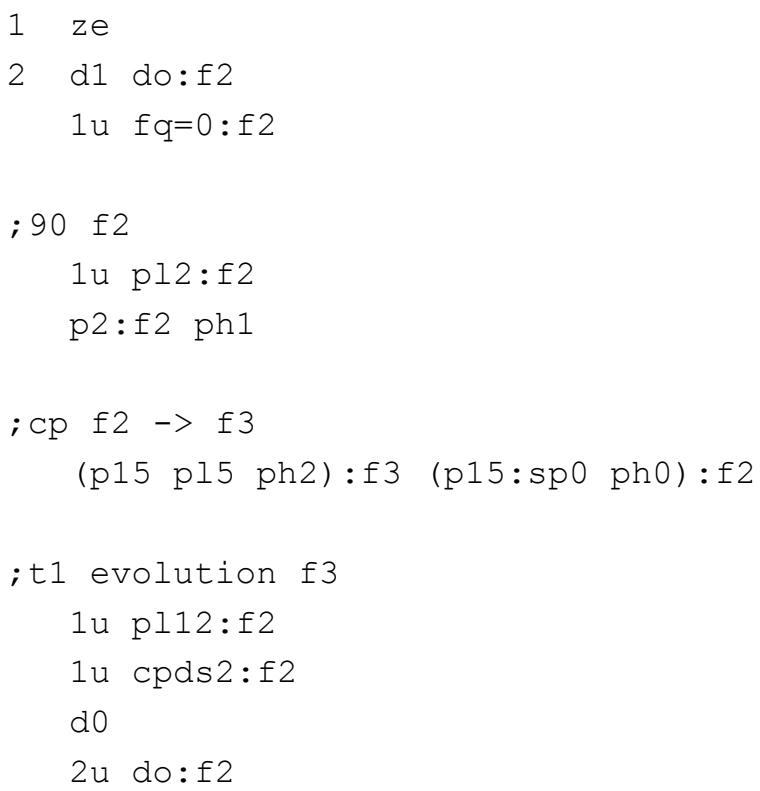




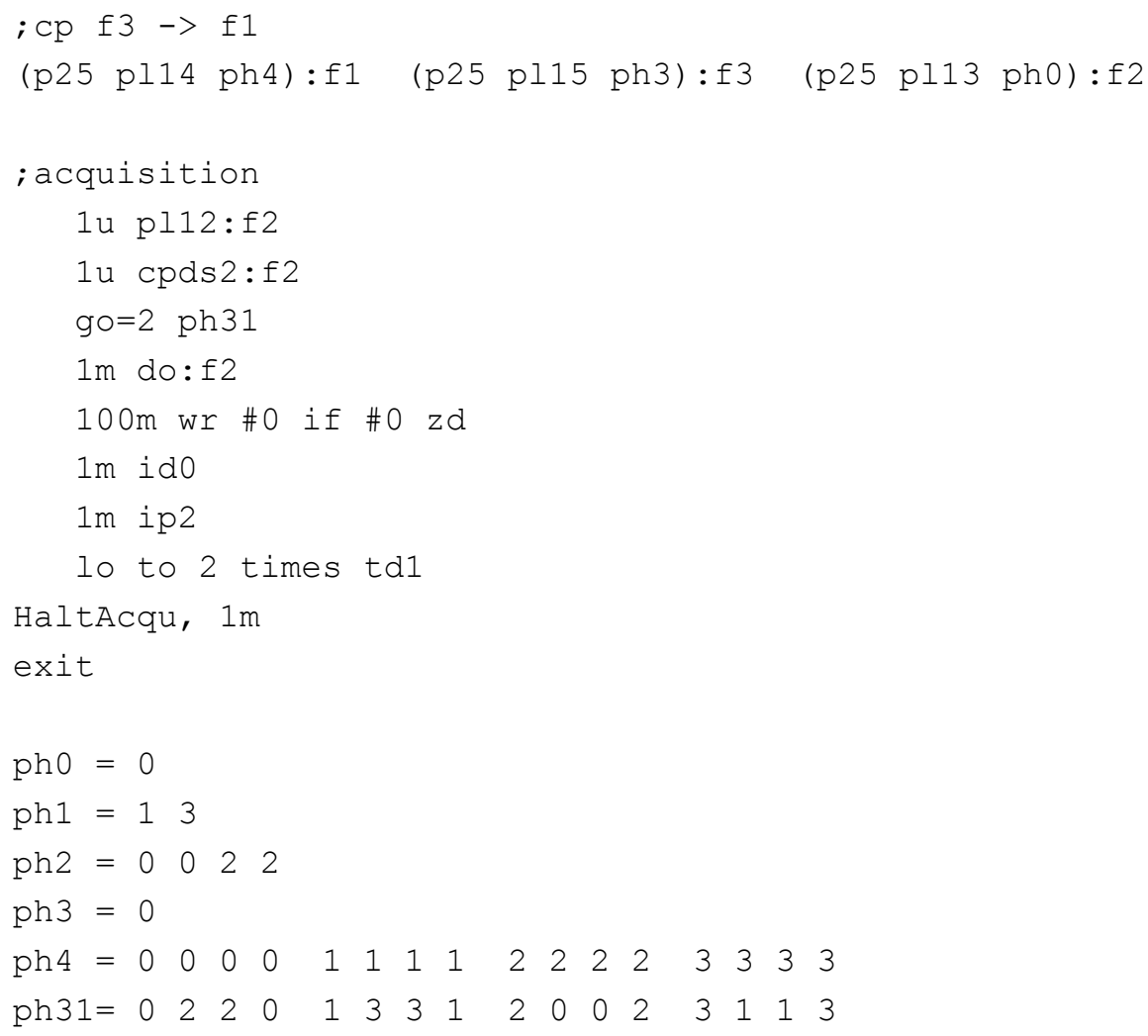


6.2.4 PDSD (Proton Driven Spin Diffusion)

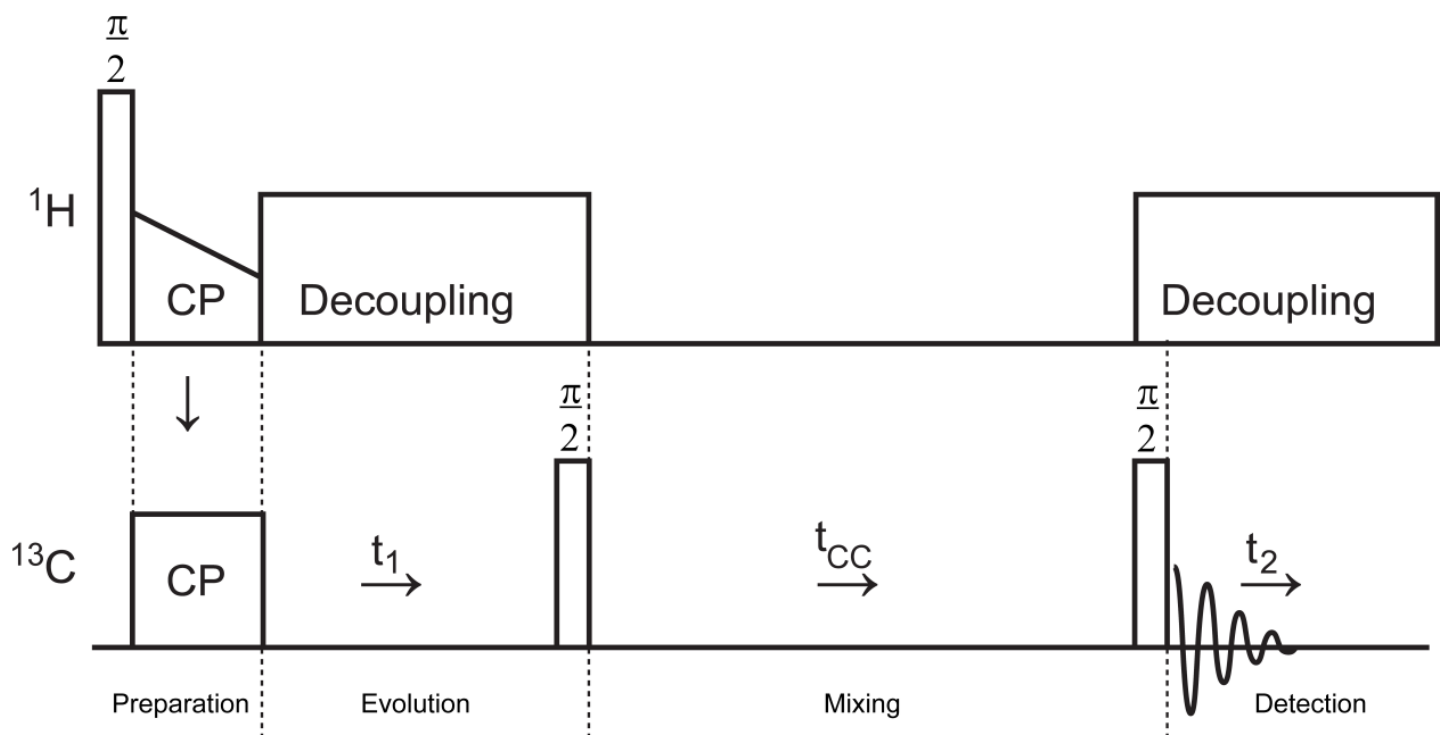

Figure A6. PDSD pulse sequence (63). $\mathrm{CP}=$ cross polarization; $\mathrm{t}_{1}=$ indirect dimension; $\mathrm{t}_{2}=$ direct dimension; $\mathrm{t}_{\mathrm{CC}}=$ ${ }^{13} \mathrm{C}-{ }^{13} \mathrm{C}$ mixing time.

Pulse program:
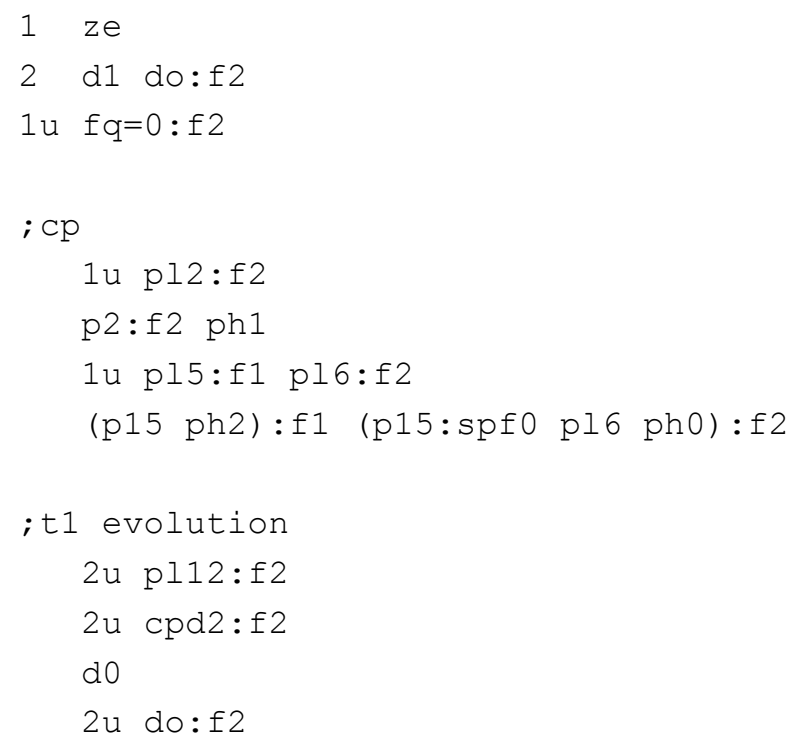

; proton-driven spin diffusion

lu pl1:f1

$\mathrm{p} 1: \mathrm{f} 1 \mathrm{ph} 3$

d11

$\mathrm{p} 1: \mathrm{f} 1 \mathrm{ph} 4$ 


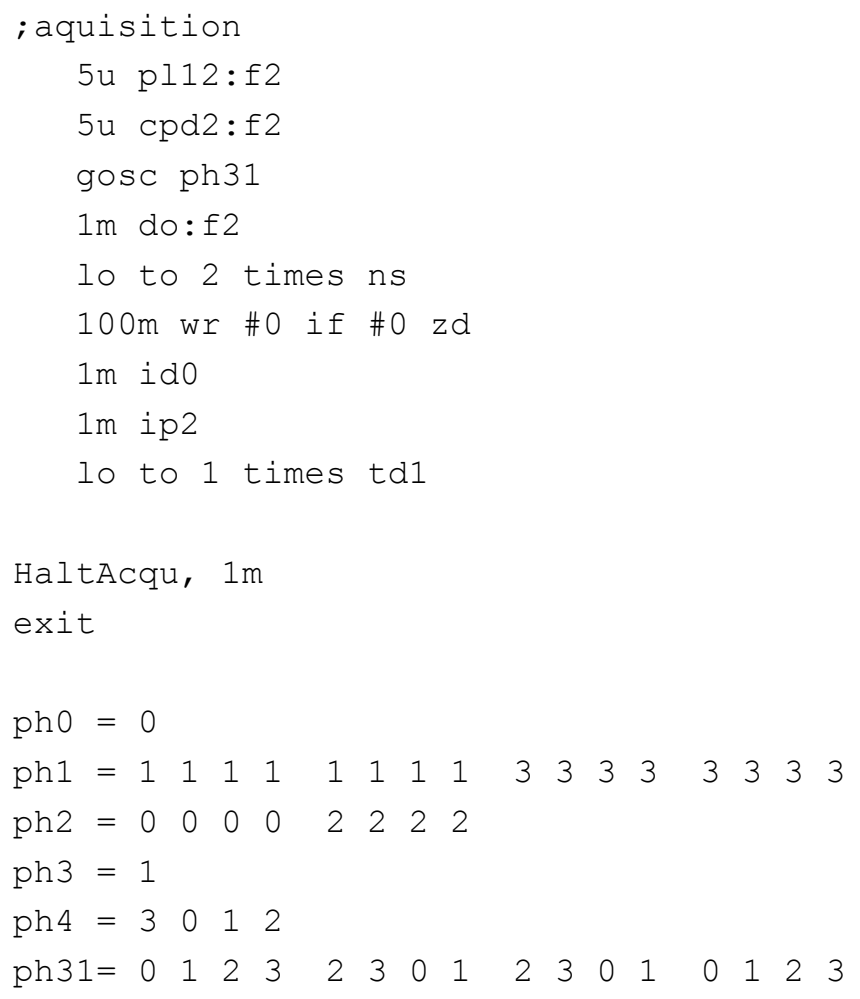


6.2.5 DCP (Double Cross Polarization: NCA/ NCO)

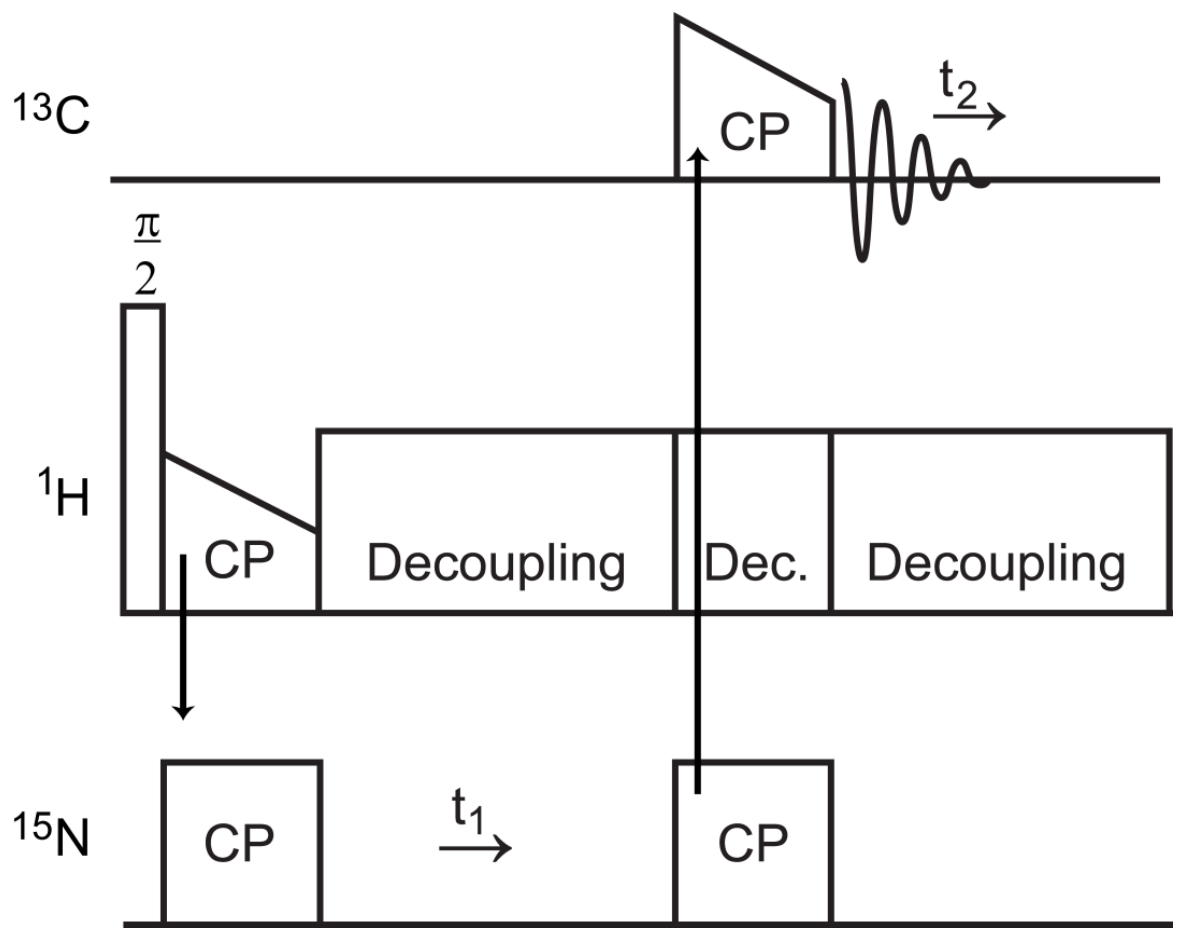

Figure A7. DCP pulse sequence (62). $\mathrm{CP}=$ cross polarization; $\mathrm{t}_{1}=$ indirect dimension; $\mathrm{t}_{2}=$ direct dimension; Dec. $=$ Decoupling.

Pulse program:

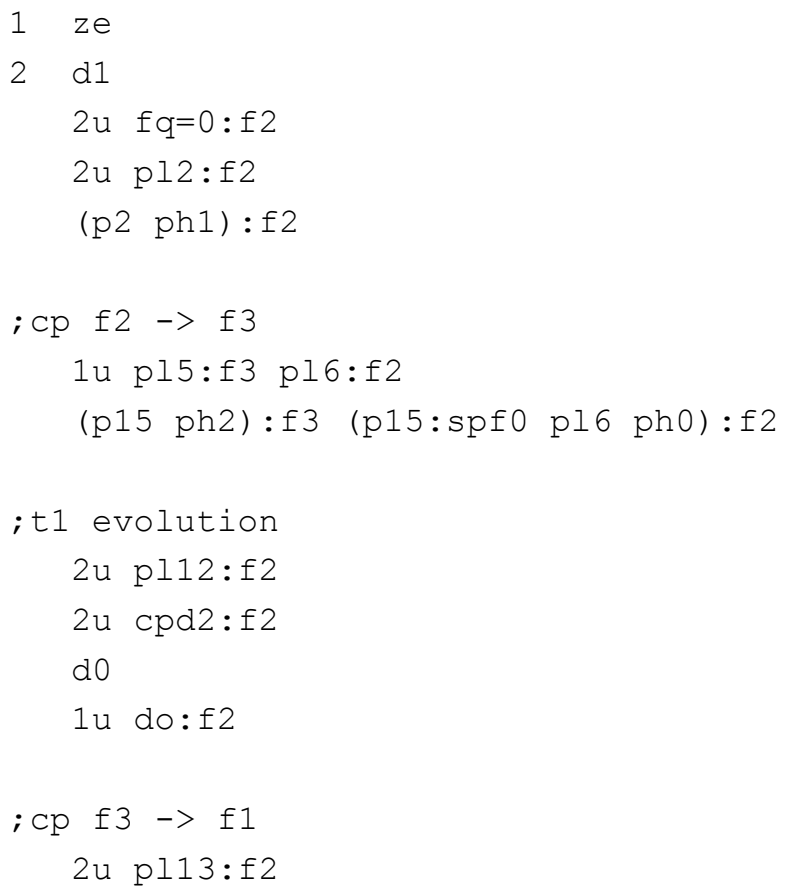




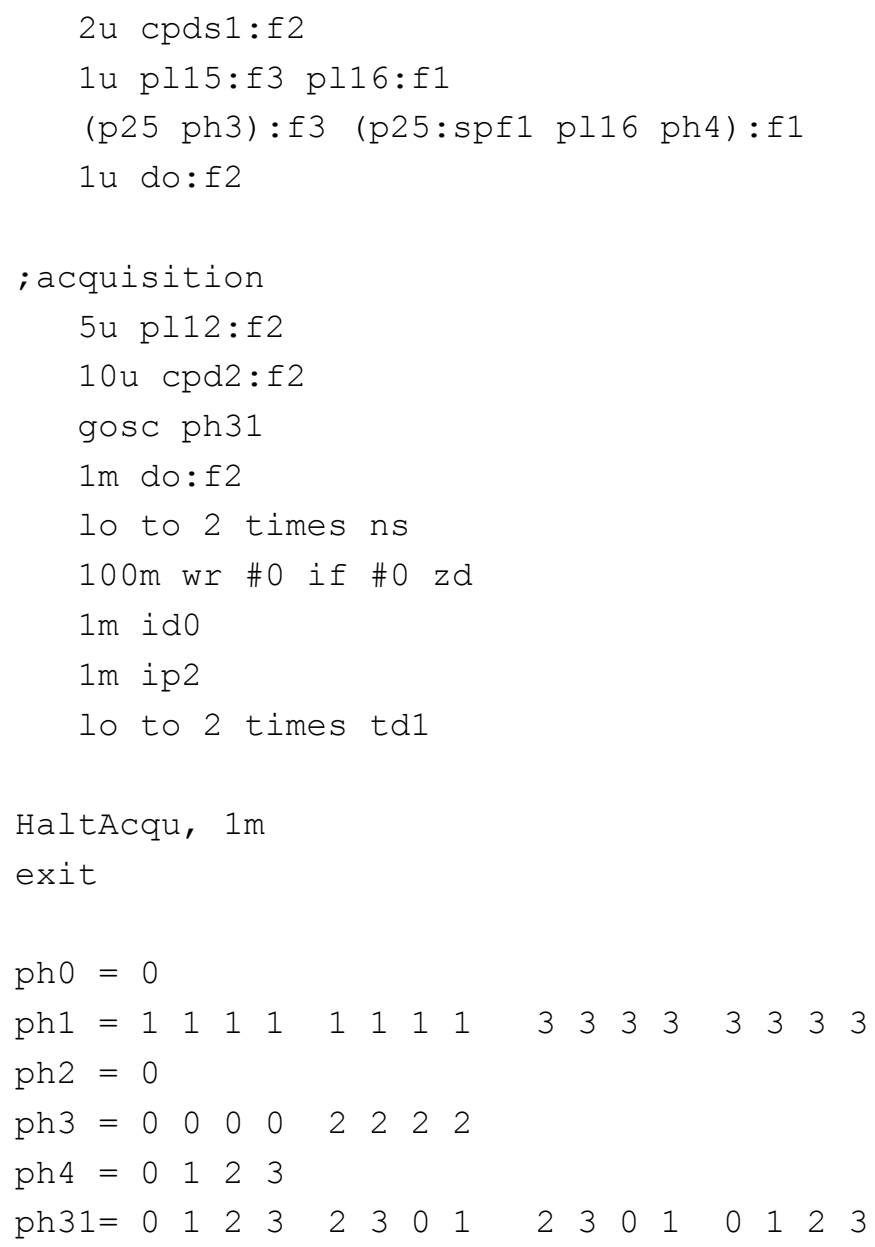




\subsubsection{NCC experiments (NCACX/ NCOCX)}

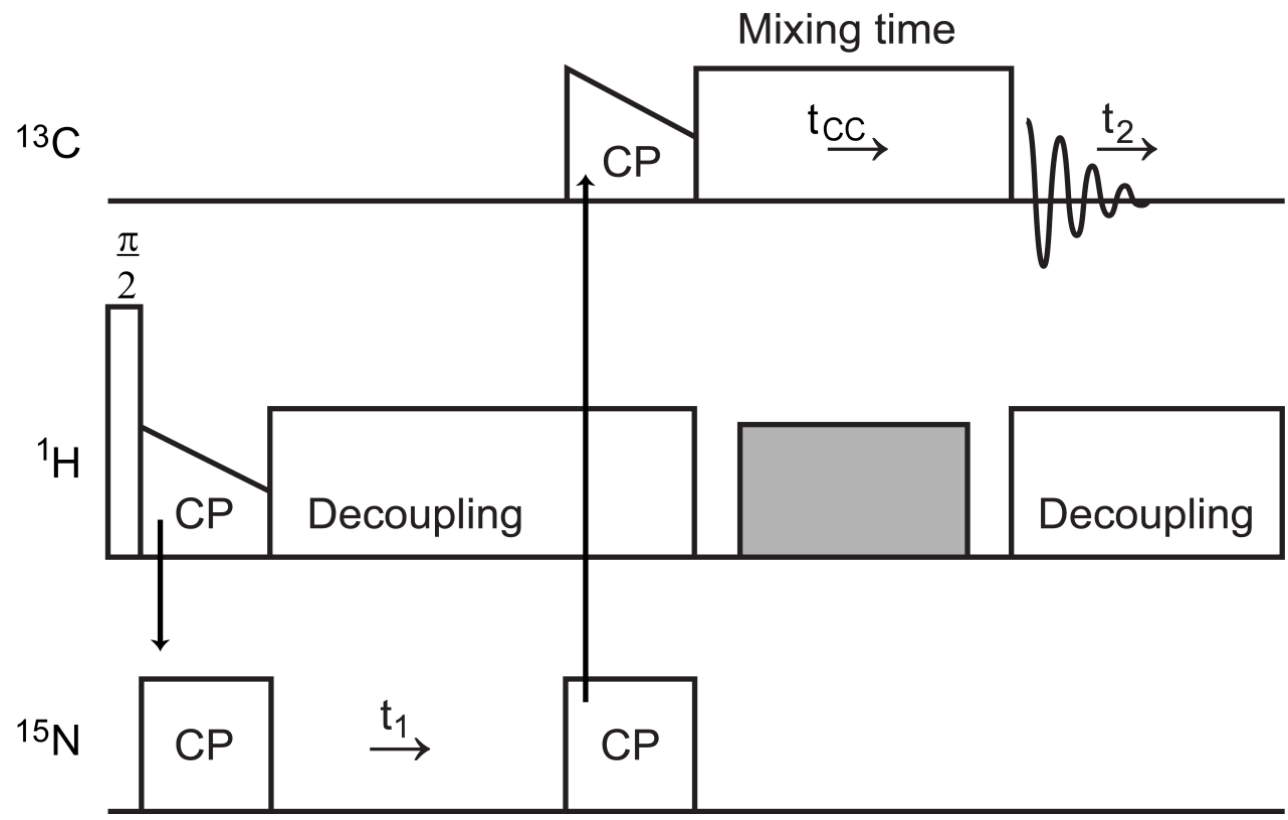

Figure A8. NCC pulse sequence $(62,63,65,66)$. The NCA/ NCO pulse sequence is combined with a ${ }^{13} \mathrm{C}-{ }^{13} \mathrm{C}$ mixing $\left(t_{C C}\right)$ using PDSD, DREAM, or DARR sequences, respectively. For the latter, a ${ }^{1} \mathrm{H}_{-}{ }^{13} \mathrm{C}-$ recoupling is achieved by proton r.f. irradiation during the $\mathrm{t}_{\mathrm{CC}}$-mixing (gray box). $\mathrm{CP}=$ cross polarization; $\mathrm{t}_{1}=$ indirect dimension; $\mathrm{t}_{2}=$ direct dimension.

Pulse program using DARR for ${ }^{13} \mathrm{C}-{ }^{13} \mathrm{C}$ mixing:

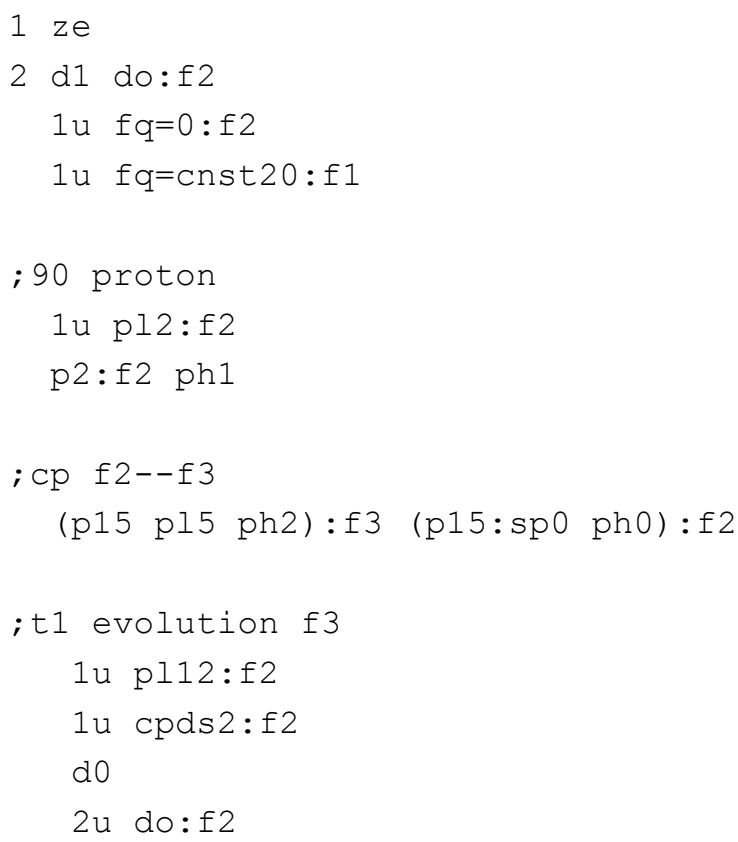




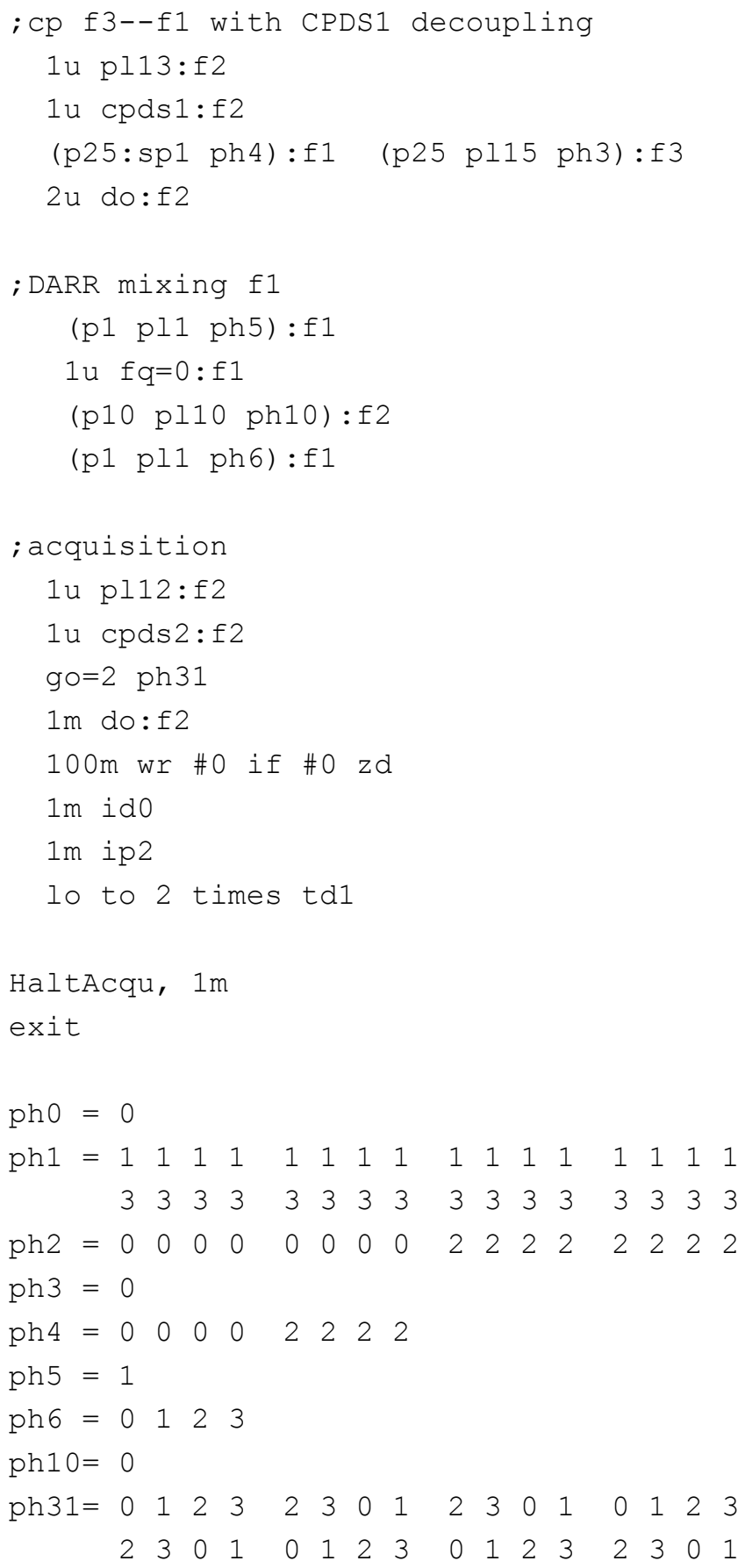




\subsection{7 $\mathrm{CHHC}$}

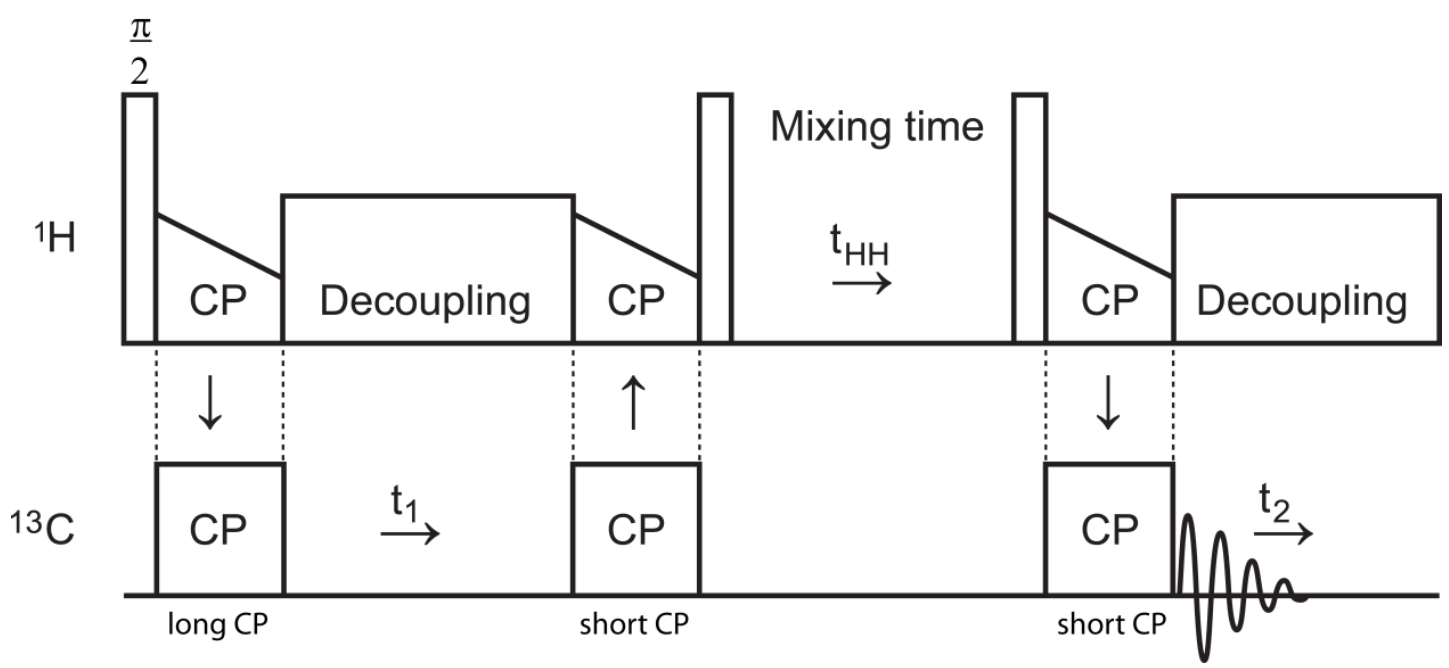

Figure A9. CHHC pulse sequence (81). $\mathrm{CP}=$ cross polarization; $\mathrm{t}_{1}=$ indirect dimension; $\mathrm{t}_{2}=$ direct dimension; $\mathrm{t}_{\mathrm{HH}}$ $={ }^{1} \mathrm{H}-{ }^{1} \mathrm{H}$ mixing time.

Pulse program:

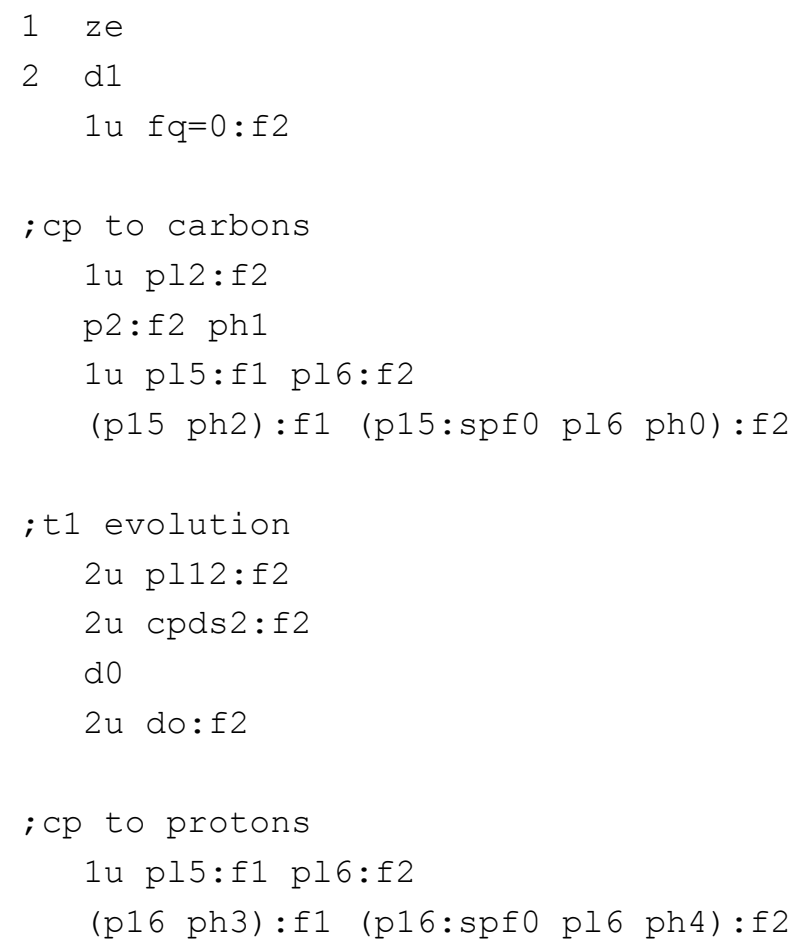

;mixing protons

1 u pl2:f2

$\mathrm{p} 2: \mathrm{f} 2 \mathrm{ph} 5$ 


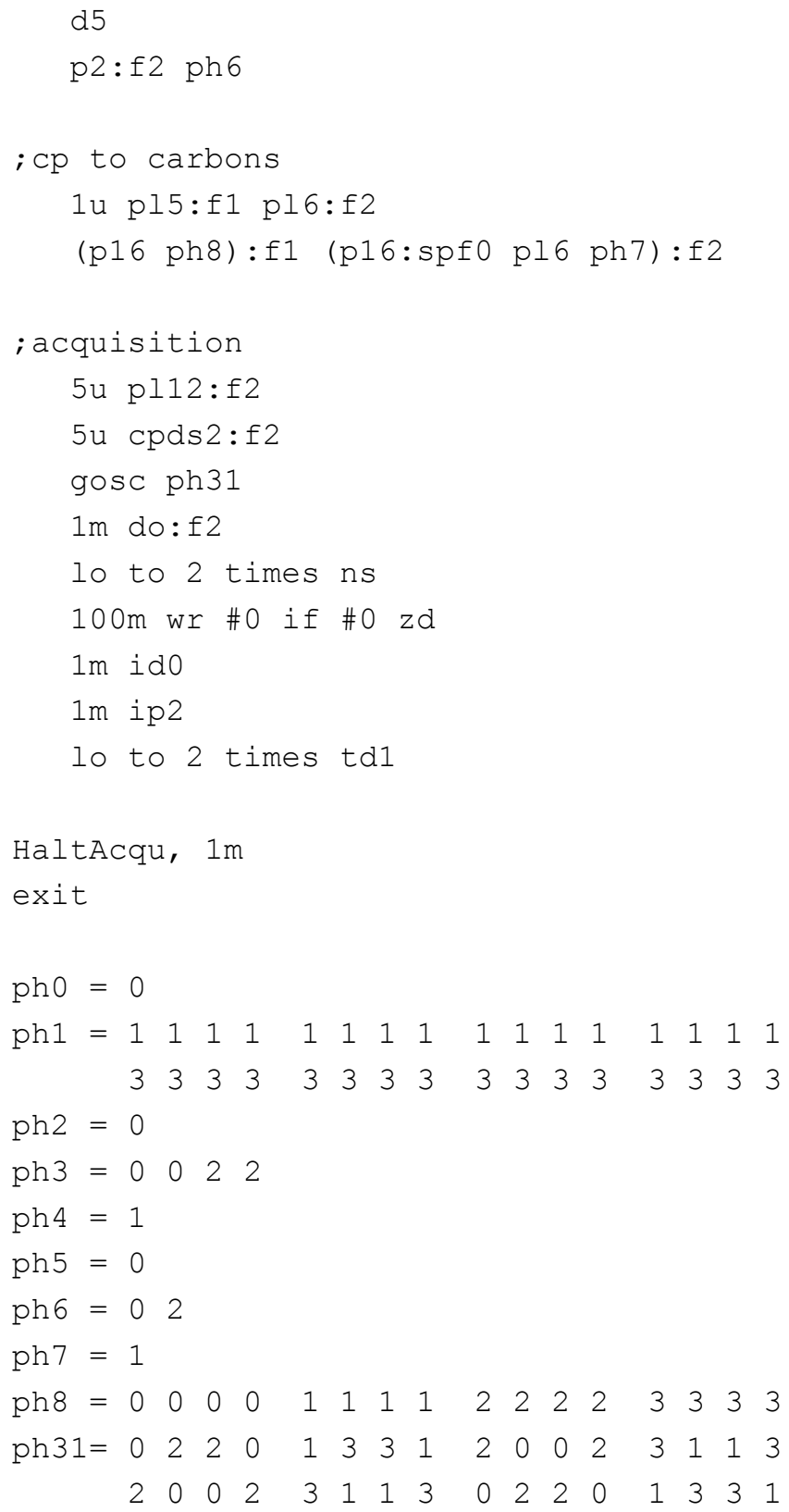




\subsection{Spectra that were used for the assignment process of K19 PHF and K19CA PHF}

6.3.1 uK19

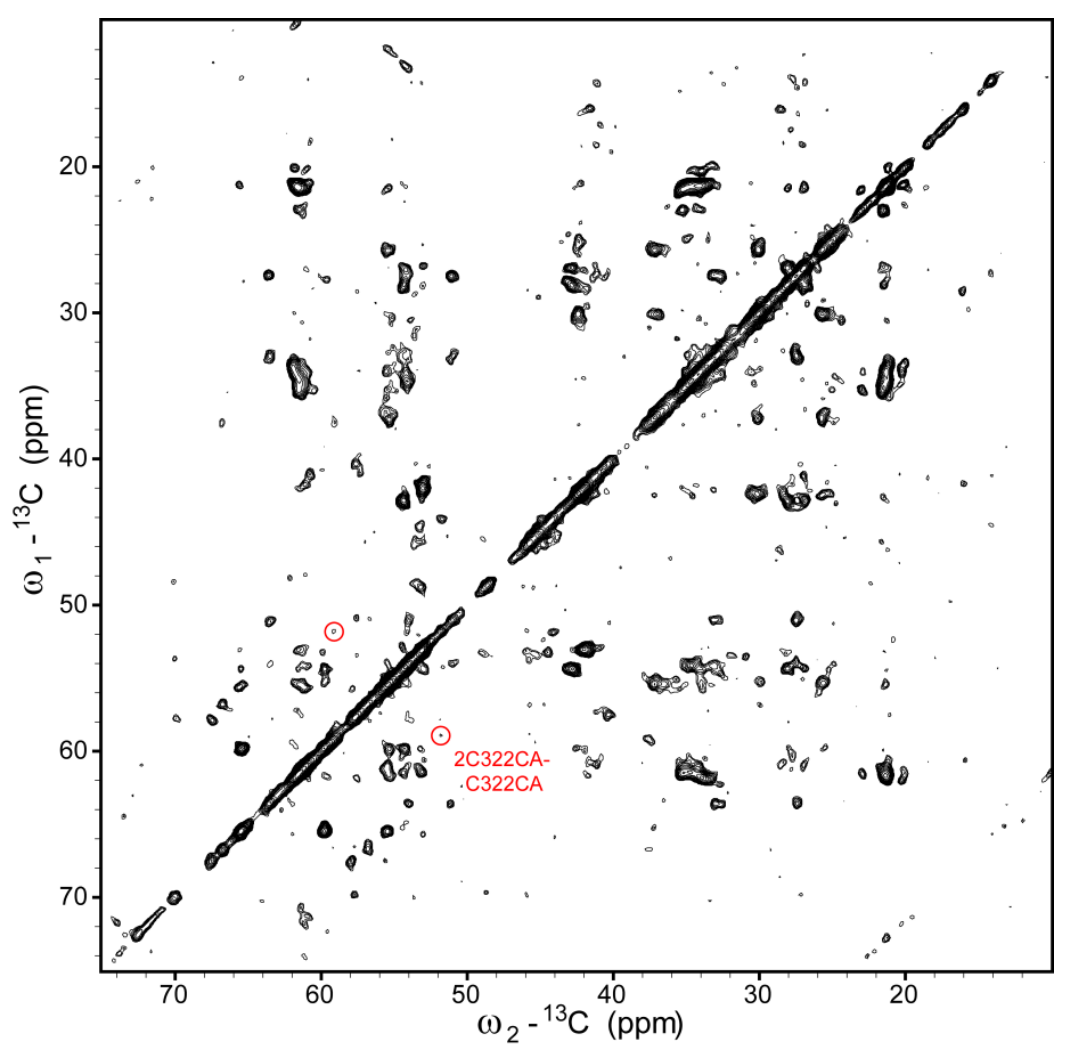

Figure A10. CHHC spectrum of uK19 PHF. Encircled in red is the CA-CA cross peak between the two cysteines, C322 and 2C322, excluding chemical exchange due to the short time scale $(250 \mu \mathrm{s})$. Experimental details are given in Table A1. 


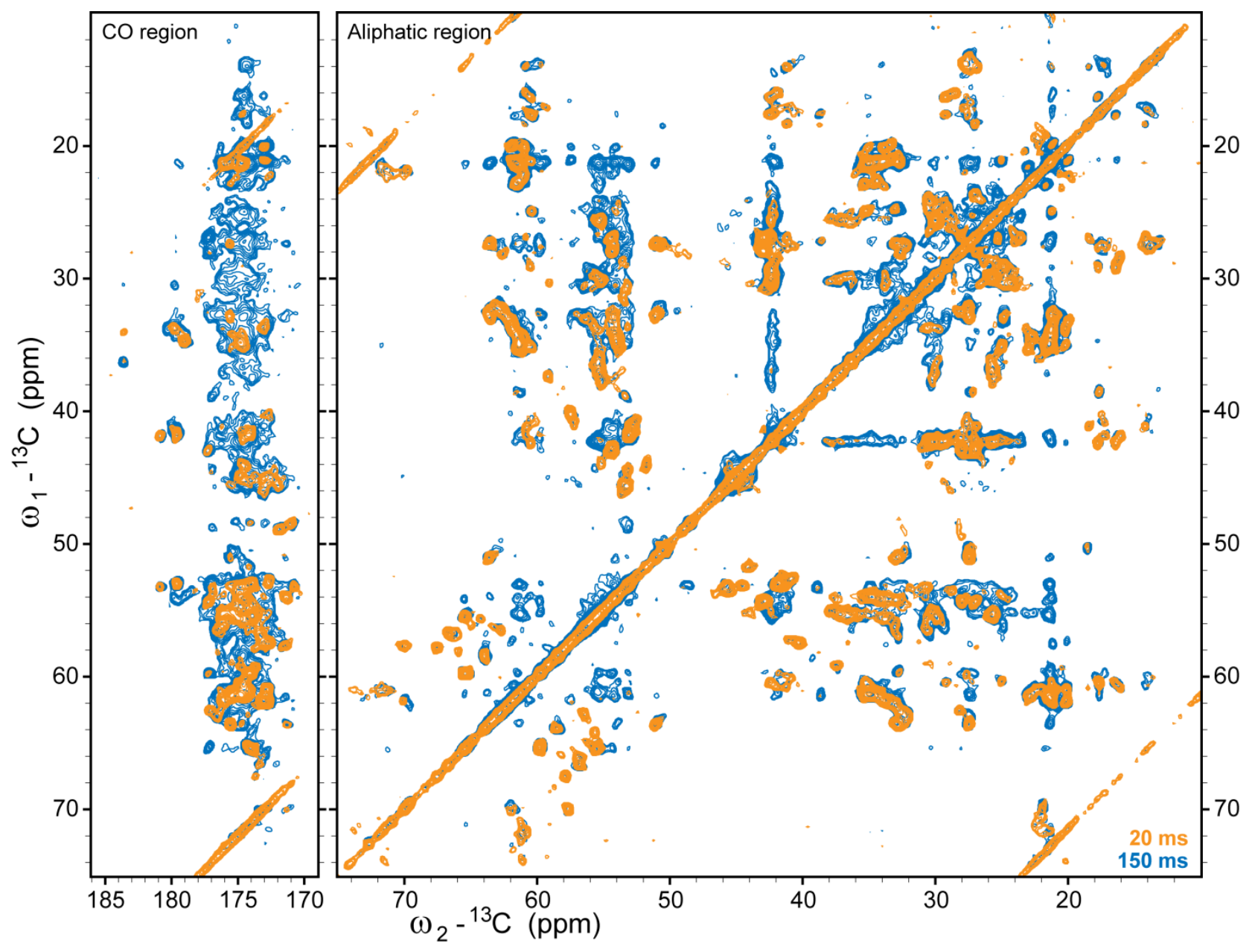

Figure A11. PDSD spectra of uK19 PHF recorded on an $850 \mathrm{MHz}$ spectrometer. ${ }^{13} \mathrm{C}-{ }^{13} \mathrm{C}$-mixing time of $20 \mathrm{~ms}$ (orange) and $150 \mathrm{~ms}$ (blue). Further experimental details are given in Table A1. 


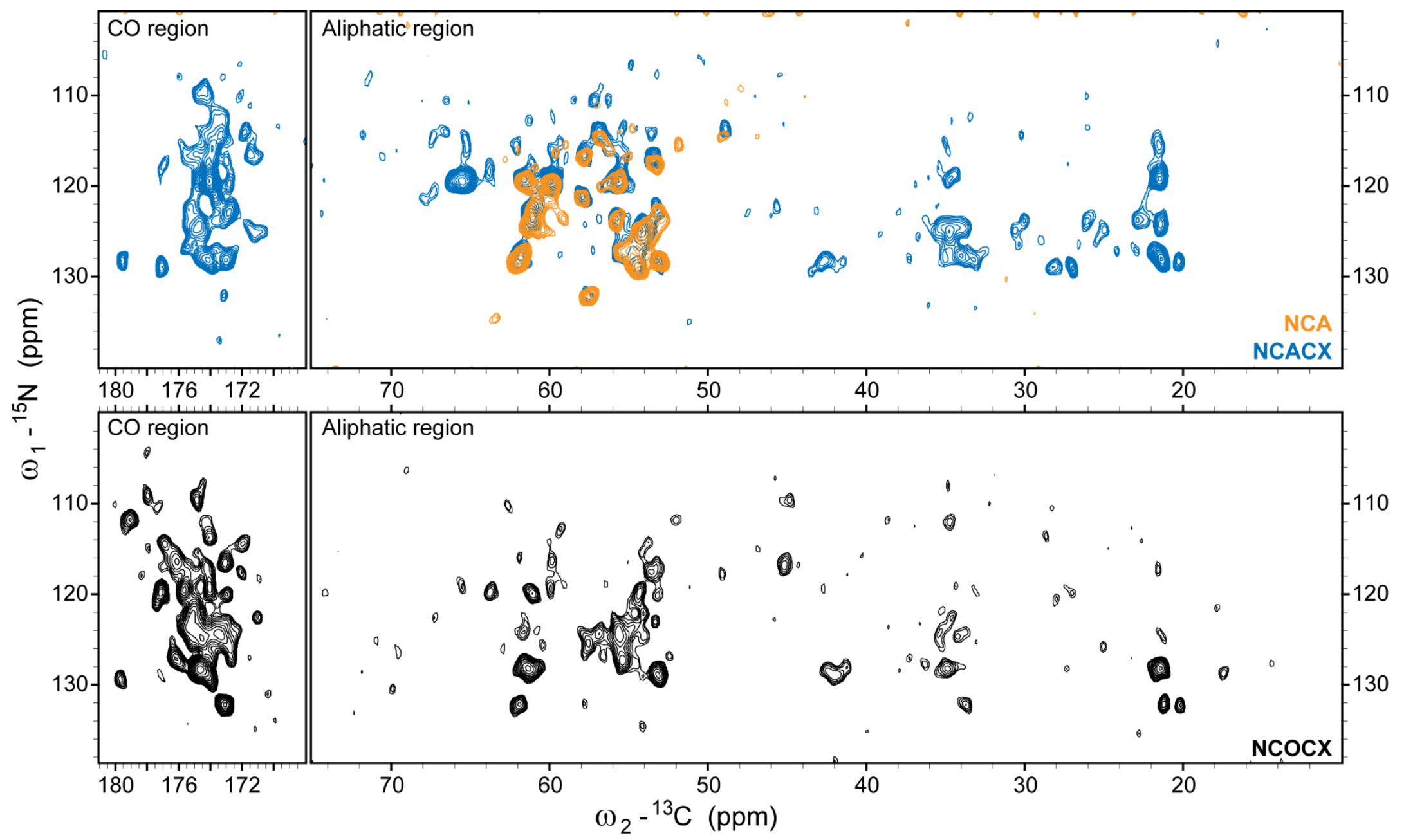

Figure A12. NC-spectra of uK19 PHF. NCACX (blue), NCA (orange) and NCOCX (black). Experimental details are given in Table A1. 
$6.3 .2\left[1,3-{ }^{13} \mathrm{C}\right]$-glycerol labeled $\mathrm{K} 19$

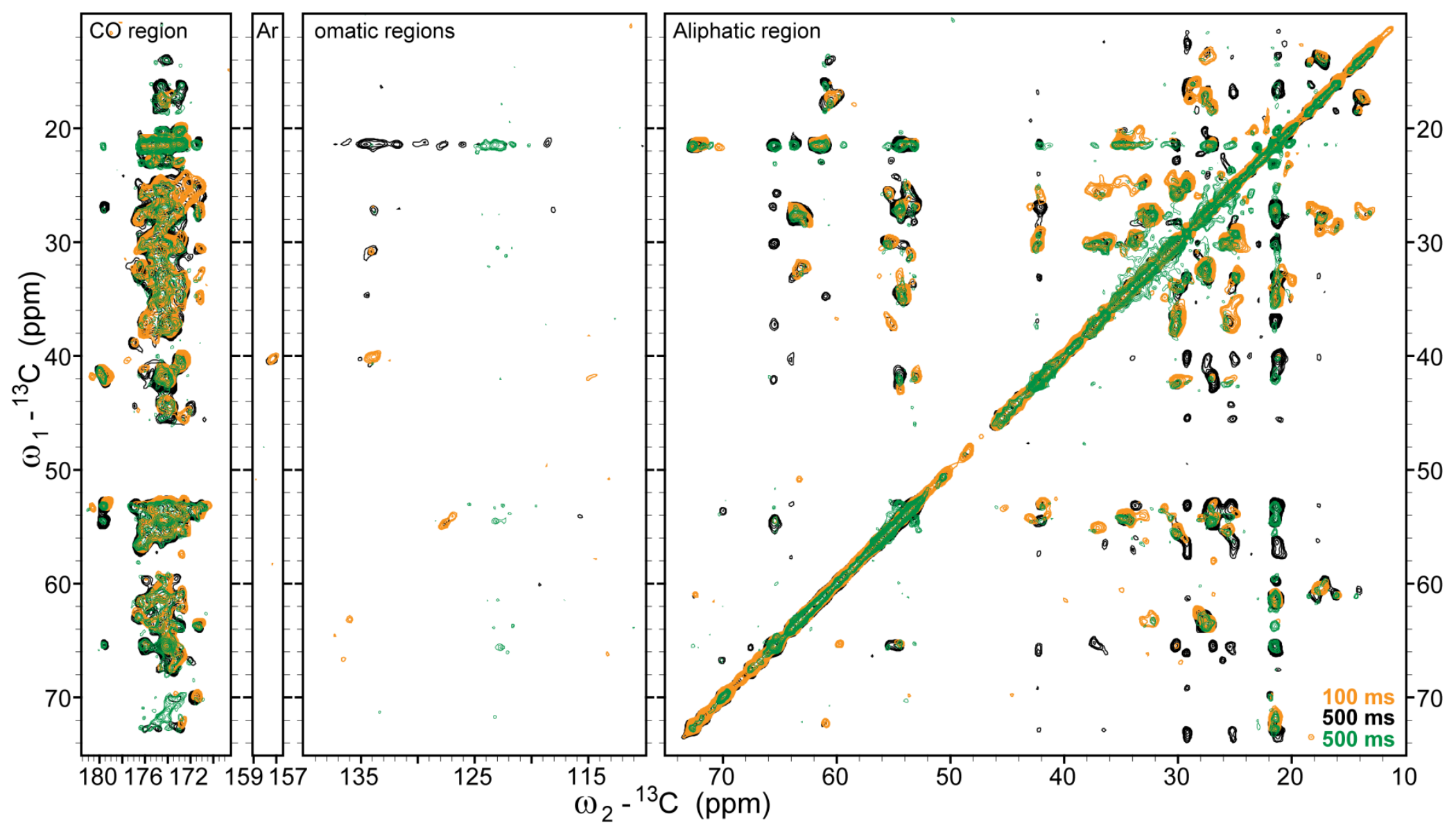

Figure A13. PDSD spectra of K19 1 ,3glyc $\mathbf{P H F} .{ }^{13} \mathrm{C}-{ }^{13} \mathrm{C}$-mixing time of $100 \mathrm{~ms}$ (orange) and $500 \mathrm{~ms}$ (black, green), recorded on a $600 \mathrm{MHz}$ spectrometer (orange, black) and $850 \mathrm{MHz}$ instrument (green). Further experimental details are given in Table A1. 


\subsection{3 $\left[2-{ }^{13} \mathrm{C}\right]$-glycerol labeled K19}

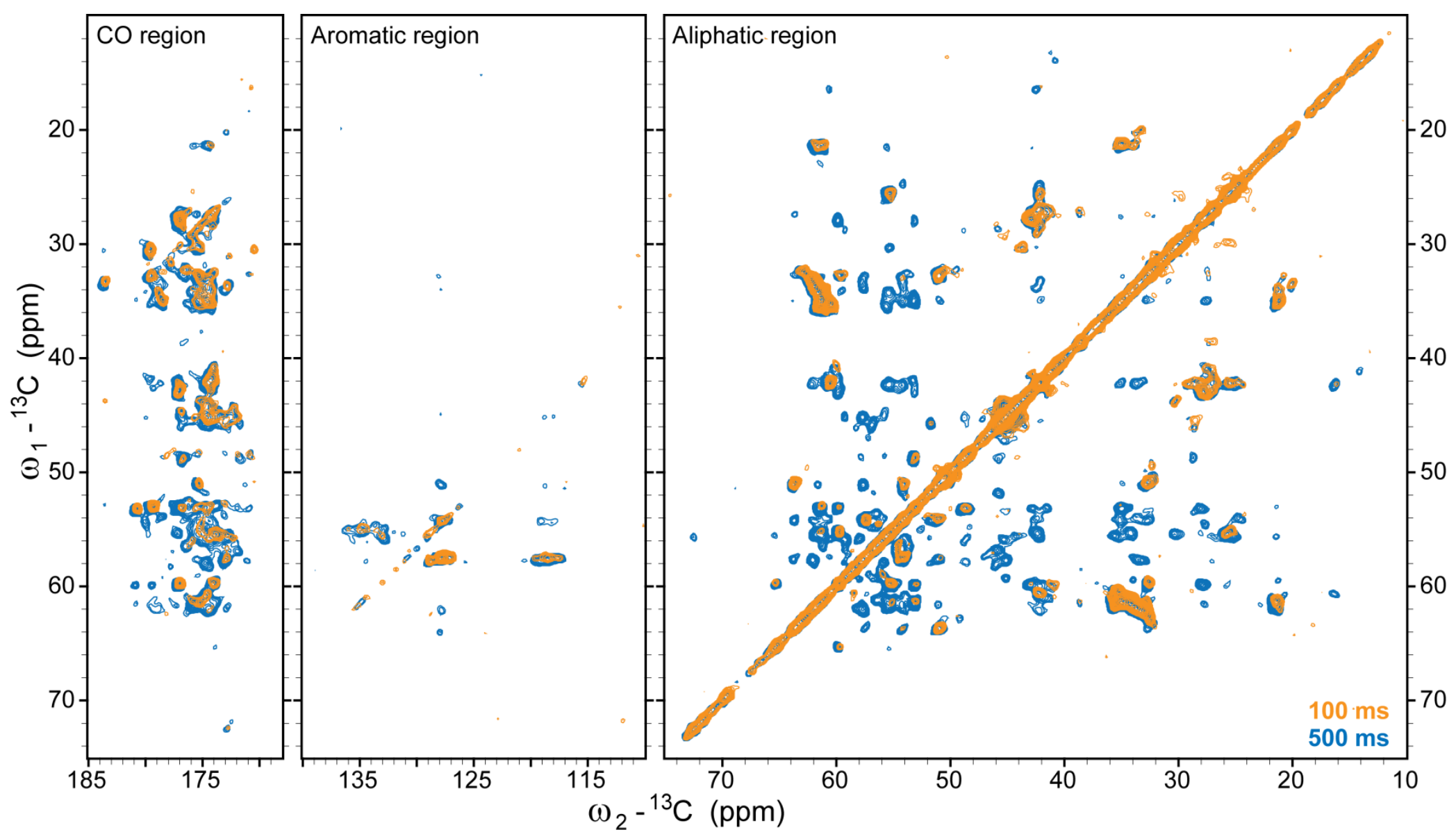

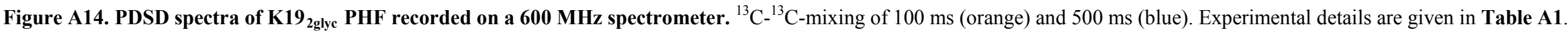




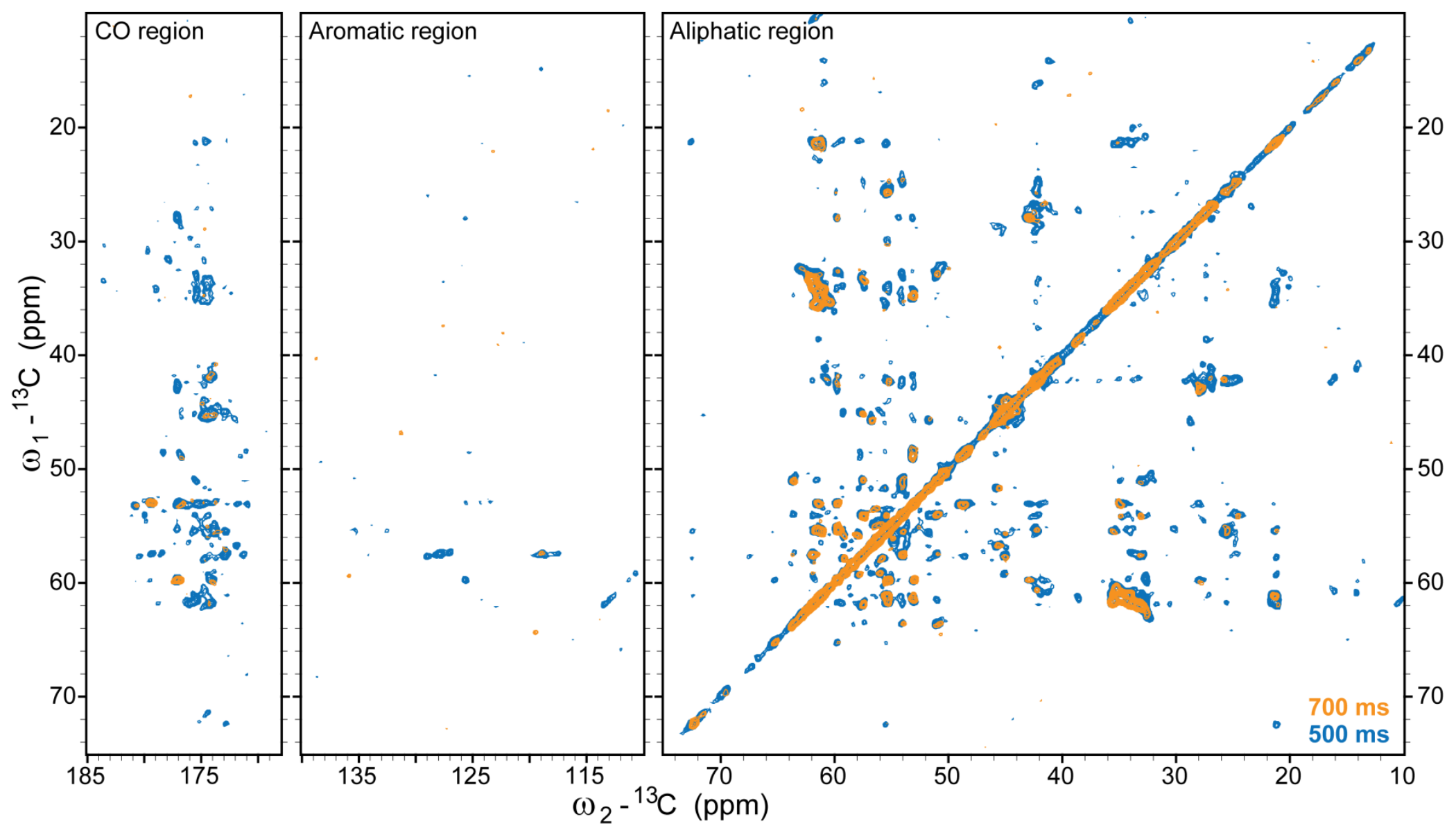

Figure A15. PDSD spectra of K19 2glyc PHF. ${ }^{13} \mathrm{C}-{ }^{13} \mathrm{C}$-mixing of $700 \mathrm{~ms}$ and recorded on an $800 \mathrm{MHz}$ spectrometer (orange). ${ }^{13} \mathrm{C}-{ }^{13} \mathrm{C}-\mathrm{mixing}$ of $500 \mathrm{~ms}$ and recorded on an $850 \mathrm{MHz}$ spectrometer (blue). Further experimental details are given in Table A1. 
6.3.4 K19

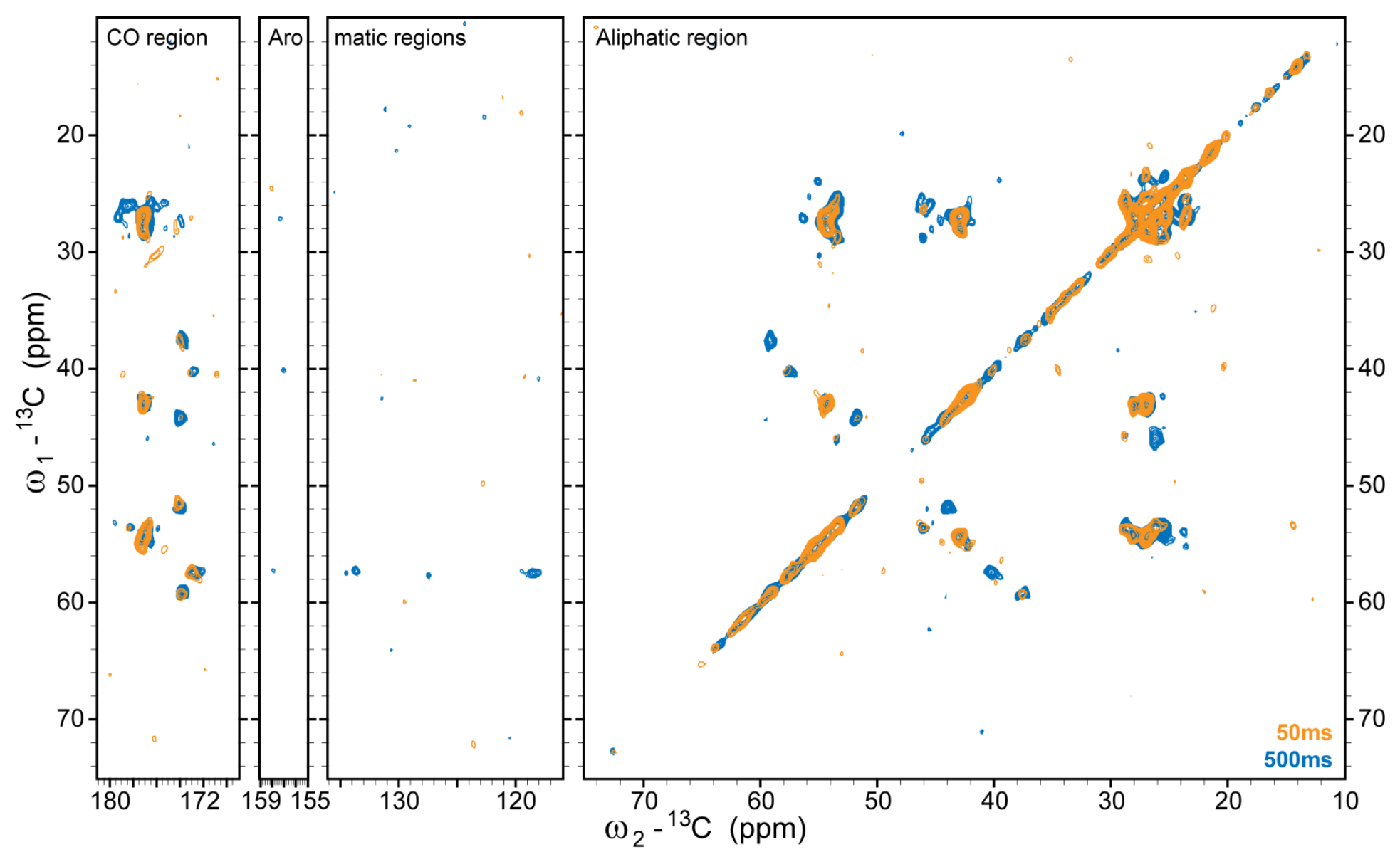

Figure A16. PDSD spectra of K19 ${ }_{\text {CYLfw }}$ PHF. ${ }^{13} \mathrm{C}^{13} \mathrm{C}$-mixing of $50 \mathrm{~ms}$ (orange) and $500 \mathrm{~ms}$ (blue). Experimental details are given in Table A1. 


\subsubsection{K19CA}

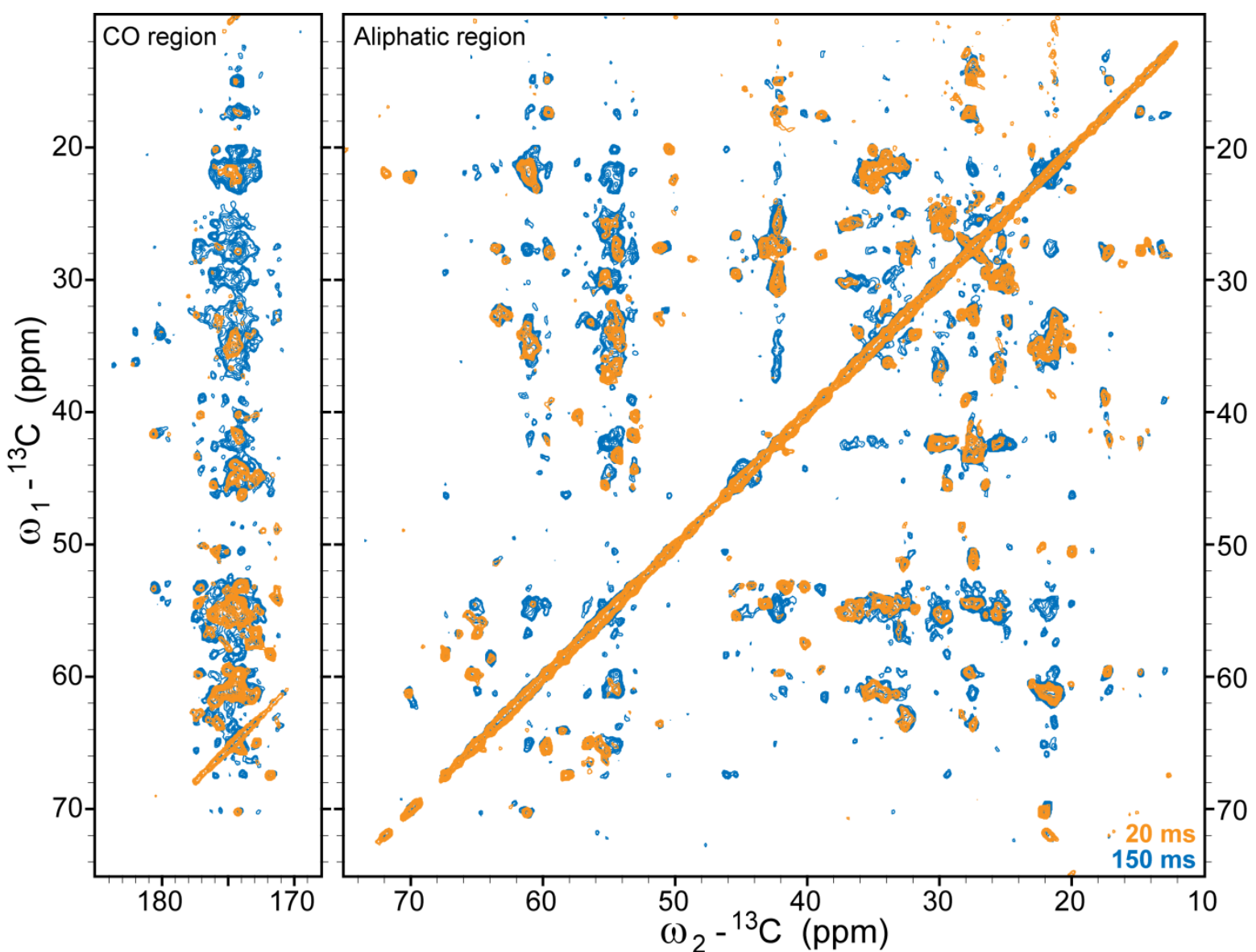

Figure A17. PDSD spectra of K19CA PHF recorded on an $800 \mathrm{MHz}$ spectrometer. ${ }^{13} \mathrm{C}-{ }^{13} \mathrm{C}$-mixing of $20 \mathrm{~ms}$ (orange) and $150 \mathrm{~ms}$ (blue). Further experimental details are given in Table A1. 


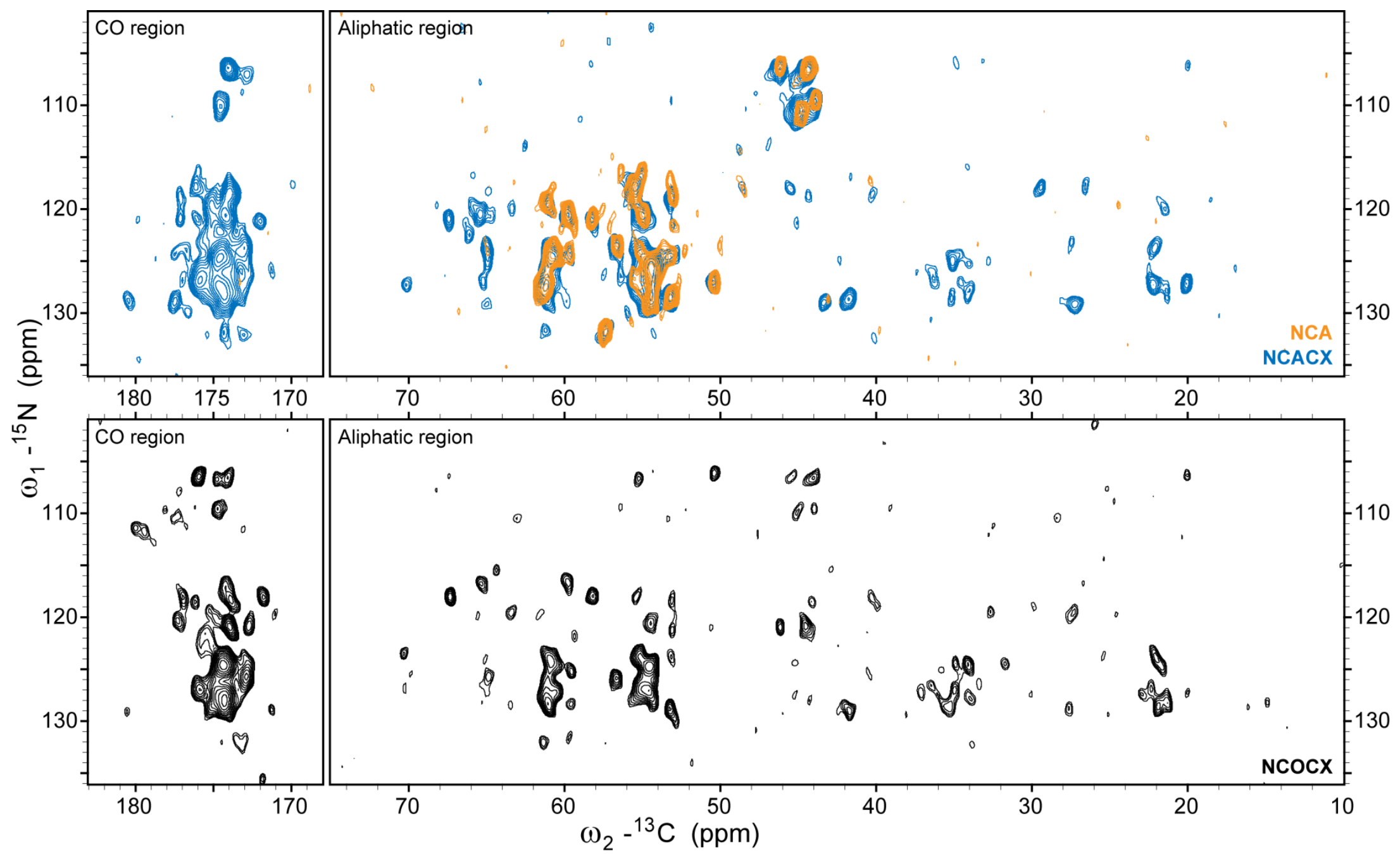

Figure A18. NC-spectra of K19CA PHF. NCACX (blue), NCA (orange) and NCOCX (black). Experimental details are given in Table A1. 
6.3.6 $\left[1,3-{ }^{13} \mathrm{C}\right]$ - and $\left[2-{ }^{13} \mathrm{C}\right]$-glycerol labeled K19CA

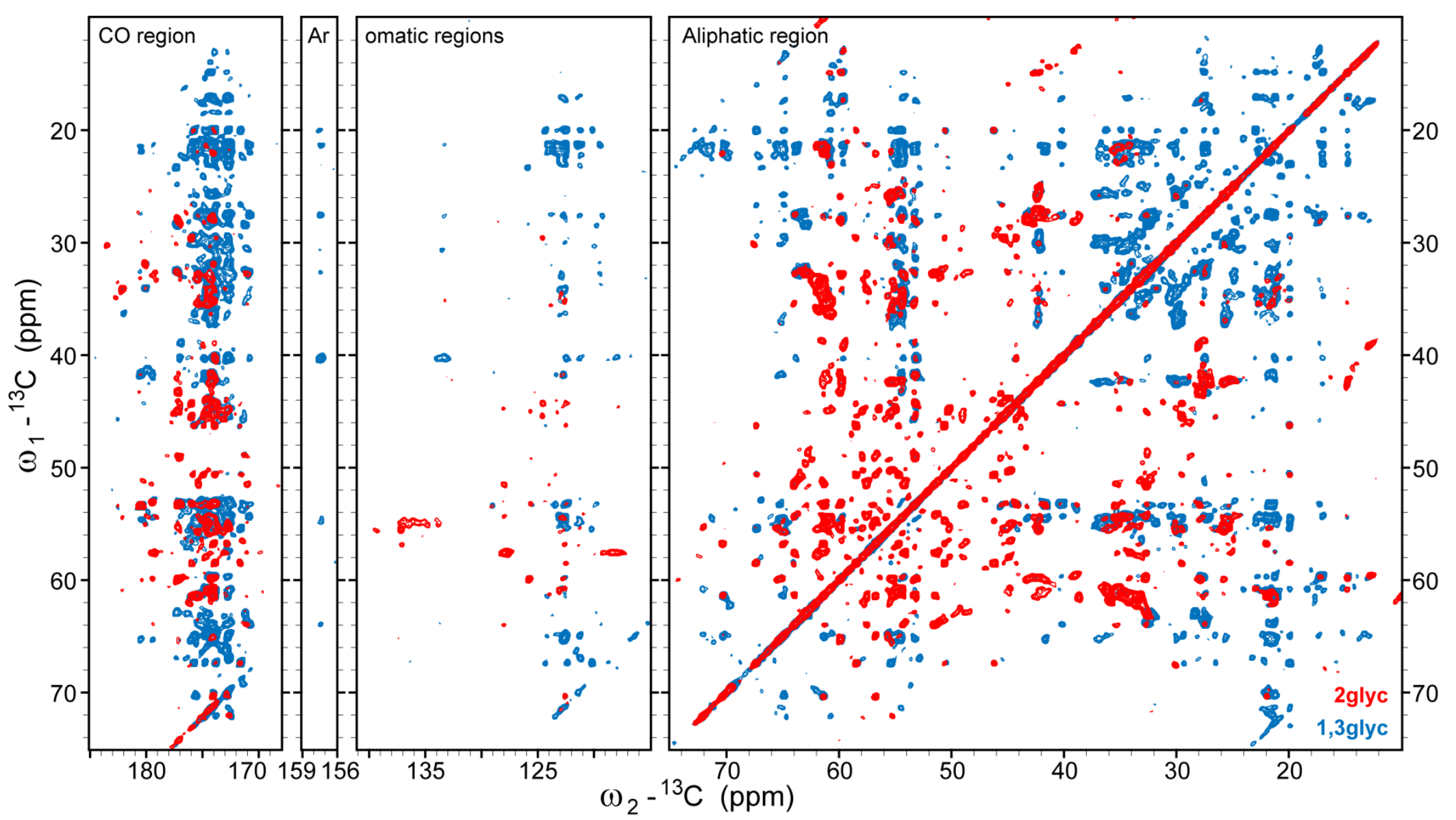

Figure A19. PDSD spectra of K19CA glyc PHF. ${ }^{13} \mathrm{C}-{ }^{13} \mathrm{C}$-mixing of $500 \mathrm{~ms}$ (blue: $\mathrm{K}_{19 C A_{1,3 g l y c}}$; red: $\mathrm{K} 19 \mathrm{CA}_{2 \mathrm{glyc}}$ ). Experimental details are given in Table A1. 



\section{Curriculum Vitae}

\section{Personal data}

Name

Birthday and -place

Citizenship

\section{Academic education}

$10 / 2003-09 / 2005$

26.09.2005

$10 / 2005-12 / 2008$

$08 / 12 / 2008$

$11 / 2008-08 / 2012$
Venita Daebel

01.04.1983, Brandenburg (Havel), Germany

German

Academic studies of biochemistry, University of Potsdam

Pre-diploma in biochemistry

Academic studies of neuroscience, University of Magdeburg

Diploma

Doctoral thesis at the Max Planck Institute for Biochemical Chemistry, department of NMR-based Structural Biology, Göttingen

\section{Scholarships}

$02 / 2009-01 / 2012$

Scholarship of the Physical and Chemical Graduate School Göttingen (PCGG) 


\section{Publication List}

-V. Daebel et al., $\beta$-sheet core of tau paired helical filaments revealed by solid-state NMR, J Am Chem Soc 2012, 134, 13982-9.

- D. Matthes, V. Gapsys, V. Daebel, B. L. de Groot, Mapping the conformational dynamics and pathways of spontaneous steric zipper peptide oligomerization, PLoS ONE 2011, 6, e19129.

- R. Schneider, M. Etzkorn, K. Giller, V. Daebel, J. Eisfeld, M. Zweckstetter, C. Griesinger, S. Becker, A. Lange, The Native Conformation of the Human VDAC1 N Terminus, Angew Chem Int Ed Engl 2010, 49, 1882-1885.

- A. Sachse, S. Demeshko, S. Dechert, V. Daebel, A. Lange, F. Meyer, Highly preorganized pyrazolate-bridged palladium(II) and nickel(II) complexes in bimetallic norbornene polymerization, Dalton Trans 2010, 39, 3903-3914.

Göttingen, September 2012 